WHOI $-73-73$

\title{
THE DESIGN, LOGISTICS AND INSTALLATION OF A SOFAR FLOAT TRACKING STATION AT GRAND TURK ISLAND, B.W.I.
}

\author{
By \\ Robert G. Walden, Henri O. Berteaux \\ and Foster Striffler \\ WOODS HOLE OCEANOGRAPHIC INSTITUTION \\ Woods Hole, Massachusetts 02543
}

October 1973

\begin{abstract}
TECHNICAL REPORT
Prepared for the National Science Foundation under Grant GX-32571.

Reproduction in whole or in part is permitted for any purpose of the United States Government. In citing this manuscmipt in a bibliography, the reference should be followed by the phrase: UNPUBLISHED MANUSCRIPT。
\end{abstract} \footnotetext{
Approved for Distribution $\frac{\text { Earl } \varepsilon \text { days }}{\text { Earl E. Hays, Chairman }}$ Department of Ocean Engineering
} 
TABLE OF CONTENTS

List of Figures and Tables

Page

Abstract

2

Acknowledgements

3

1. Introduction

2. System Design

2.1 Environmental Specifications

2.2 Structural and Mechanical Design

2.3 Electrical Design

3. Procurement

4. System Deployment

4.1 Logistics

4.2 Deployment Analysis

35

4.3 Field Operations

5. Conclusion

6. References

7. Appendices

Appendix 1

Dynagrip

Computer Program to compute the equilibrium trajectory of a cable supporting a Point load 


\section{LIST OF FIGURES}

\begin{tabular}{|c|c|c|c|}
\hline & & & \\
\hline Figure & 1 & MODE Location & 5 \\
\hline Figure & 2 & Contours and Tracks & 6 \\
\hline Figure & 3 & Moored Hydrophone Array & 8 \\
\hline Figure & 4 & Wire Rope Termination & 10 \\
\hline Figure & 5 & Hydrophone Assembly & 11 \\
\hline Figure & 6 & Anchor Assembly & 13 \\
\hline Figure & 7 & U-frame & 14 \\
\hline Figure & 8 & E/M Cable Clamps & 15 \\
\hline Figure & 9 & Anchor & 16 \\
\hline Figure 1 & 10 & $\mathrm{E} / \mathrm{M} \mathrm{Cable}$ & 19 \\
\hline Figure 1 & 11 & E/M Termination Assembly & 21 \\
\hline Figure 1 & 12 & E/M Termination Assembly Photograph & 22 \\
\hline Figure 1 & 13 & Hydrophone Directivity Curve & 24 \\
\hline Figure 1 & 14 & Hydrophone Impedance Curve & 26 \\
\hline Figure 1 & 15 & $\mathrm{E} / \mathrm{M}$ Cable Cross Section & 28 \\
\hline Figure 1 & 16 & Shore Electronics Diagram & 29 \\
\hline Figure 1 & 17 & GOVERNMENT BARGE & 31 \\
\hline Figure 1 & 18 & GOVERNMENT BARGE & 32 \\
\hline Figure 1 & 19 & R/V GULF STREAM & 33 \\
\hline Figure 2 & 20 & Loaded Truck & 34 \\
\hline Figure 2 & 21 & Transfer of Heavy Equipment & 36 \\
\hline Figure 2 & 22 & Computer Plot & 37 \\
\hline Figure 2 & 23 & Bottom Profile & 40 \\
\hline Figure 2 & 24 & Pay-out Rate Parameters & 41 \\
\hline Figure 2 & 25 & Ship Speeds, Pay-out Speeds, and Distances & 43 \\
\hline Figure 2 & 26 & Aerial Photograph & 45 \\
\hline Figure 2 & 27 & PHASE I of Deployment Sequence & 46 \\
\hline Figure 2 & 28 & PHASE II of Deployment Sequence & 47 \\
\hline Figure 2 & 29 & PHASE III of Deployment Sequence & 48 \\
\hline Figure 3 & 30 & PHASE IV of Deployment Sequence & 49 \\
\hline Figure 3 & 31 & PHASE V of Deployment Sequence & 50 \\
\hline Figure 3 & 32 & Typical Float Signal Received & 54 \\
\hline & & LIST OF TABLES & \\
\hline Table 1 & & $\begin{array}{l}\text { Subsurface Buoy Depths - Computer Program } \\
\text { Results (with 5/16" wire rope) }\end{array}$ & 7 \\
\hline Table 2 & & Computer Results & 38 \\
\hline
\end{tabular}


ABSTRACT

The Mid-Ocean Dynamics Experiment (MODE) under the Office of the International Decade of Oceanography, National Science Foundation, included plans for the deployment of long-range SOFAR floats in a two degree square area approximately 400 miles Southwest of Bermuda. The floats are located by AFETR, MILS system hydrophones at Bermuda, Eleuthera and Puerto Rico. An additional station at Grand Turk Island, British West Indies, was requested to provide an expanded and more reliable location. In addition a spare installation was to be provided which could be installed within relatively short notice at Eleuthera or Puerto Rico if required.

The design, logistical considerations and installation of the Grand Turk Island station are documented in this report. 


\section{ACKNOWLEDGEMENTS}

The authors wish to thank the many people who contributed to the ultimate success of this installation. It would be impossible in the space provided to acknowledge every individual who helped make a logistically difficult operation of this sort possible. Personnel of the Woods Hole Oceanographic Institution in the shop and welding services, drafting, computing and shipping permitted a tight time schedule to be maintained. Special thanks to Mr. Patrick O'Malley and Mr. Peter Clay are given for their untiring efforts in the design, testing, preparation and deployment efforts.

We gratefully acknowledge the encouragement and help of the MODE Executive Committee, particularly Professor Henry Stommel and the chief scientific user of the system, Professor H. Thomas Rossby of Yale University.

CDR. Jon Carlmark, Code 480, Office of Naval Research, Washington, D. C. provided helpful liaison with the U. S. Navy. Dr. Gordon R. Hamilton, formerly of the Palisades Sofar Station, St. David's, Bermuda, provided helpful technical advice concerning the mechanics of our installation.

Dr. William S. Richardson of Nova University, Fort Lauderdale, Florida generously made available the R/V GULF STREAM and its able skipper, Captain William Campbe11, for survey and navigation use at the site.

The success of the operation was ensured by the complete cooperation of local Grand Turk Island Governmental Staff including the Administrator, Mr. Alex Mitche11, Head of the Department of Public Works, Mr。 R. G. Rae and his helpful assistant, Mr. David Hill.

We also wish to thank Mr. Connor Smythe, our agent at Grand Turk Island and especially two of the hardest working underwater divers we know, Mr. Chauncey Dunn and Mr. Robert Rowley.

The use of the dock and crane facilities of the U. S. Air Force Station at Grand Turk Island under the command of Major Gary Agard are gratefully acknowledged.

This work was supported by the National Science Foundation, office of the International Decade of Oceanography, under Grant No. GX 32571. 


\section{Introduction}

The MODE-I experiment (Mid-Ocean Dynamics Experiment) supported by the National Science Foundation under the office of the International Decade of Oceanography and the office of Naval Research, U. S. Navy, includes the deployment of long-range SOFAR floats to track water mass movements. (Reference No. 1) These floats are ballasted to float at a depth of approximately 1200 meters. The MODE area is approximately 400 miles Southwest of Bermuda and encompasses a two degree square area. Signals from these SOFAR floats can be detected at ranges of $1000 \mathrm{~km}$ or more by hydrophones situated in the sound channel. Existing stations at Bermuda, Eleuthera and Puerto Rico can provide only limited coverage of this area. To permit a listening capability further to the Northwest where a shadow zone exists at the Bermuda hydrophone and to improve overall reliability through redundance, an additional receiving station was requested at Grand Turk Island, B.W.I. Additionally, a spare station was needed for installation at Eleuthera or Puerto Rico in the event of failures at these locations.

Figure 1 shows the MODE-I location and the shadow zone of the Bermuda listening station due to the Plantagenet Banks. As can be seen, the addition of a station at Grand Turk Island considerably extended the coverage to the North and West.

\section{System Design}

\subsection{Environmental Specifications}

A location was selected 3.8 NM North of Grand Turk Island as a site for the hydrophone installation. It was necessary that the water depth be greater than the sound channel axis depth (1200 m) and that there be no topographic rises between this site and the MODE area to be covered. Figure 2 shows the site chosen. All available bathymetric data was gathered to permit a determination of slope and length of cable required for a cable run from this point to a van to be located on the Northern tip of the island. Hydrographic data was obtained to ascertain the depth of minimum sound velocity.

A preliminary site visit was made to visually inspect the site with particular emphasis on a possible cable route through the reef adjacent to the island. Wave heights and prevailing winds were noted. During moderate swell conditions breaking waves on the reef reached 10 to 15 feet. Storm situations created appreciably larger waves. Prevailing winds were moderate (10-15 knots) from the East. Occasional storms bring stronger winds from the North and West. Attempts to obtain accurate information on current profiles in the area were unsuccessful. Conservatively estimated current profiles were used for design purposes. 


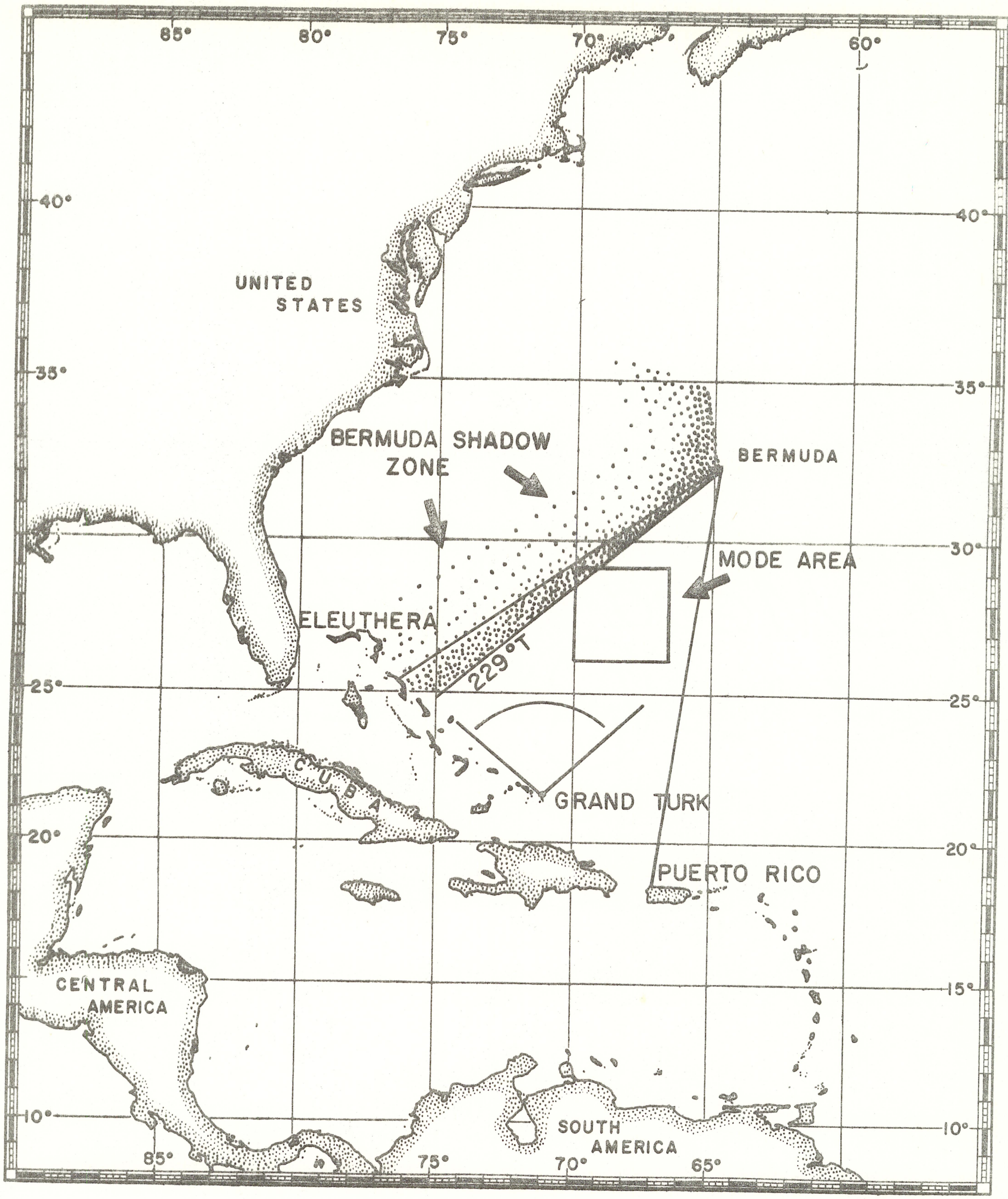

Figure 1. MODE Location 


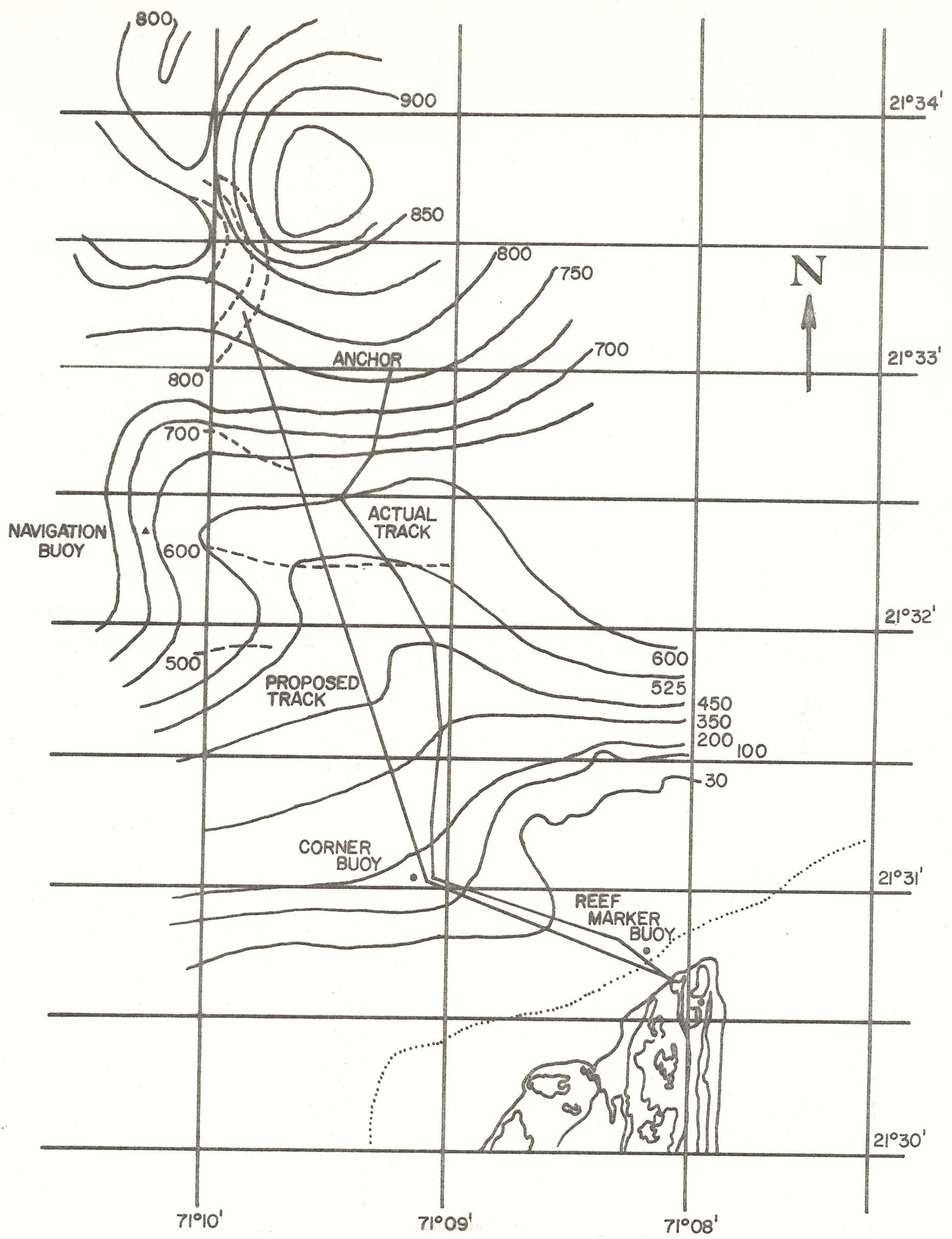

Figure 2. Contours and Tracks 


\subsection{Structural and Mechanical Design}

The moored structure supporting the hydrophone array consisted of a subsurface float, 1000 meters of wire rope, the hydrophone assembly, the anchor assembly, and 9143 meters $(30,000 \mathrm{ft}$.$) of electromechanical$ cable connecting the hydrophones to the shore station. The general configuration of the moored array is depicted in Figure No. 3.

Detailed description of these components together with the rationale for their selection are hereafter outlined.

\section{Subsurface Float}

The purpose of the subsurface float was to provide enough huoyancy to maintain the hydrophones at their specified depth (1200 meters) as well as to permit the eventual recovery of the hydrophone array by command releasing of the anchor.

A readily available 48 inch steel sphere (Ocean Research Equipment Company) providing 1450 lbs. of buoyancy down to a working depth of 500 meters was selected for this purpose. This sphere had enough buoyancy to insure adequate rigidity of the implanted array and, when called to the surface, to support with a margin of $400 \mathrm{lbs}$. the weight of the first 1500 meters of the moored array.

Dip and excursion of the subsurface buoy were computed for different buoy depths and current profiles using the computer program described in Reference No. 2. The results of this analysis, shown in Table 1 indicated that an implantation depth of 200 meters was a reasonable compromise between minimum desirable wire rope length and allowable working depth.

\section{TABLE 1}

Subsurface buoy depths - Computer Program Results (with 5/16" wire rope)

Profile Number (See Note)

1
1
1
2
2
2
Buoy Depth (zero current) (meters) 100 200

300

100

200

300
Depth Reached by Buoy (meters)

157

236

323

400

435

483

Note: Profile Number 1: One knot down to 300 meters from the surface and then tapering linearly to 0.25 knots at the bottom.

Profile Number 2: Two knots down to 300 meters from the surface and then decreasing linearly to 0.5 knots at the bottom. 


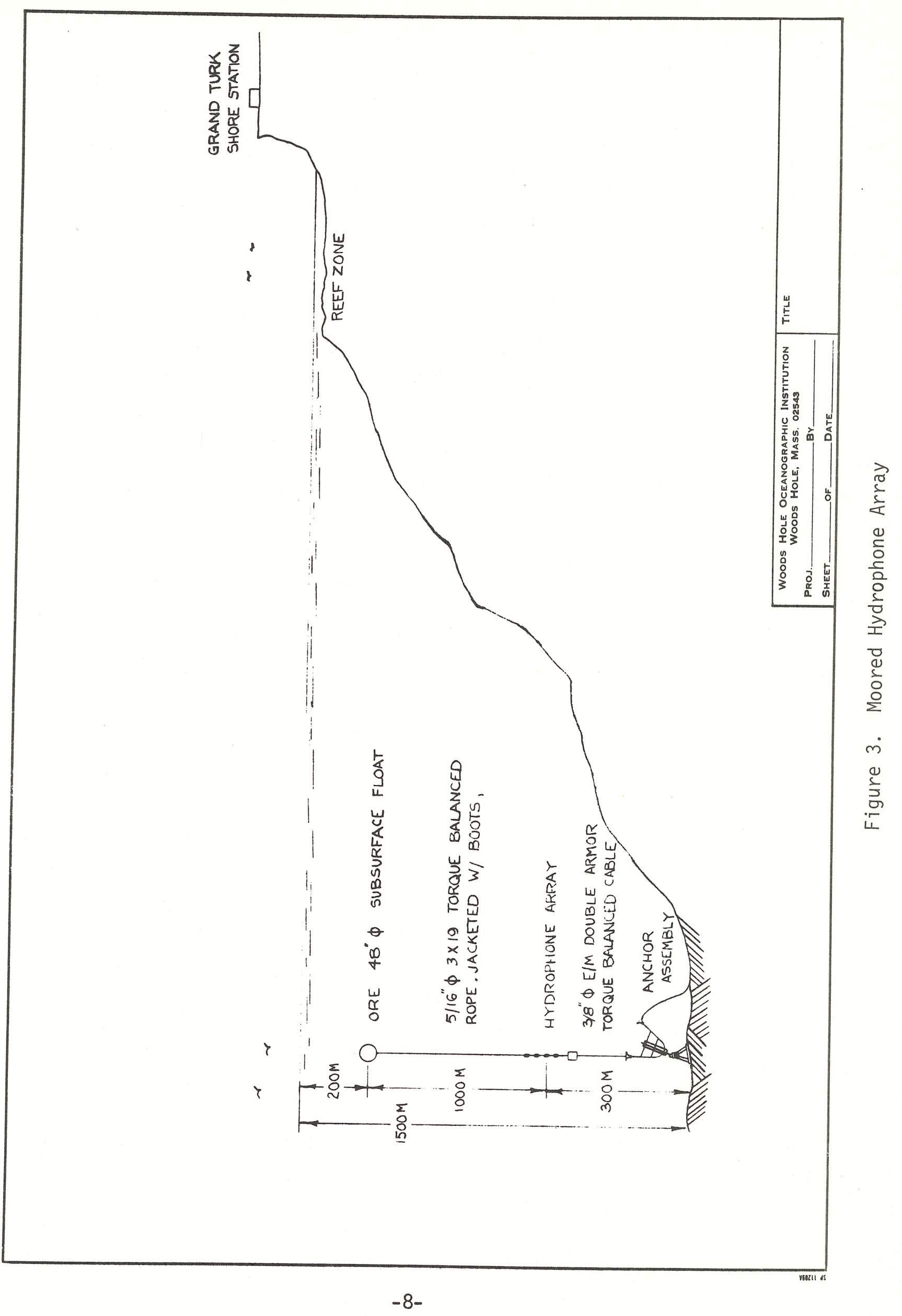


Wire Rope

The hydrophone assembly and the subsurface buoy were connected by 1000 meters of wire rope. Wire rope was selected for its good strength to drag ratio and its resistance to fishbite attacks which are likely to occur at the site and depth of implantation. The type of wire rope used was a 5/16" diameter $3 \times 19$ torque balanced construction galvanized wires and plastic jacketed oceanographic rope (U. S. Steel Company) with a breaking strength of 10,300 1bs. The rope size and type were judged adequate to sustain the deployment and operational loads and deterioration experienced during the 18 months of the system life expectancy.

The rope was terminated at both ends by swaged fittings and polyethylene boots as shown in Figure No. 4. Delrin inserts were placed in the fittings to insure a minimum noise level at the points of mechanical attachment.

\section{Hydrophone Assembly}

The hydrophone assembly was inserted in the mooring line between the end of the wire rope and the beginning of the electromechanical cable. It consisted of four hydrophone cages and one preamplifier housing secured to $10 \frac{1}{2}$ meters of uninterrupted $3 / 8^{\prime \prime} 3 \times 19$ wire rope. Figure No. 5 shows the general dimensions of the assembly and the mechanical details of its components. The electrical and acoustic characteristic of the hydrophone array are described in section 2.3.

The hydrophone cages were of concentric design so as to permit ease of attachment to the strength member of the assembly. They consisted of a central steel tubing, two end plates and a neoprene housing wall. Tie rods were used to hold the cage together. The cylindrical hydrophone transducer was clamped between the end plates. The housing was oil-filled. To assemble the array the wire rope was first passed through the central tubing of the hydrophone cages. Cable end fittings were then swaged on both sides of the properly spaced cages. A clevis (open socket) fitting was also swaged at the lower end of the wire rope to mechanically connect the wire rope to the upper plate of the preamplifier housing.

The hydrophones were electrically connected by four conductor armored cable and Glenair bulkhead penetrators. The electrical cable was secured to the wire rope by watertight neoprene boots and jacket.

A conventional steel pressure case containing the two preamplifiers was attached at the lower end of the array. The hydrophone array was electrically connected to the upper end plates of the housing by a Glenair through-hull penetrator. The lower end plate was connected to the electromechanical cable by an underwater electrical receptacle. 


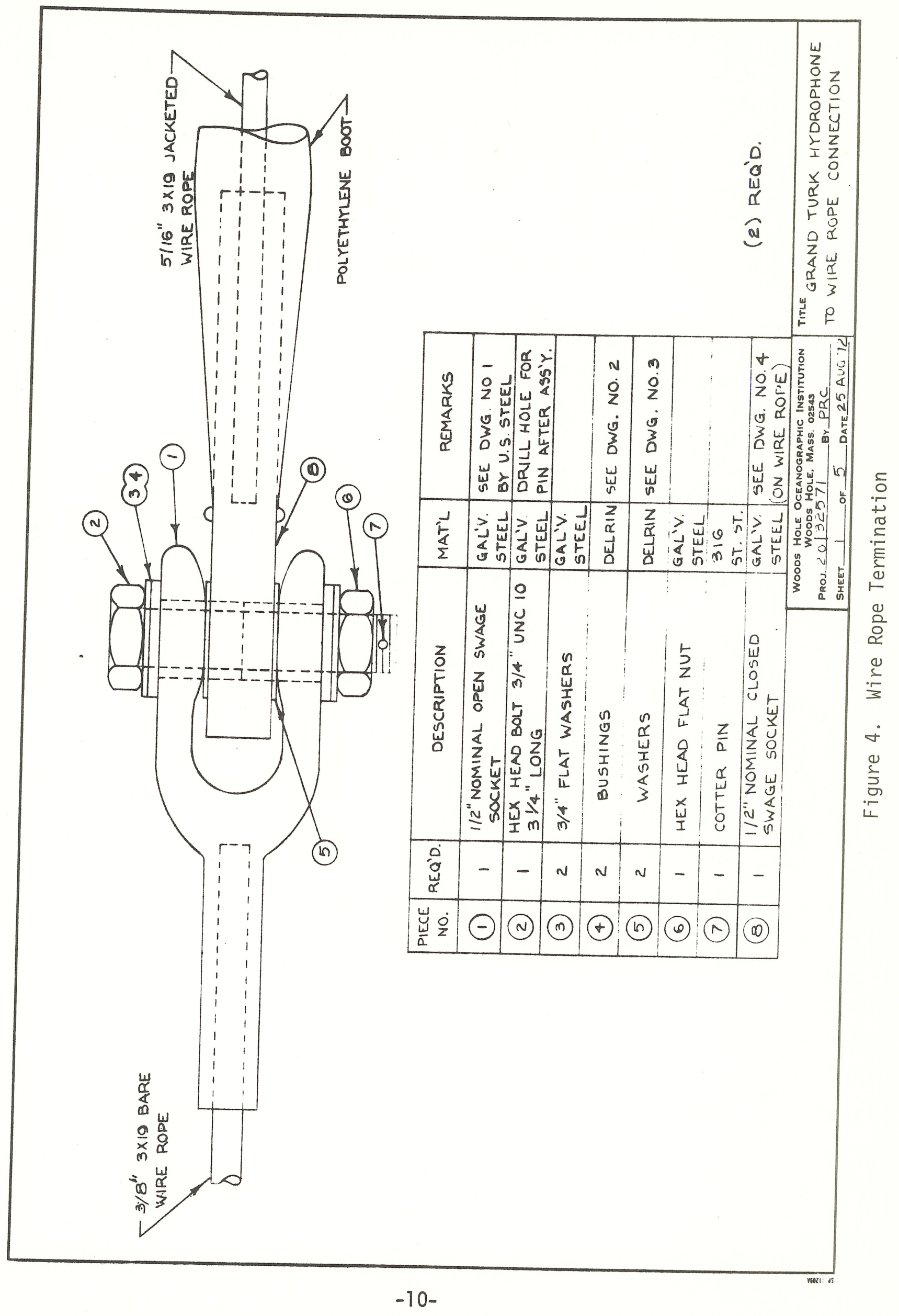




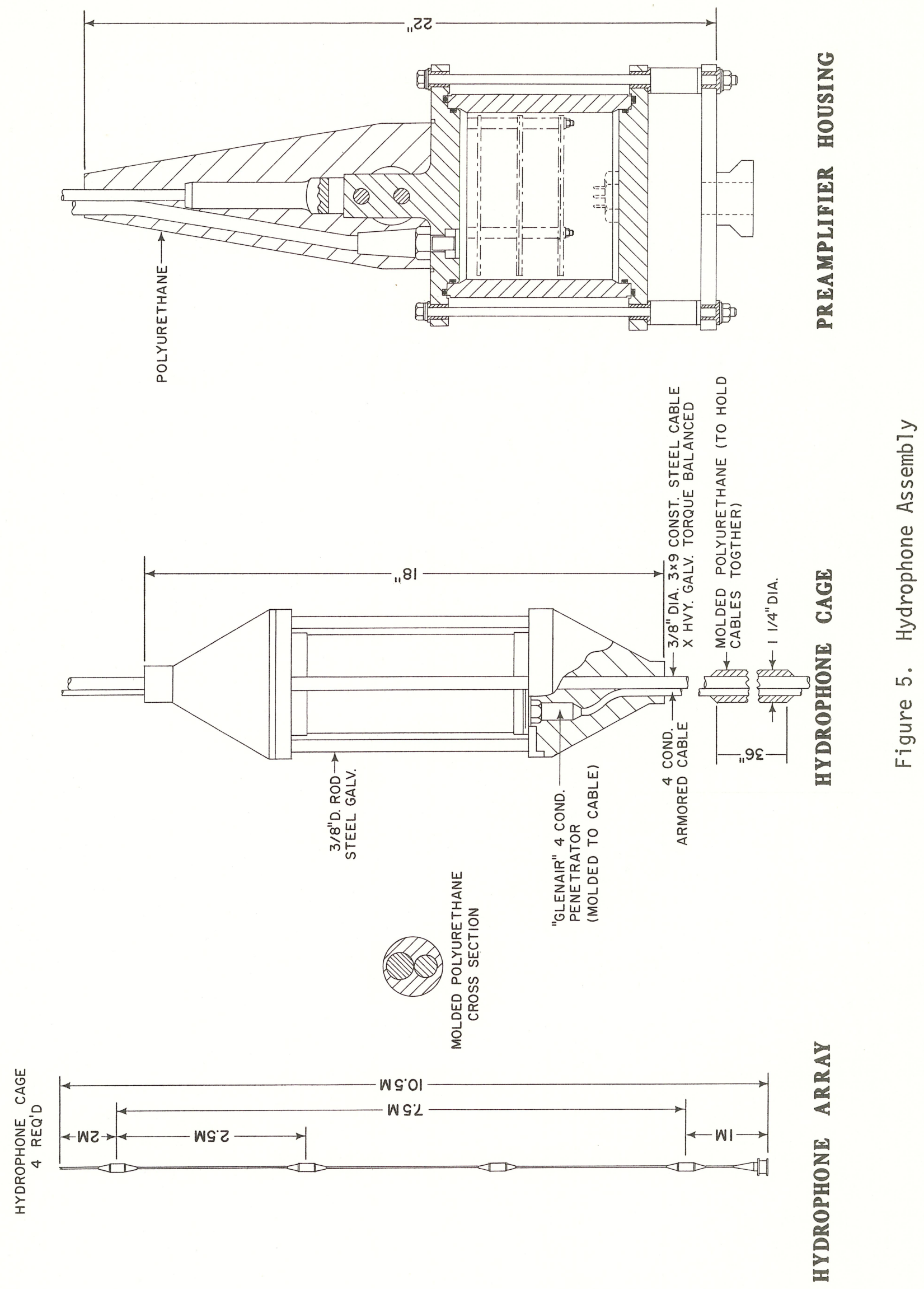


Anchor Assembly

The anchor assembly had to meet the following criteria:

- Provide adequate holding power and yet not be unduly heavy and cumbersome.

- Provide means of attaching the electromechanical cable (E/M cable) to the anchor without interruption or break in the length of the cable.

- Insure that the attachment will not impair the integrity of the $\mathrm{E} / \mathrm{M}$ cable.

- Take into account the possibility of tangling of the two sides of the $\mathrm{E} / \mathrm{M}$ cable (the buoy side and the bottom side) during and after deployment.

- Provide for an anchor release capability for system recovery.

The anchor assembly was made of three components: the U-frame, the anchor, and the anchor release. The configuration of the anchor assembly is depicted in Figure No. 6.

\section{U-Frame}

An eight foot by six foot U-frame made of 4 inch x 5.4 lbs. carbon steel channels was built to provide adequate attachment of the $\mathrm{E} / \mathrm{M} \mathrm{cable}$ and support for the anchor release. (Figure No. 7) A fibreglass bell mouth was mounted at each end of the U-frame to provide a smooth bending radius for the $\mathrm{E} / \mathrm{M}$ cable during anchor lowering and during implantation. The $\mathrm{E} / \mathrm{M}$ cable was attached to the U-frame by six specially designed clamps depicted in Figure No. 8. The armor of the E/M cable was reinforced by preformed helical steel rods (Preformed Line Products Company) which were wrapped on at the points of attachment.

The U-frame was sandblasted and Demitcoated. The weight of the U-frame was 150 lbs.

\section{Anchor}

The anchor was made of an anchor base plate and four legs bolted to an attachment plate. It was designed to permit assembly in the field. The base plate provided the bulk of the dead weight needed to anchor the array. The legs insured rigid connection between the $\mathrm{U}$-frame and the anchor. They also permitted the release to be placed a fixed distance above the sea floor. Figure No. 9 shows the dimension and the details of the anchor. The anchor weight was 2250 1bs. in air.

\section{Anchor Release}

The anchor release was an AMF acoustic release Model 242. It was secured to the U-frame by stainless steel grips fastened to the 


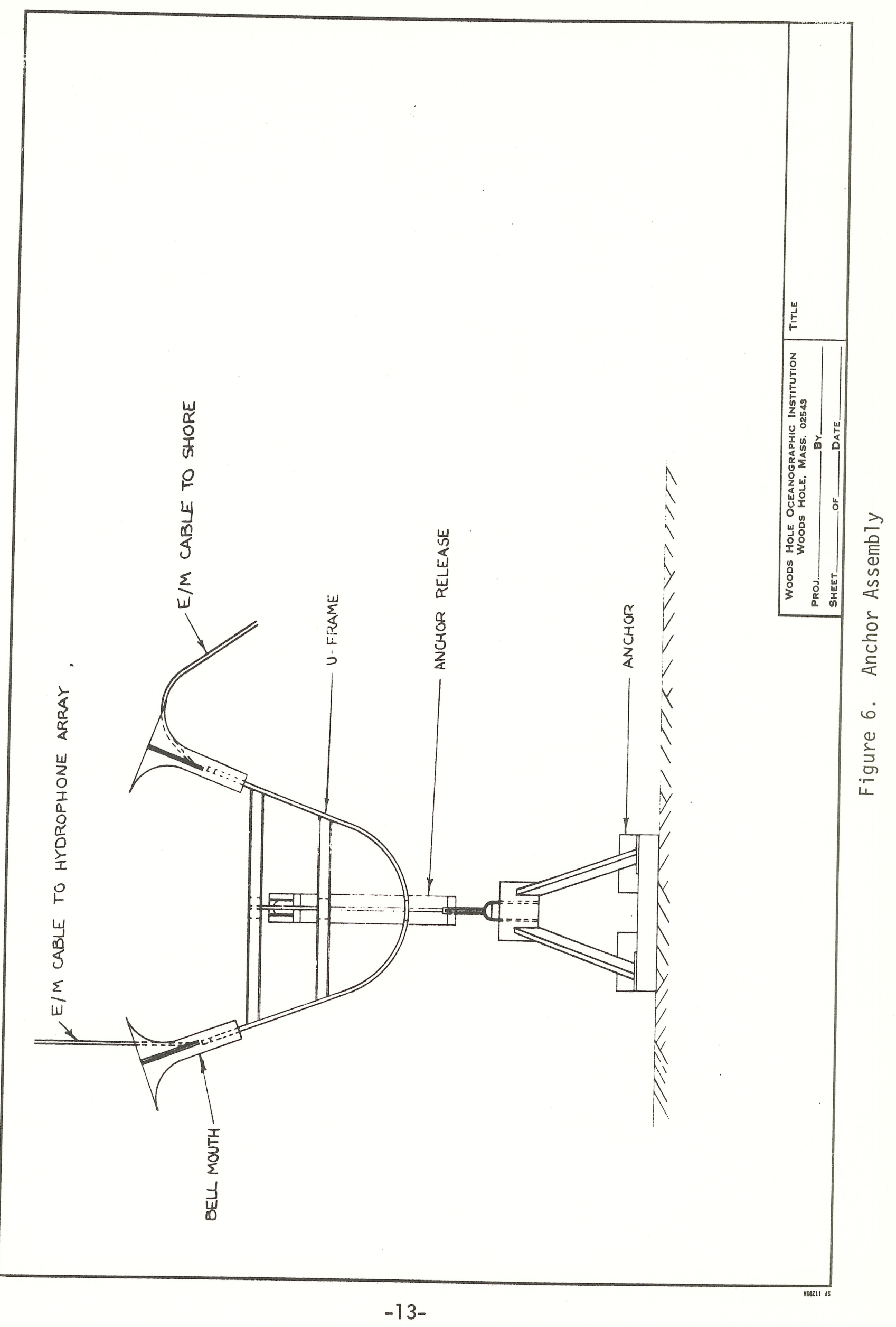




\begin{tabular}{|c|c|c|c|c|c|c|c|c|c|c|c|c|c|c|}
\hline 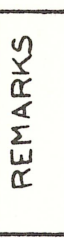 & 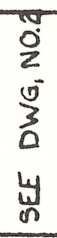 & {$\left[\begin{array}{ll}0 & \\
0 & 0 \\
2 & 0 \\
0 & 0 \\
3 & 1 \\
0 & 3 \\
w & 2 \\
w & 0 \\
0 & 0\end{array}\right]$} & 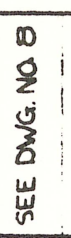 & 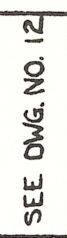 & 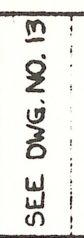 & 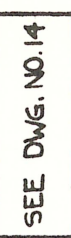 & & & & & & 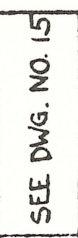 & 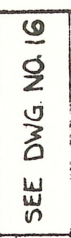 & 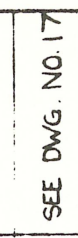 \\
\hline$\frac{d}{\Sigma}$ & & & & & & & $\begin{array}{l}\frac{\varphi}{m} \\
\dot{n} \\
\frac{1}{n}\end{array}$ & $\begin{array}{l}\frac{6}{m} \\
5 \\
5 \\
5\end{array}$ & $\begin{array}{l}\frac{0}{n} \\
5 \\
5 \\
5\end{array}$ & $\begin{array}{l}\frac{6}{m} \\
\stackrel{5}{n} \\
5 \\
5\end{array}$ & 总 & $\frac{z}{\frac{a}{u}}$ & $\frac{z}{\vec{a}}$ & $\frac{z}{\frac{\alpha}{\vec{u}}}$ \\
\hline 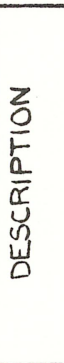 & 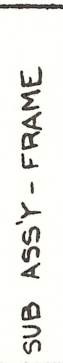 & 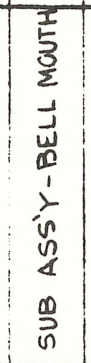 & 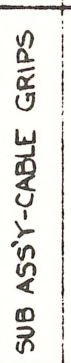 & 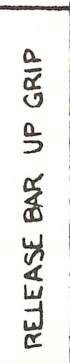 & 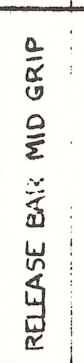 & 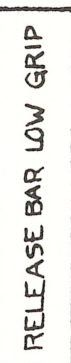 & 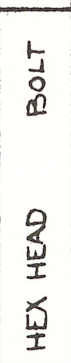 & 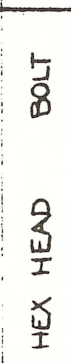 & 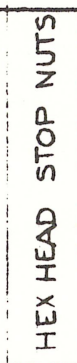 & 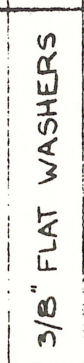 & 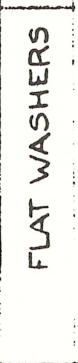 & 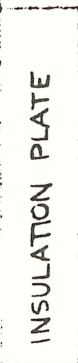 & 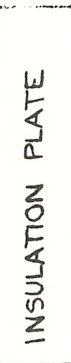 & 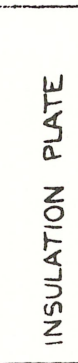 \\
\hline $\begin{array}{l}0 \\
\text { 岀 } \\
\widetilde{\alpha}\end{array}$ & - & $\sim$ & 0 & $N$ & U & $N$ & & & & & & $r$ & 0 & - \\
\hline & & & & & & & & & & & & & & \\
\hline
\end{tabular}

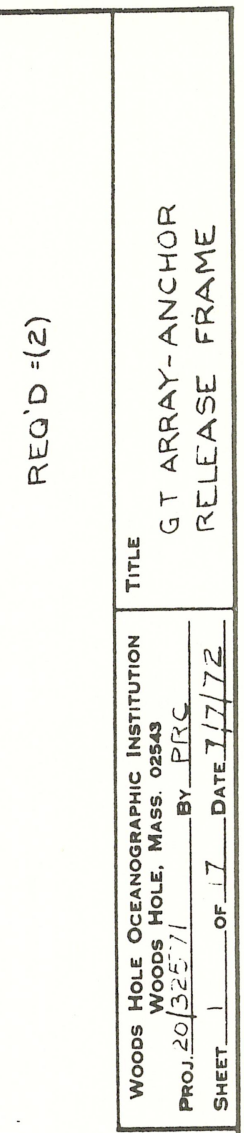

0
E.
5
4
1
5
$ن$
0
5
5
$\frac{5}{4}$
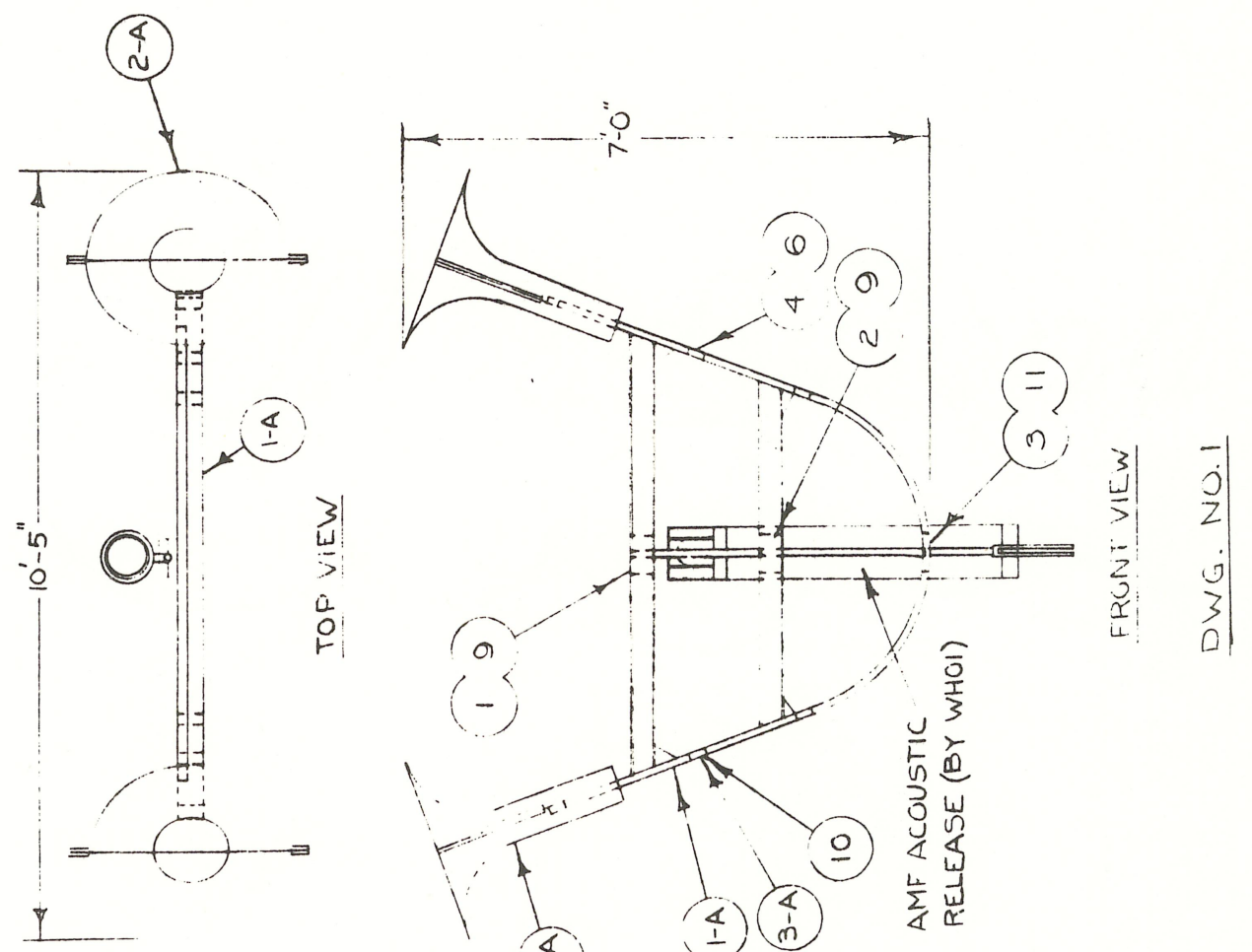


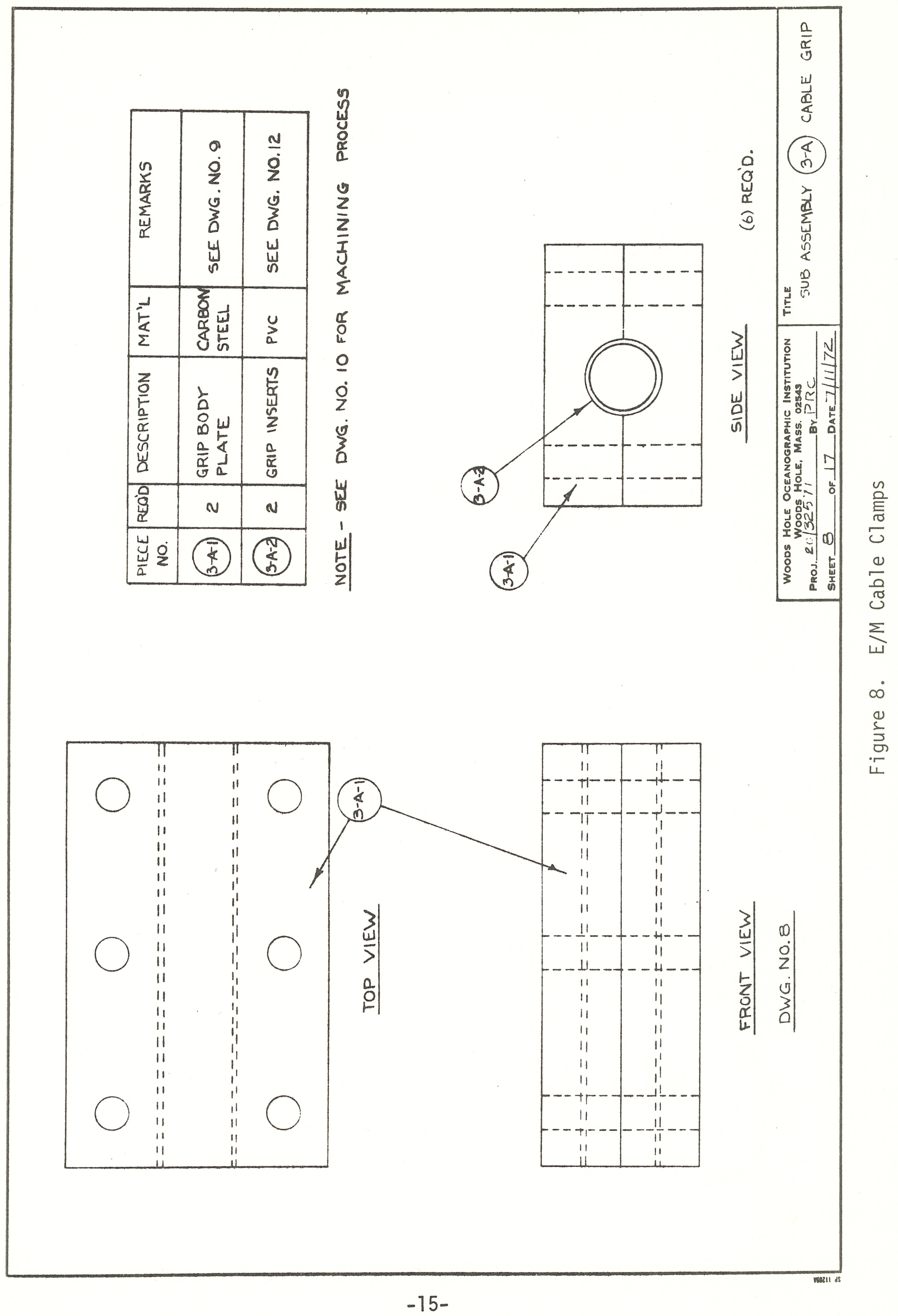




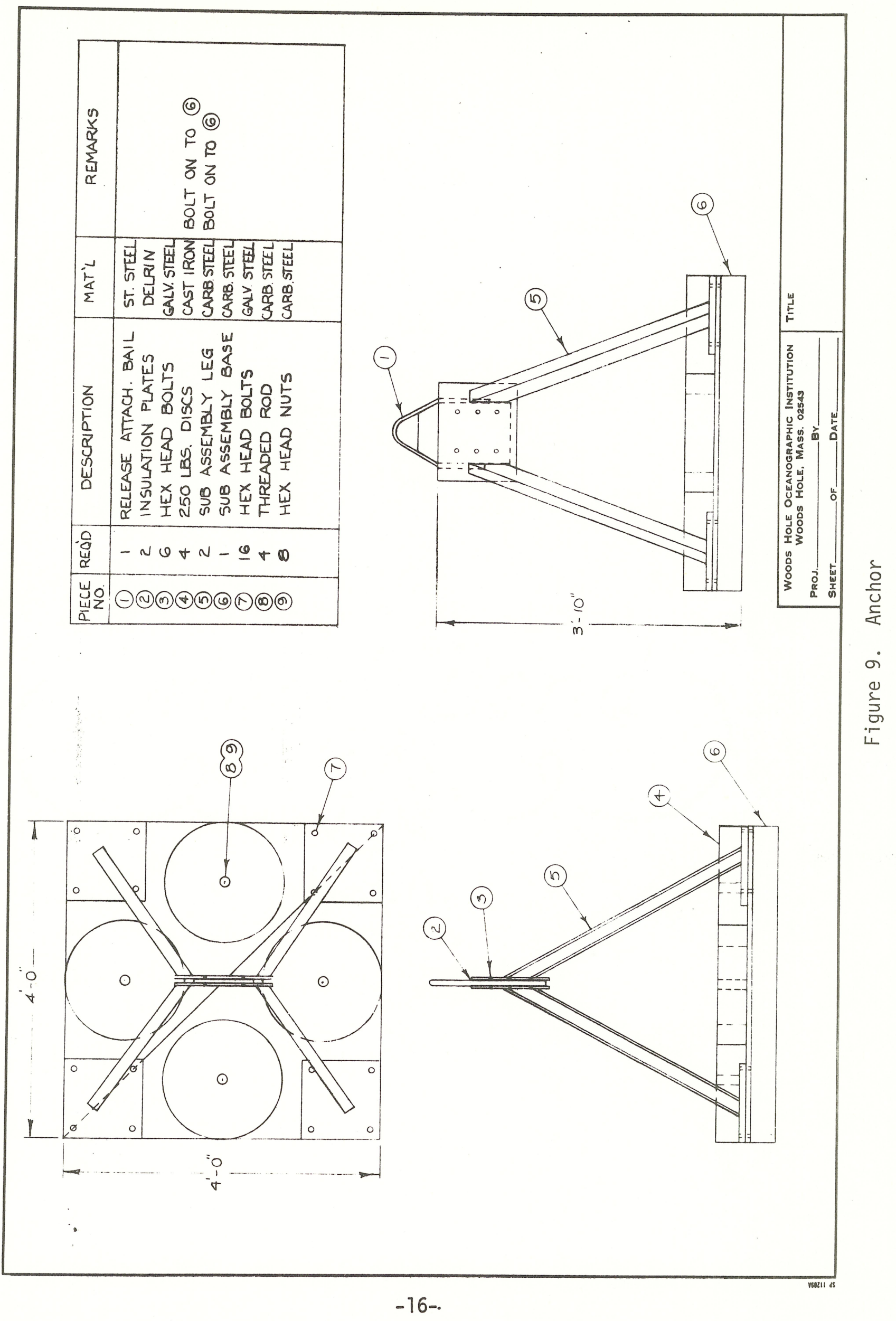


stainless steel strength member of the release. The grips were insulated from the carbon steel U-frame by Delrin inserts. The immersed weight was 80 lbs.

\section{Electromechanical Cable}

In addition to the electrical specifications (number of conductors, insulation, line losses, etc...see Section 2.3) the $\mathrm{E} / \mathrm{M}$ cable had to meet certain mechanical requirements of strength, torque balance and

The cable selected was a $3 / 8$ inch outside diameter, double armored, four conductor cable with the following specifications:

A. Four 非2 AWG stranded conductors each containing 7 wires $0.010^{\prime \prime}$.

B. Conductors to be insulated with polypropylene $0.013^{\prime \prime}$ wa11 thickness.

C. Conductor insulation to be color coded.

D. Conductors to be twisted with C.F. nylon fillers and binding tape - minimum water absorption desired.

E. A jacket or sheath of polyurethane not less than $0.035^{\prime \prime}$ wall thickness.

F. Double armor torque-balanced construction. Maximum number of turns allowable 4 turns/100 ft. measured under following conditions: free end loaded to 3000 pounds when lifted vertically with upper end fixed.

G. Minimum rated breaking strength 10,500非。

H. Armor wires to be extra-heavy galvanized.

I. Outside of cable to be marked at $1000^{\prime}$ intervals by color coding.

J. Maximum conductor DC resistance at $68^{\circ} \mathrm{F}: 17 \mathrm{ohms} / 1000 \mathrm{ft}$.

K. Voltage rating 200 volts. Finished cable to undergo high voltage test in water to insure no pinholes.

L. Capacitance not greater than $35 \mathrm{MMFD} / \mathrm{ft}$. at $1 \mathrm{kHz}$.

M. Insulation resistance: 100 megohms/1000' minimum at 500 VDC each conductor to all other conductors and armor.

The total length of $\mathrm{E} / \mathrm{M}$ cable needed for the array was 9143 meters $\left(30,000 \mathrm{ft} \mathrm{t}_{0}\right)$. The last 914 meters $(3000 \mathrm{ft}$ ) were quadruple armored to insure maximum protection in the reef zone. The total weight of cable and reel was 8500 lbs. 
Torque balance was achieved by reversing the lay of the two armors and by replacing a number of strength bearing wires in the outer armor by smaller wires coated with polyethylene thus reducing the torque contribution of the outer armor. The actual torque balance characteristics and strength of the cable were experimentally established and found to be well within the specifications, namely 16 degrees of rotation per $100 \mathrm{ft}$. of cable length at $5000 \mathrm{lbs}$. of tension, and 10,580 1bs. breaking strength. Figure No. 10 is an exploded view of the $\mathrm{E} / \mathrm{M}$ cable.

\section{Electromechanical Termination}

Designing and building an extremely reliable termination to electrically and mechanically connect the hydrophone array to the $\mathrm{E} / \mathrm{M}$ cable was essential for the success of the array.

The design had to provide the following features:

- Excellent electrical continuity.

- Water tightness of electrical connections.

- Absence of mechanical loads on all electrical components.

- Stress relief of $\mathrm{E} / \mathrm{M}$ cable at the termination.

- Mechanical protection of the electrical components against such hazards as fishbite, abrasion, rough handing and problems associated with environment.

- Ease of assembly in the field.

The design of the termination was done in collaboration with the Marine Systems Division of the Preformed Line Products Company who built the prototype needed for the Bermuda deep-sea testing and the actual termination used in the Grand Turk array.

The essential parts of the E/M termination were:

- A Marsh and Marine Bulkhead penetrator RMS4SPS-P and a mating plug with locking sleeve XSK 4 BCL.

- An adaptor plate fastened to the preamplifier housing.

- A split sleeve connecting the adaptor plate to the dynagrip and therefore the housing to the $\mathrm{E} / \mathrm{M}$ cable. The split sleeve protects the electrical components from environmental hazards. It is held together by two bolts and is readily assembled.

- A polyurethane gland insuring watertightness of the crimped and soldered electrical connections in two ways: 1) by bonding of the polyurethane to the polyurethane sheath of the $\mathrm{E} / \mathrm{M}$ cable and to the neoprene insulation of the 


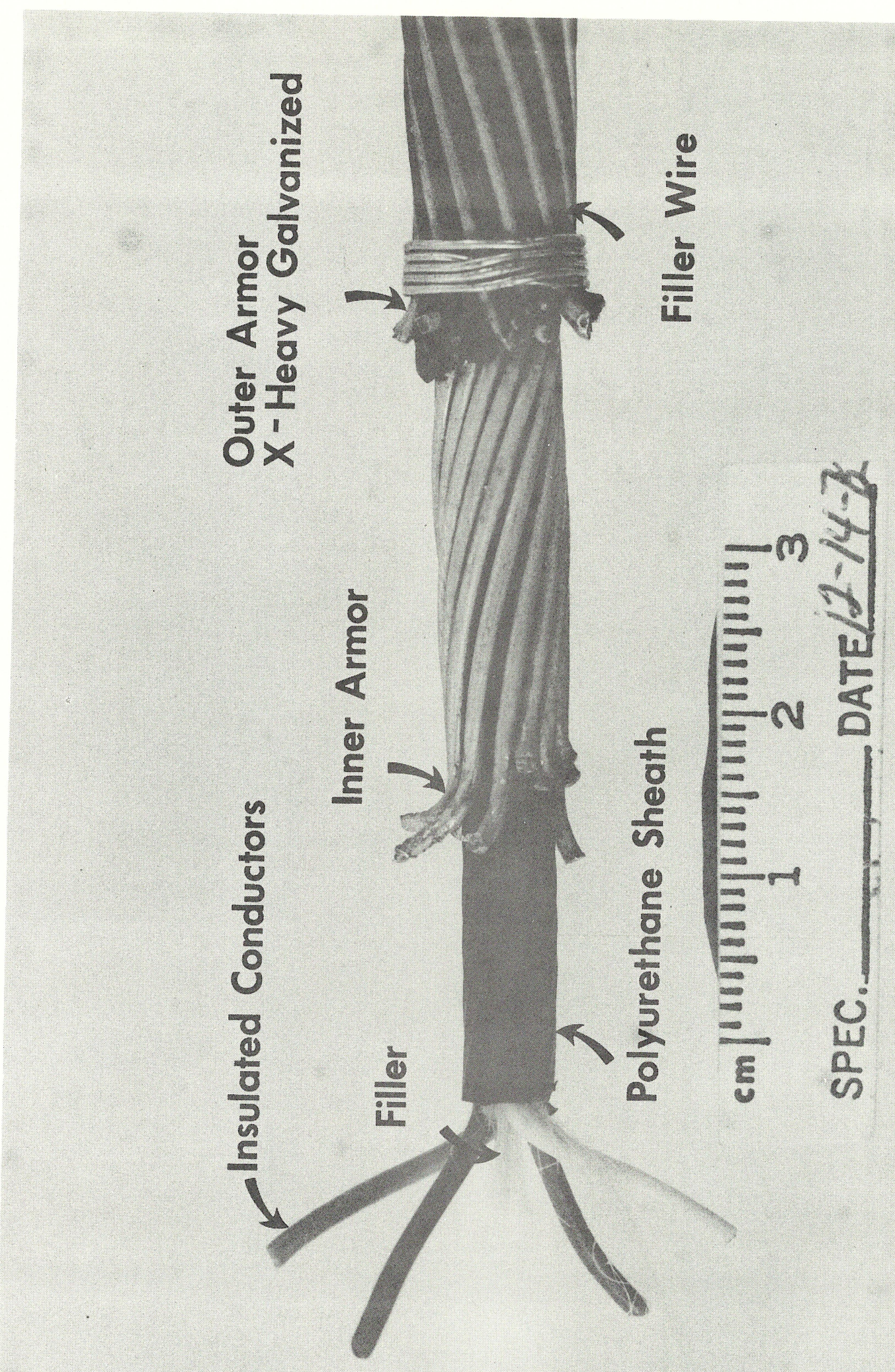

$\frac{0}{0}$
$\frac{0}{0}$
$\sum$

$\stackrel{\circ}{\circ}$

号 
electrical leads of the Marsh and Marine plug, 2) by sealing the conductors as they pass through the polyurethane compression discs in the center of the gland.

- A dynagrip mechanical termination (Appendix No. 1).

Figure No. 11 is a drawing showing the details of the $E / M$ termination assembly.

Figure No. 12 is a photograph of the actual termination.

\subsection{Electrical Design}

The primary purpose of the system was to receive acoustic signals from SOFAR floats in the MODE area and transmit those signals to a shore station via electromechanical cable for processing and recording. This was to be done in an optimum manner so that little information was lost or degraded by any component.

The hydrophone array consisted of two groups of two hydrophones each, two preamplifiers, a strength member running through the hydrophones, and an electromechanical connector. The electrical specifications for the array were:

- Frequency reaponse 50 to $10 \mathrm{kHz} \pm 30 \mathrm{db}$. Note: This will be used only at $300 \pm 50 \mathrm{~Hz}$.

- Dynamic range > $60 \mathrm{db}$.

- Maximum sensitivity change over 0 to 3000 psi-1 db.

- Output impedance $\leqslant 50$ ohms.

- Noise added by the preamp referred to the pressure spectrum level in the ocean shall be $-70 \mathrm{db}$ referred to 1 microbar at $300 \mathrm{~Hz}$ with $1 \mathrm{~Hz}$ bandwidth. (All this means is that there must be a $20 \mathrm{db}$ margin between the preamp noise and the zero sea state noise.) The sensitivity of the hydrophones that were purchased was $-90 \mathrm{db}$ re 1 volt per microbar. (Reference No. 3.)

The electromechanical cable which runs from the hydrophones to the shore station must transmit the signals without distortion or degradation of the signal-to-noise ratio. Samples of cables were obtained and tested and these results were compared to the theoretically calculated parameters. A careful study was made to determine what effects the cable parameters would have on the signals. It was determined that even though the characteristic impedance of the cable was changing rapidly with frequency at the frequency of interest $(300 \mathrm{~Hz})$, that by using a very low impedance driver and not terminating the receiving end, the characteristics of the line could change considerably without adversely affecting the transmitted signal. Therefore, the electrical specification for the electromechanical cable dealt mainly with the insulation properties and the DC resistance of the conductors. 


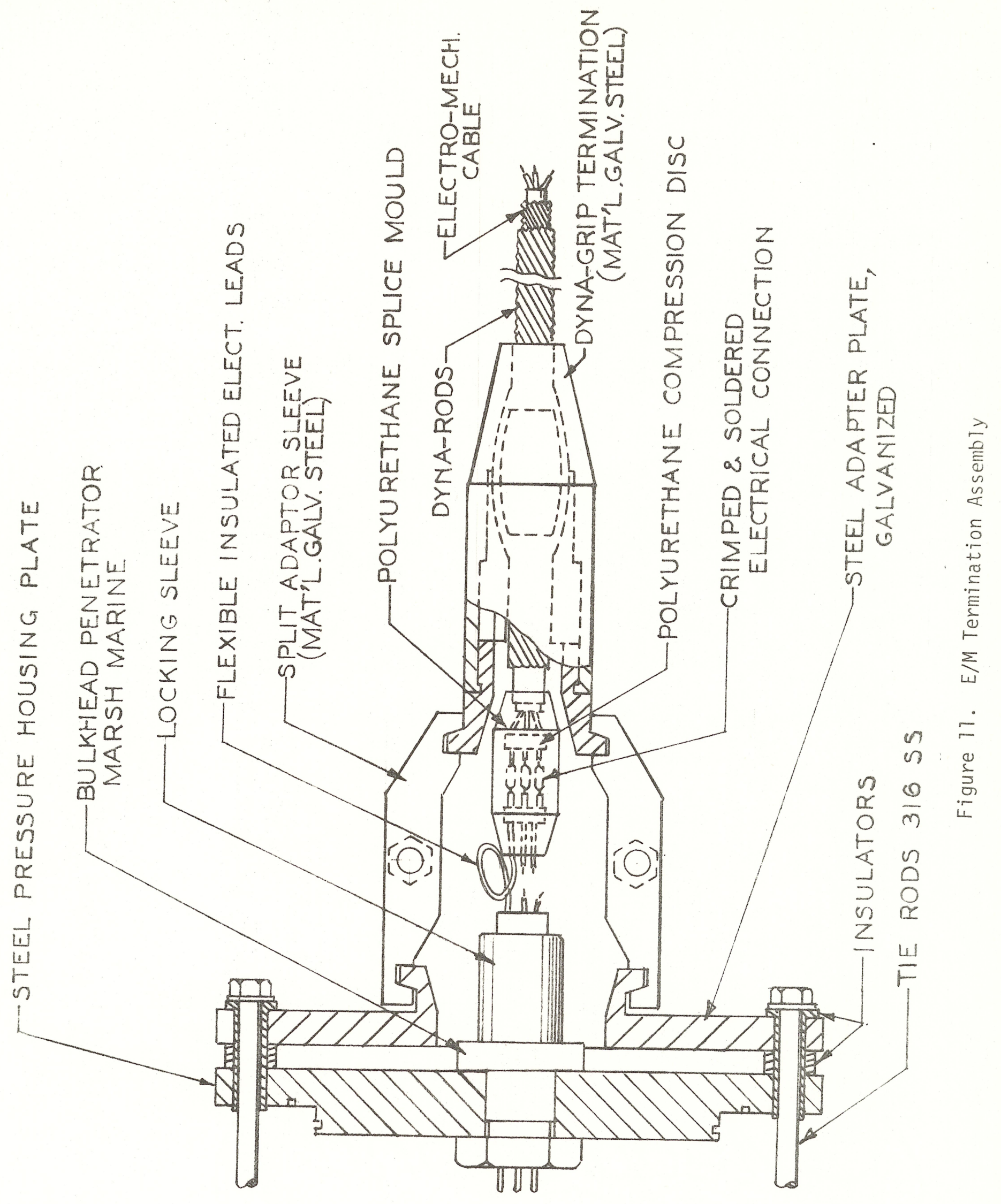




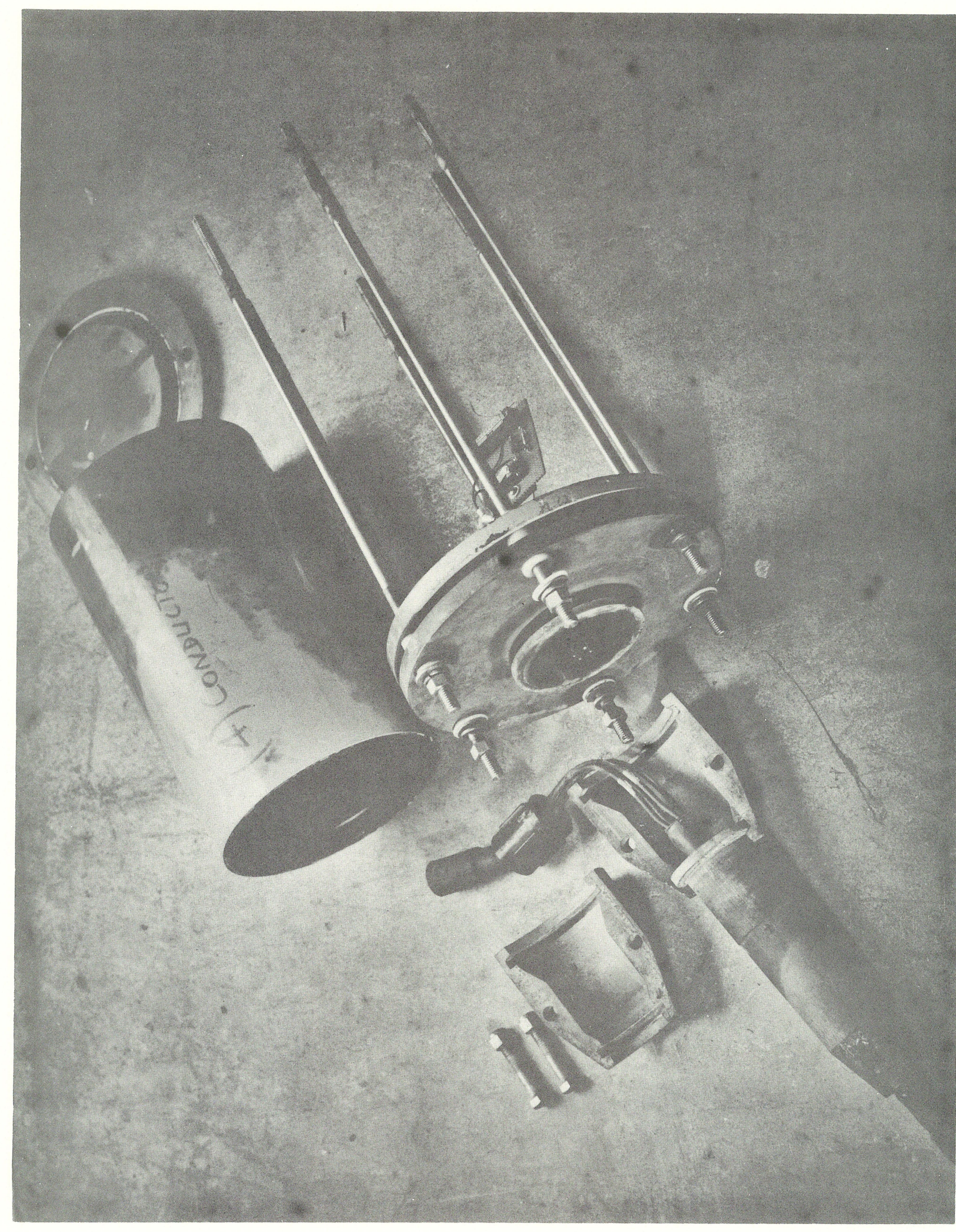

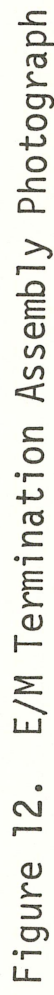


The original system responsibility concept as reflected in the proposal for this task was limited to the installation and test of the hydrophone array and cable to the shore. This included the furnishing of power via the cable to the preamplifiers at the hydrophone location. Towards the end of this program it was requested that additional gain be provided before the signal reached the processing equipment. The requirement for this electronic package was as follows:

1. Electrostatically shielded input transformer.

2. High-pass filter with $f_{c}=200 \mathrm{~Hz}$ to reduce the effects
of $60 \mathrm{~Hz}$ ground loops.

3. Step adjustment of gain of $0 \mathrm{db}, 20 \mathrm{db}$, and $40 \mathrm{db}$.

\section{Hydrophones}

It was decided to design into this system two features - redundancy and hydrophone directivity. The redundancy requirement meant that there had to be two or more hydrophones and also directivity could only be obtained with two or more hydrophones. The criteria for hydrophone directivity was looked at rather closely. The reason for directivity is to improve the signal-to-noise ratio. If the signal is arriving from only one direction and the received noise is of equal power from all directions then the signal-to-noise ratio improvement will be determined by the directivity gain. If most of the noise power is coming along the sound channel (from the same direction that the signal is coming) then there is no improvement in the signal-to-noise ratio and no reason to have a directional array. However there are two sources of noise in this situation; one is noise coming down the sound channel and the other is locally generated noise coming from the local sea surface. Therefore in most situations the directional gain will give a signal-to-noise ratio improvement.

Different hydrophone configurations were examined in the search for an optimum system. These systems had two, four, and six hydrophones in a linear vertical array with half wave length (at $300 \mathrm{~Hz}$ ) spacing between hydrophones. A compromise configuration was chosen consisting of four hydrophones. Figure 13 shows the directivity pattern for a four element hydrophone array. This is the calculated directivity as obtained from the expression:

$$
\begin{aligned}
E_{\theta} & =E_{0} \frac{\sin \left(\frac{m \pi d}{\lambda} \sin \theta\right)}{n \sin \left(\frac{\pi d}{\lambda} \sin \theta\right)} \\
\text { where } \lambda & =5 \text { meters } \\
d & =2.5 \text { meters } \\
f & =300 \mathrm{~Hz} \\
n & =4
\end{aligned}
$$




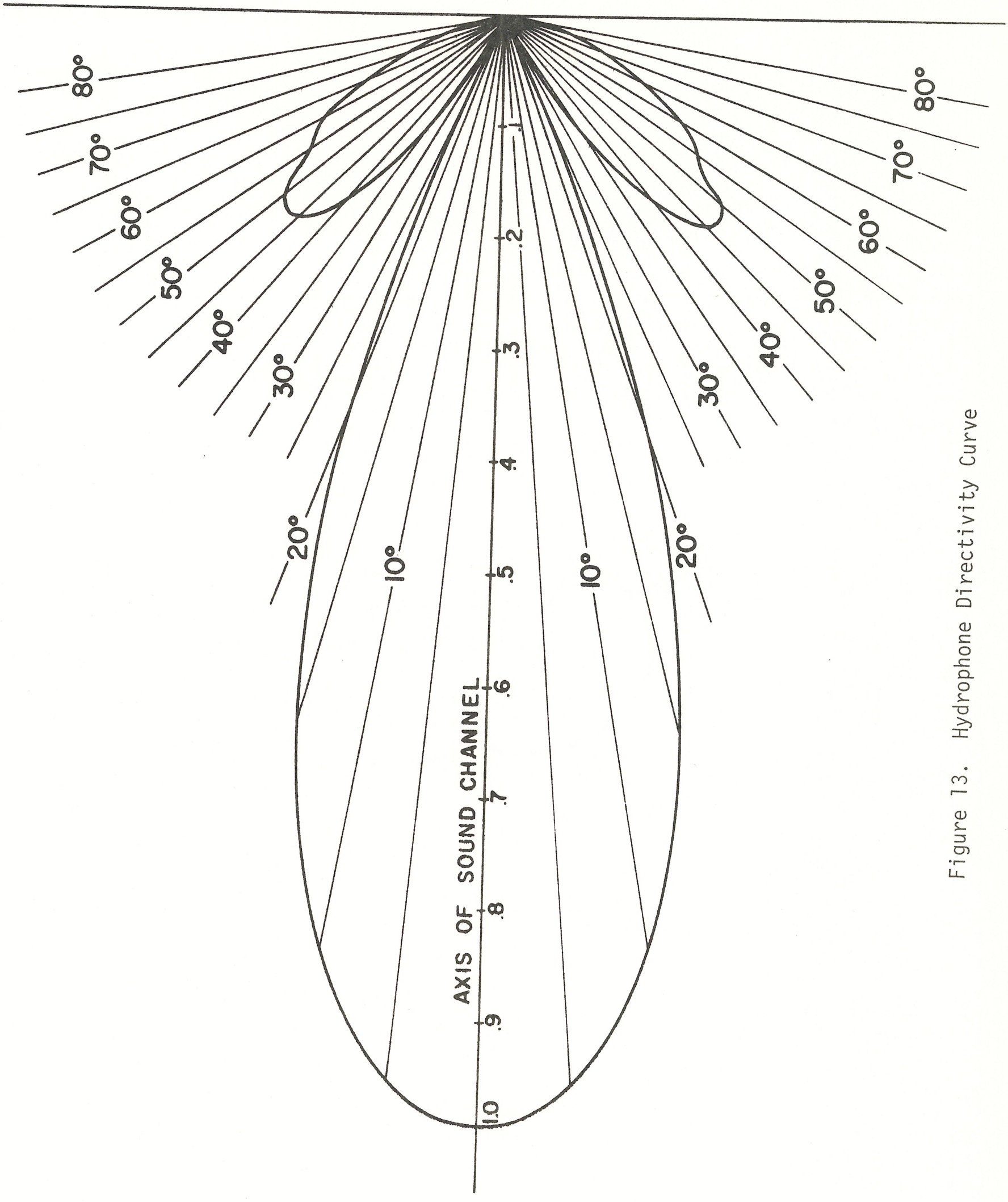


The directional gain of this array is given by the expression

$$
d_{r}=10 \log \frac{2 n d}{\lambda}
$$

where $d_{r}$ calculates to be $6 \mathrm{db}$ gain (Reference No.3)

The system was designed so that each component that was inaccessible and necessary to the operation of the system was duplicated so that a failure in any single component would not interrupt the system operation. The hydrophones were connected so that alternate pairs fed separate preamplifiers which in turn drove separate line pairs in the electromechanical cable. Also each preamplifier had a test oscillator which fed a test signal in series with a hydrophone pair. These oscillators are turned on by increasing the supply voltage to a specified value greater than the normal operating voltage value. The test signal level injected into the preamplifiers was calculated to be $20 \mathrm{db}$ above the pressure spectrum level of sea state 3 at the oscillator frequency. This allows the operator to monitor the quality of all components from the preamplifiers input back to the shore station.

\section{Electromechanical Cable}

As was mentioned previously the characteristics of the electromechanical cable were carefully studied and measured to determine if there were any properties which could cause degradation to the system.

First studied was the possible generation of triboelectric noise. This is noise generated by capacitance changes in a flexing cable. This noise was small compared to the signal amplitude in the long cable run after the preamplifiers and therefore the only source of noise due to the effect was the cable which connects the hydrophone to the preamplifiers. This section of cable was short and had little motion or flexing during its operation. Therefore noise generated from this source was insignificant.

The characteristic impedance of the cable was calculated and measured on both a 100 foot and on a 4000 foot sample. These measurements and calculations agreed quite well and are shown in Figure 14. As can be seen from the curve the impedance at $300 \mathrm{~Hz}$ is about 950 ohms and the impedance is changing rather rapidly with frequency. This means, of course, that there are equal resistive and capacitive components. If the output of the preamplifier is a very low impedance then the frequency response will be uniform in spite of the frequency varying load, and if the shore end is left unterminated then the termination will not cause a nonuniform frequency response. Normally one would terminate such a line in the complex conjugate of its characteristic impedance, but this is the criteria for maximum power transfer and the complex conis maximum vould at only one frequency. What is required here is maximum voltage out and flat frequency response which is 


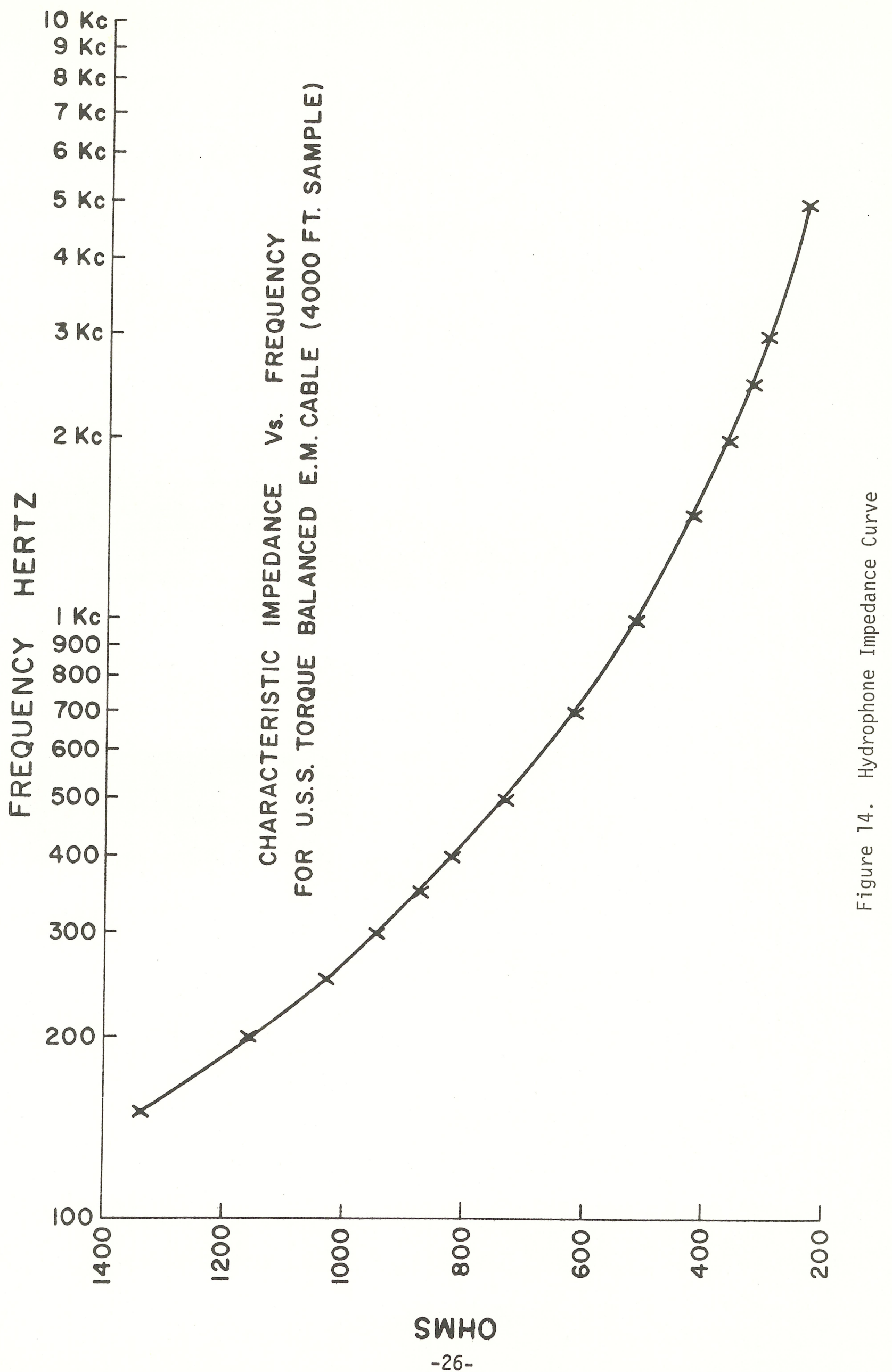


satisfied by the open circuit termination. The 4000 foot sample was very carefully measured for attenuation versus frequency with the far end unterminated. No attenuation could be detected on this 4000 foot sample with the measuring equipment used, but it was conservatively estimated that the maximum measurable attenuation was $0.2 \mathrm{db}$. The attenuation for the 30,000 foot length from the hydrophones to the shore station would therefore not be greater than $1.5 \mathrm{db}$.

The cross talk of the cable pairs was examined. The four electrical conductors in this cable were laid up in a square pattern and this spacing and configuration was maintained throughout the full length of the cable. This means that there was no random twisting of the cables. Diagonally opposite wires (not adjacent) were used in each cable pair (Figure 15), which meant that any one wire (1) had equal capacitive coupling to the two wires that made up the other pair (2 and 3 ). Since the signal phase angles are at $0^{\circ}$ (in 2) and $180^{\circ}$ (in 3 ) in this other pair the capacitively coupled signal in the first wire ( 1 ) is exactly zero. This was demonstrated experimentally in the 4000 foot sample with the measured cross talk being greater than $-40 \mathrm{db}$.

The block diagram of the shore electronics (that portion for which we were responsible) is shown in Figure 16.

Power for the preamplifiers and test oscillator was sent down the same lines that the signals from the hydrophones come up. The DC power and AC signals were separated by the series inductors in the DC path and the blocking capacitors in the AC path. The AC signal is further transformer coupled. This transformer was especially balanced and incorporated electrostatic shielding to reduce any common mode interference. The signals were then fed to high pass filters (UTC HMI-200) whose cut-off frequency was at $200 \mathrm{~Hz}$. These were used to reduce the $60 \mathrm{~Hz}$ power line interference caused by the difference between the ocean ground and the power line ground bus at this point. Next the signals drive variable gain $($ ( $+10 \mathrm{db},+20 \mathrm{db}$, and $+40 \mathrm{db})$ amplifiers. These amplifiers were used to adjust the gain so that the received sea noise on different days would not saturate the processing electronics. The signals then are fed to a summation amplifier where the final directional beam formation takes place. Additional circuits were added to this electronics panel for the convenience of the operator: 1) an audio amplifier with loudspeaker for aural monitoring, 2) two narrow band filters and amplifiers tuned to the frequencies of the preamplifier test oscillators, 3) a built-in AC voltmeter for monitoring the various levels throughout this system.

\section{Procurement}

Bids were solicited for various components of the systems. Three electromechanical wire rope companies responded to our specifications for two 30,000 ft. lengths and one 4,000 ft. length of four conductor armored cable. The United States Steel Company, Electro-Mechanical Cable Division, Worcester, Massachusetts, was selected as the sup- 


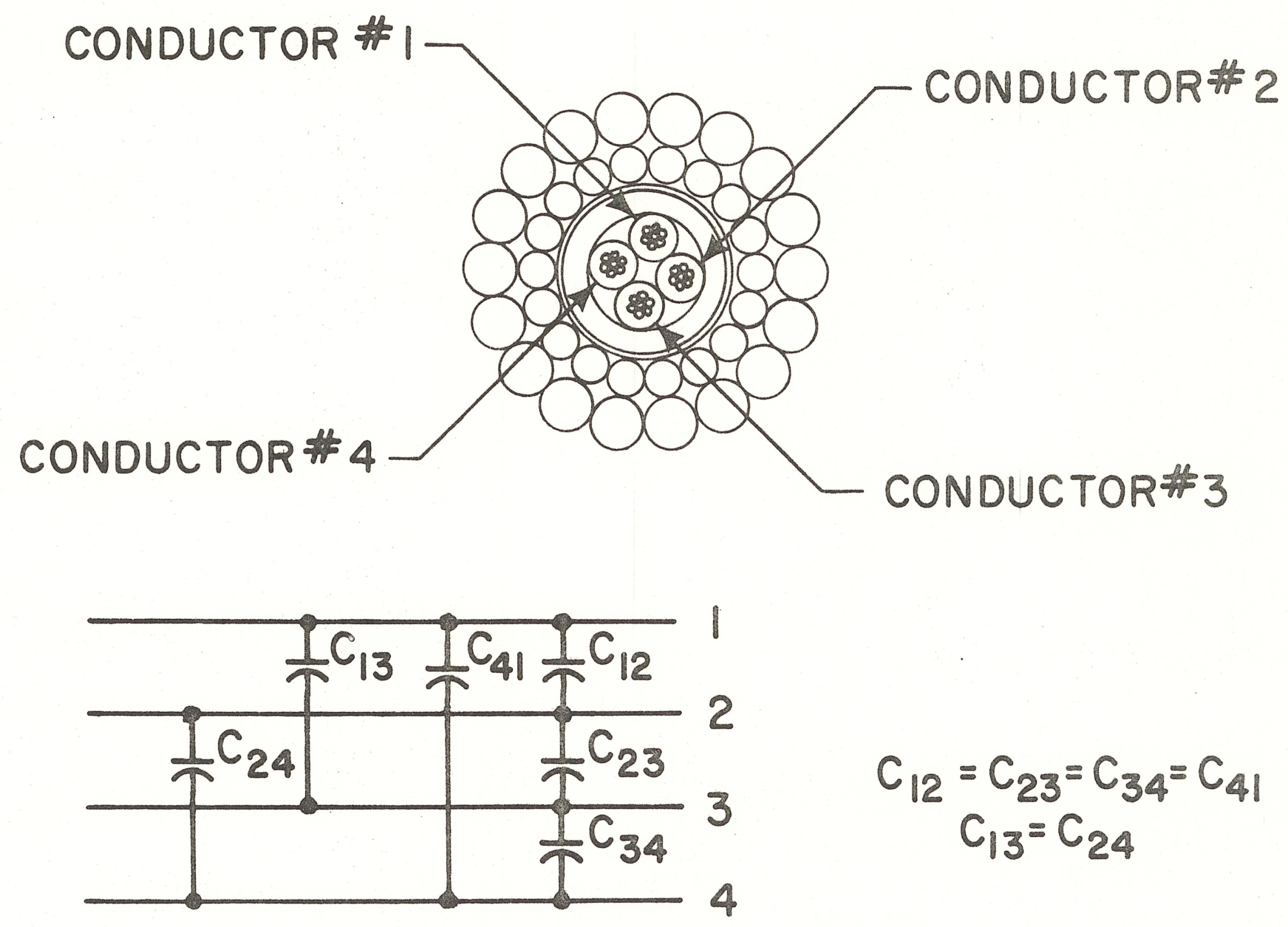

CABLE CONSTRUCTION

Figure 15. E/M Cable Cross Section 


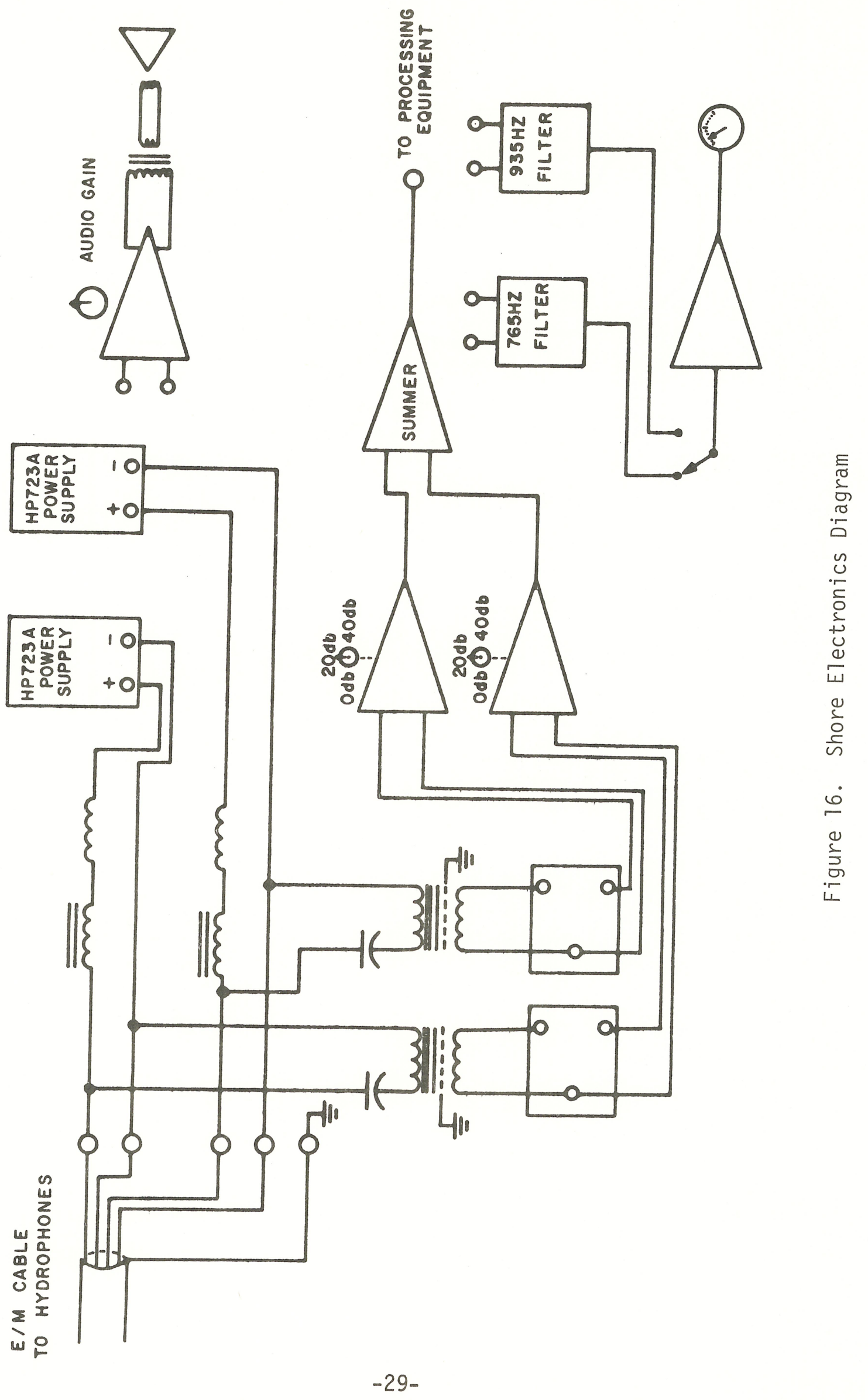


plier on the basis of price, delivery, cable characteristics and single uninterrupted length capabilities. The Massa Corporation, Hingham, Massachusetts, was selected from five bidders to supply two hydrophone arrays. Their proposed design met the system specifications at a reasonable price.

The remaining components of the system were obtained from single sources on the basis of our previous experience. These included sub-surface floats, wire rope, acoustic releases and various items of hardware.

Assurance of the quality of major components was obtained through inspection during the manufacturing process and by a comprehensive series of laboratory and environmental tests performed prior to system installation.

4. System Deployment

\subsection{Logistics}

The original concept of the Grand Turk Island installation prescribed an independent operation which would require little or no support by military facilities or transport. To this end arrangements were made to utilize, wherever possible, institutional and commercial vessels and equipment.

A test of the hydrophone and cable components in deep water was performed from the Bermuda Biological Station's R/V PANULARIS.

The actual deployment operation at Grand Turk Island required two vessels. A barge was leased from the Turks and Caicos Islands Department of Public Works to be used as the primary deployment vessel. The vessel was 80 feet long by 20 feet beam and powered by two diesel Harbormaster power plants. A hydraulic power supply, powered reel stand and cable engine was leased from MAS-Tracor, Port Everglades, Florida to deploy the underwater system. This equipment plus a bow sheave and A-frame had to be installed on the barge and checked out. (Figures 17 and 18, the GOVERNMENT BARGE) The R/V GULF STREAM (Figure 19) funded by NSF, and owned by Nova University Oceanographic Laboratories of Dania, Florida, was generously loaned with crew to perform the site survey and assist in the installation. A radar was loaned by W.H.O.I. and installed on the GULF STREAM for navigation.

Approximately 40,000 pounds of equipment was shipped from Dania, Florida to Grand Turk Island on the M/V ENRUS, an inter-island cargo vessel operated by the Windward Shipping Company, Fort Lauderdale, Florida. All equipment, with the exception of that leased from MAS-Tracor, was shipped from Woods Hole to Dania on a flat bed truck (Figure 20). 


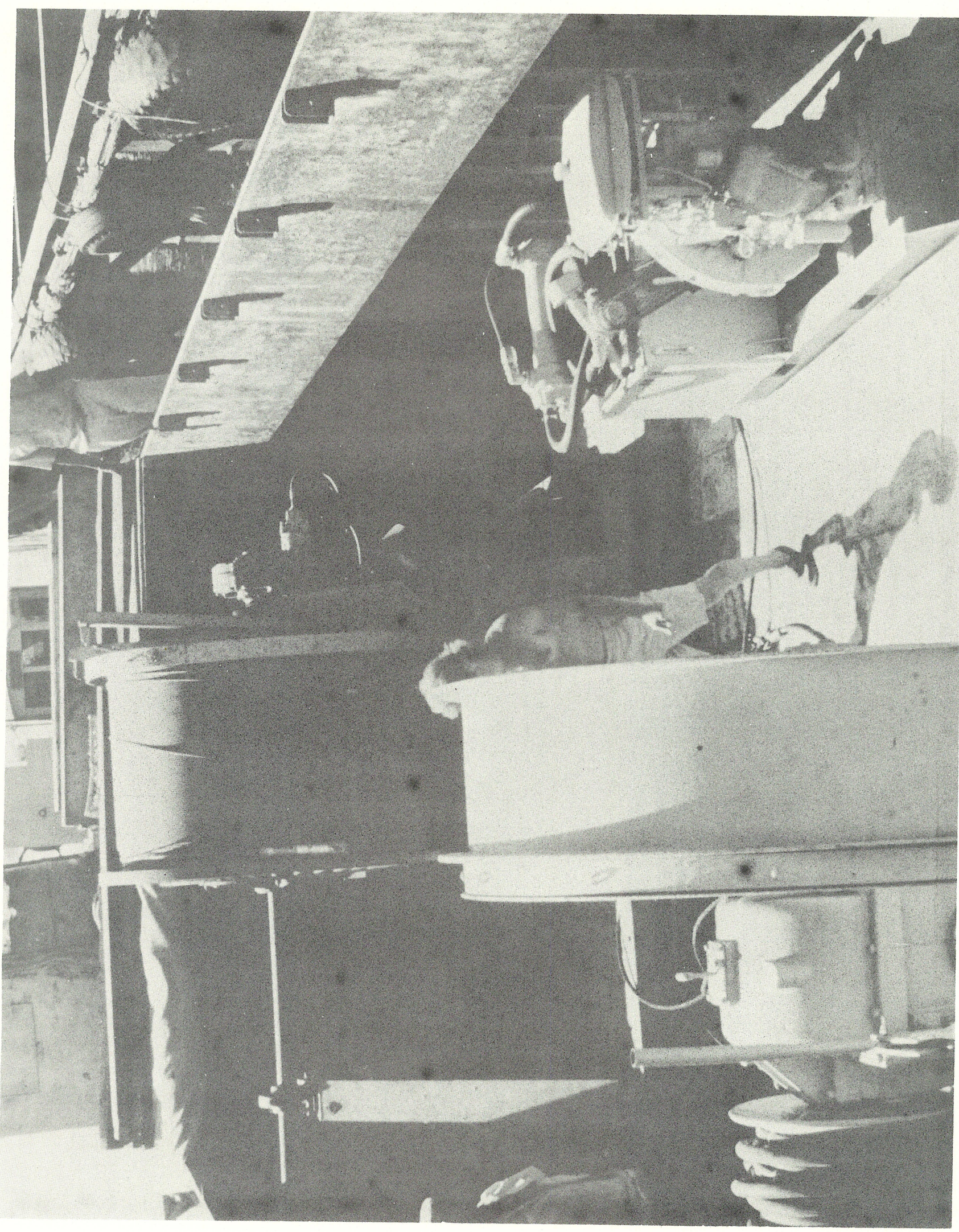

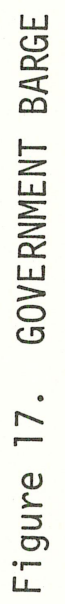




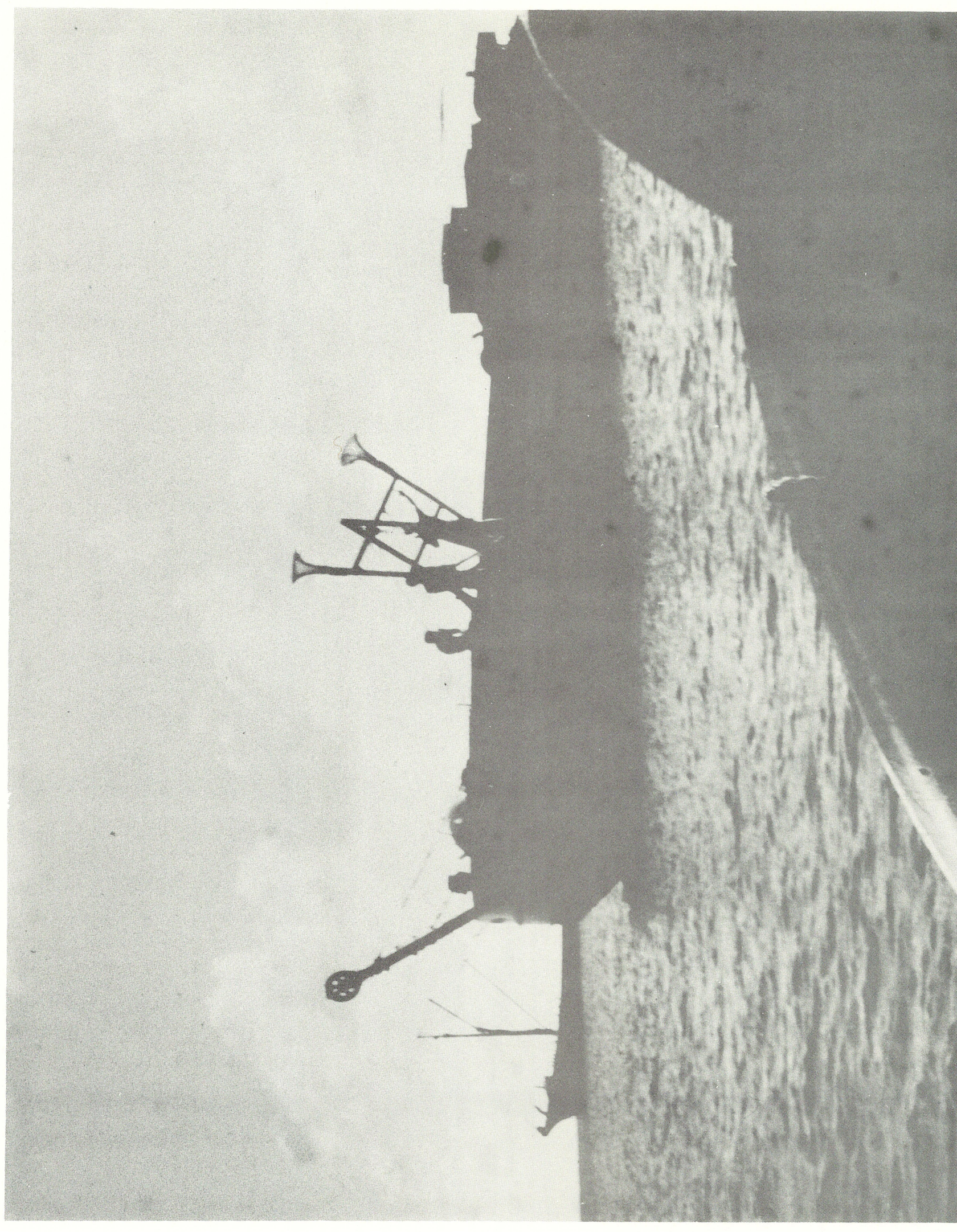

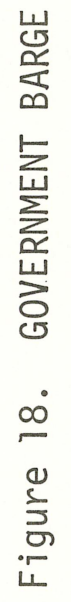




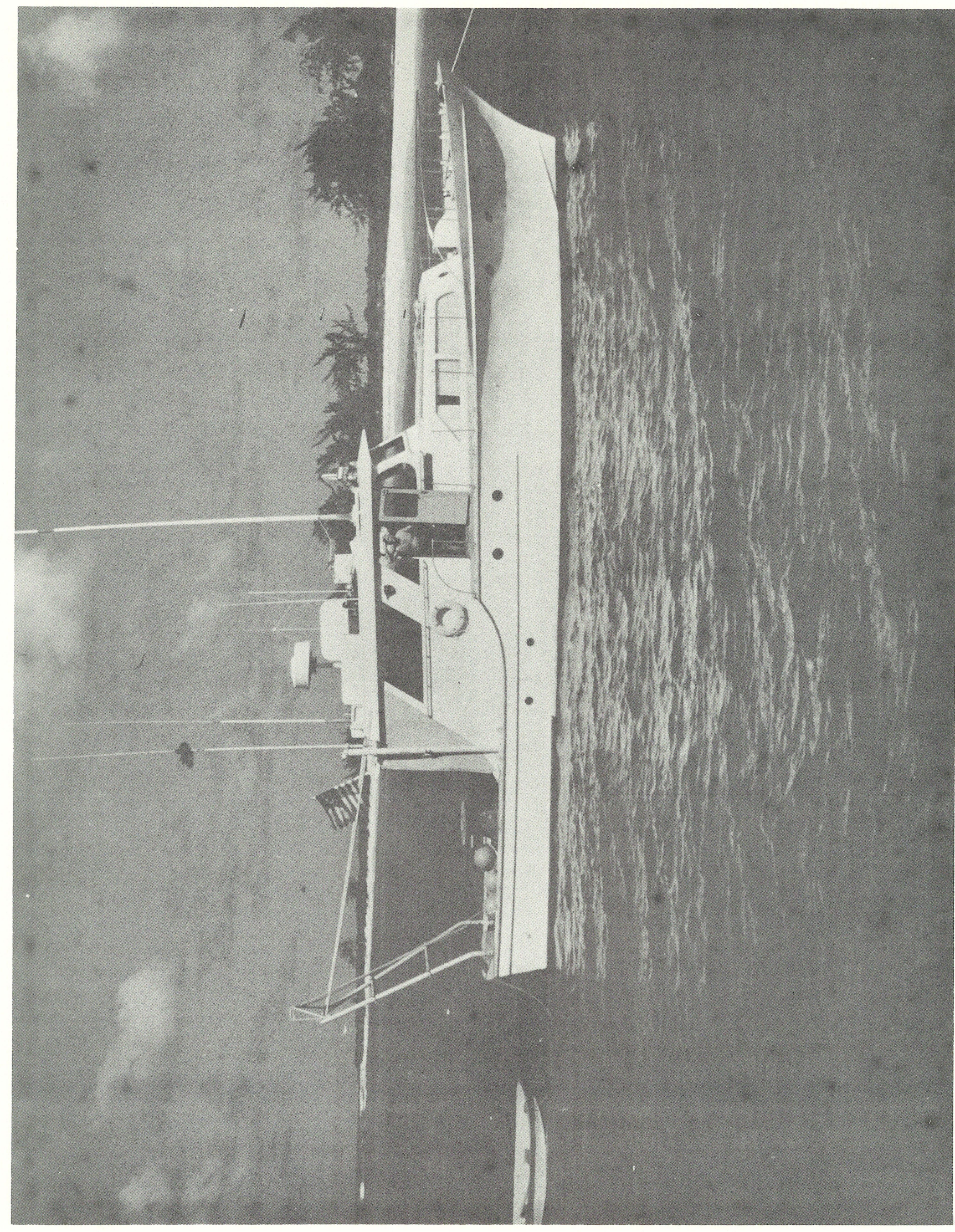

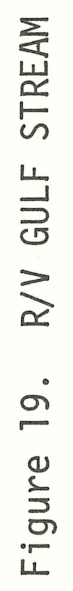




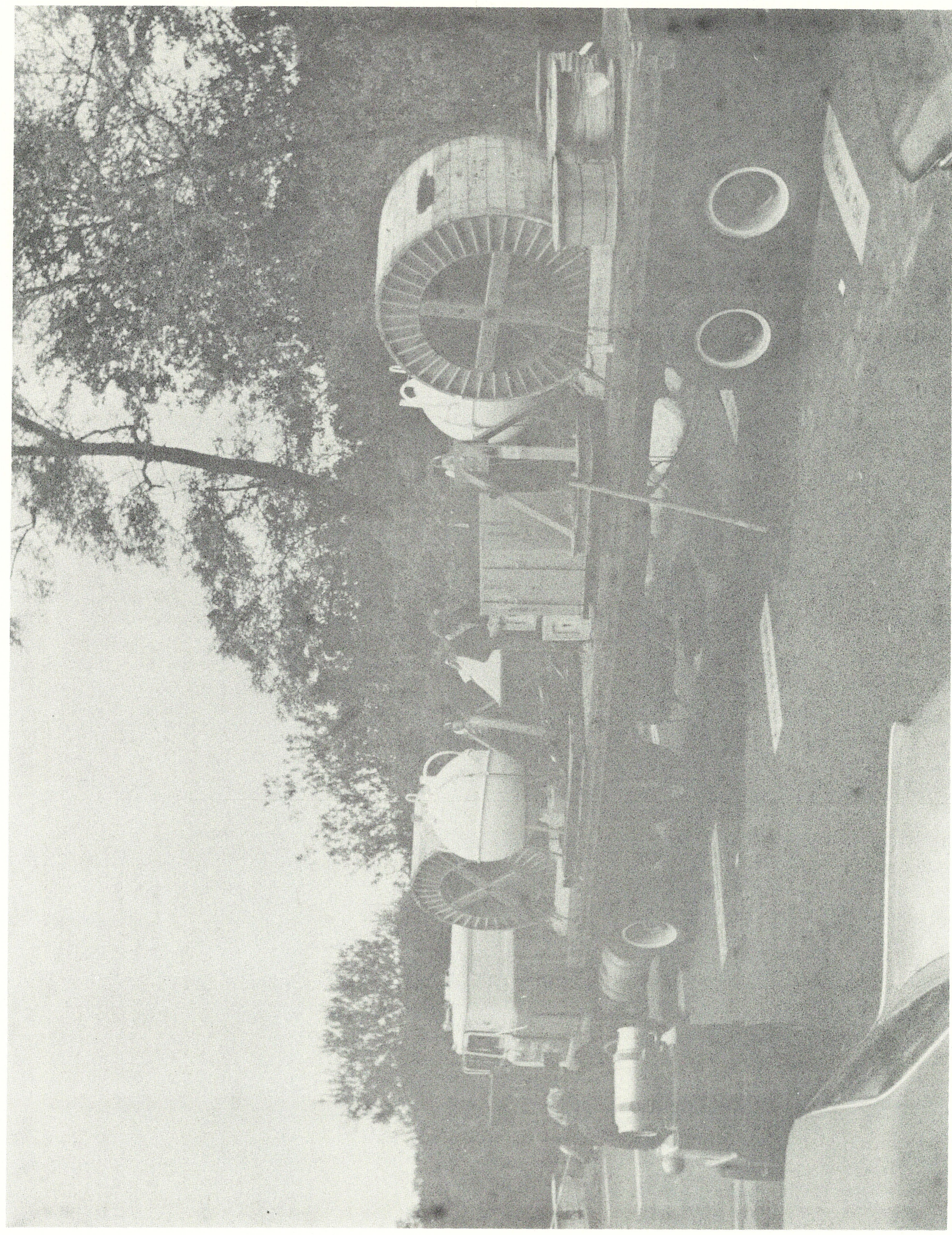

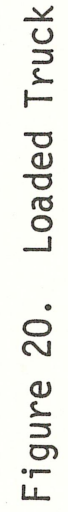


A large crane was furnished by the U. S. Air Force at Grand Turk Island to off-load the heavy equipment from the ENRUS to the GOVERNMENT BARGE. (Figure 21) The Department of Public Works of the Turks and Caicos Island Government made available on a rental basis a crane for loading and unloading the barge, and a tractor for hauling the cable ashore. Our local agent provided a truck and men for various cartage requirements.

Diving services were provided by a local concern, Underwater Research Ltd.

Because of the uncertainty of locally procuring materials and specialized services such as welding, all tools and materials required to outfit the barge and to make the installation were shipped from Woods Hole. Project personnel performed all installation tasks.

\subsection{Deployment Analysis}

Anchor Lowering Analysis. The deployment scheme, illustrated in Figures No. 27 to 31, utilized two vessels for the lowering of the anchor. One, the GULF STREAM held the subsurface buoy and the first 1300 meters of the array, the other, the GOVERNMENT BARGE, payed out the E/M cable until the anchor bottomed.

Analyses of the tension in, and the geometry of, the lowering lines were made as a function of the distance between the two ships and the amount of cable payed out in order to:

1) Select an optimum distance between ships during anchor lowering. Should the ships be far apart the tension in the lowering lines would then be too large. Should the ships be too close, the angle at the anchor between the lowering lines would then be small and tangling could occur.

2) Determine, knowing the distance between the two ships, the horizontal distance between the anchor and the lowering ships at the time of anchor bottoming in order to properly position both ships with respect to the desired anchoring point at the beginning of the deployment sequence.

3) Predict, knowing the distance between the two ships, the amount of cable payed out at the time the subsurface buoy is pulled under, and at the time the anchor bottoms.

In order to compute this analysis a computer program was written by $\mathrm{R}$. Goldsmith of the Woods Hole Oceanographic Institution Computer Center. Appendix 2 explains the logics of the program. Appendix 3 is a listing of the program. Figure No. 22 shows a typical computer plot of the equilibrium trajectories of the lowering lines for a given distance between ships and for different amounts of $\mathrm{E} / \mathrm{M}$ cable payed out. Results from the computer studies were used to select an optimum distance of 1300 meters between ships. Table 2 shows a typical set of data tabulated for this particular distance. Similar tables were 


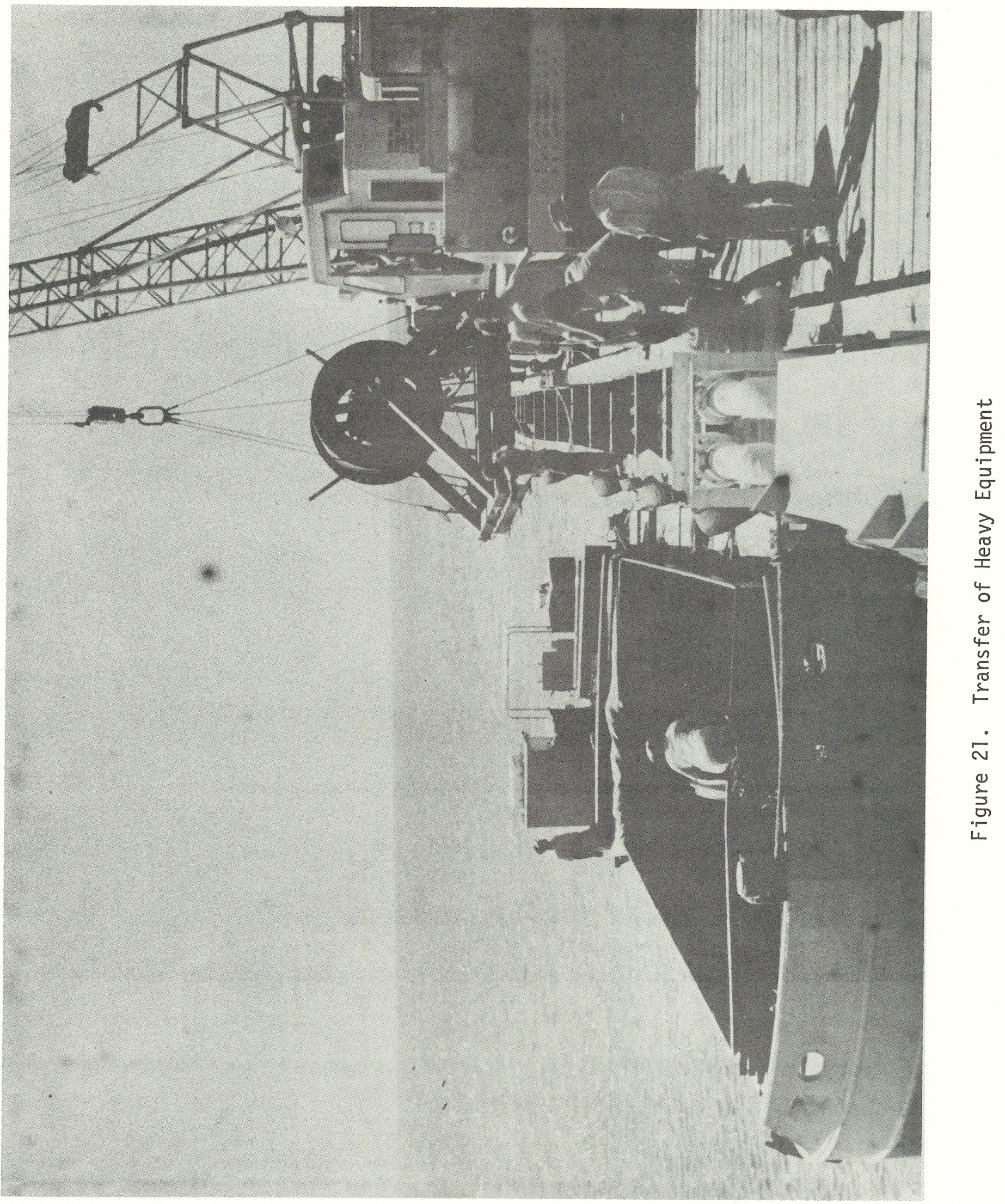




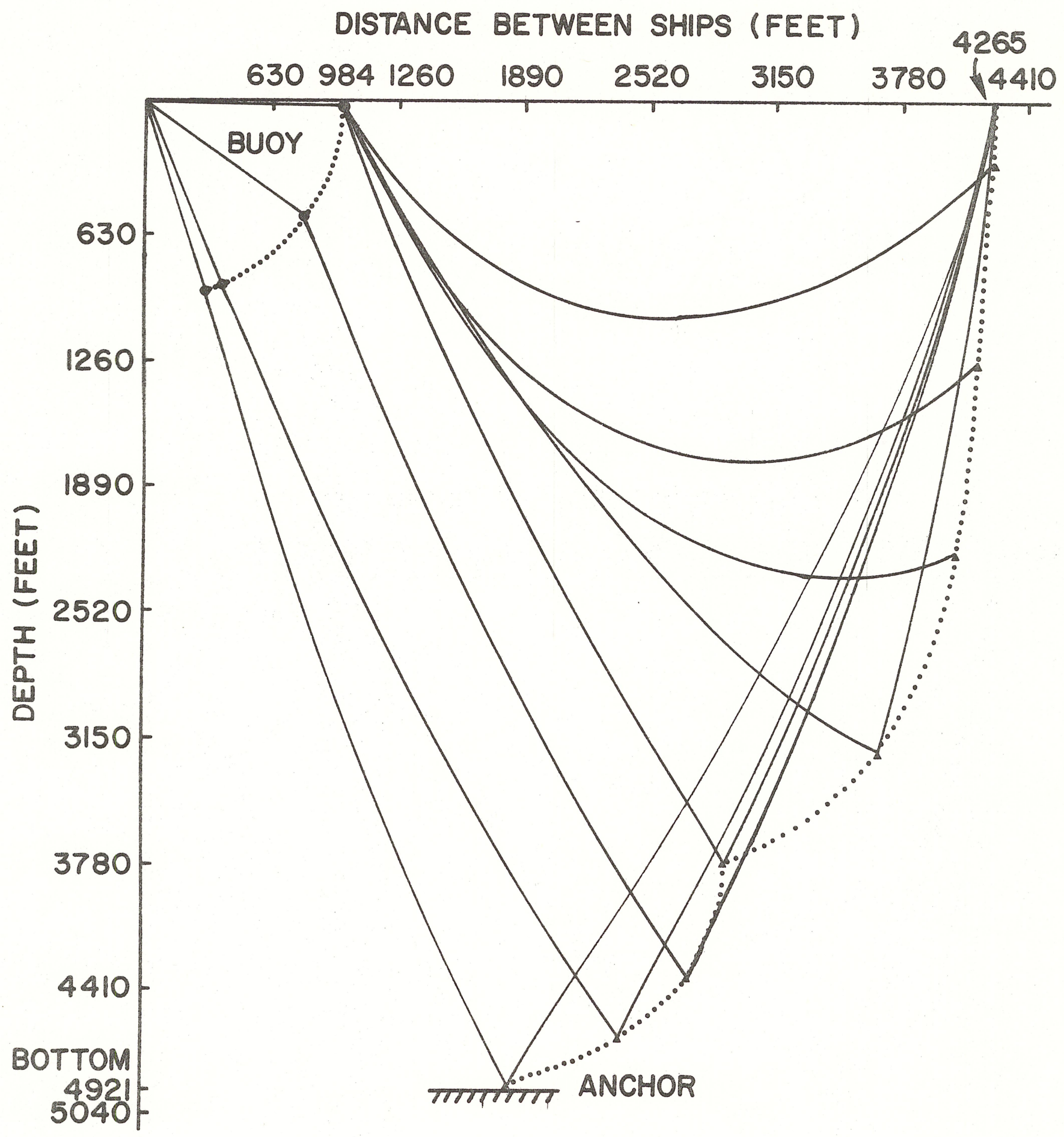

Figure 22. Computer Plot 
TABLE 2

\begin{tabular}{|c|c|c|c|c|c|c|}
\hline \multicolumn{2}{|c|}{ Ship to Anchor Cable Length } & \multicolumn{2}{|c|}{ Anchor Coordinates } & \multirow{2}{*}{$\begin{array}{c}\text { Tension At } \\
\text { Gov't. } \\
\text { Barge }\end{array}$} & \multirow{2}{*}{$\begin{array}{c}\text { Tension At } \\
\text { Buoy }\end{array}$} & \multirow{2}{*}{$\begin{array}{c}\text { Tension At } \\
\text { Gulf } \\
\text { Stream }\end{array}$} \\
\hline & & $x$ & $Y$ & & & \\
\hline Feet & Meters & Feet & Feet & Lbs. & Lbs. & Lbs. \\
\hline 25 & 7.6 & 3279 & 26 & 2608 & 319 & 172 \\
\hline 50 & 15.2 & 3277 & 48 & 2611 & 320 & 171 \\
\hline 100 & 30.5 & 3274 & 102 & 2617 & 323 & 171 \\
\hline 250 & 76.2 & 3265 & 249 & 2636 & 332 & 170 \\
\hline 750 & 228.6 & 3231 & 747 & 2697 & 367 & 172 \\
\hline 1250 & 381 & 3799 & 1250 & 2756 & 407 & 180 \\
\hline 1750 & 533 & 3160 & 1743 & 2810 & 456 & 196 \\
\hline 2250 & 686 & 3092 & 2249 & 2850 & 523 & 224 \\
\hline 2750 & 838 & 2989 & 2733 & 2858 & 637 & 285 \\
\hline 3250 & 990 & 2720 & 3206 & 2751 & 899 & 420 \\
\hline 3750 & 1143 & 2250 & 3607 & 2471 & 1341 & 575 \\
\hline 4000 & 1219 & 1968 & 3778 & 2280 & 1593 & 625 \\
\hline 4500 & 1372 & 2942 & 4323 & 2660 & 1337 & 1347 \\
\hline 4750 & 1448 & 2686 & 4498 & 2536 & 1518 & 1532 \\
\hline 5000 & 1524 & 2410 & 4660 & 2392 & 1707 & 1724 \\
\hline 5250 & 1600 & 2124 & 4800 & 2233 & 1902 & 1922 \\
\hline 5500 & 1676 & 1832 & 4922 & 2060 & 2100 & 2125 \\
\hline
\end{tabular}


established for distances of 1000, 1100, 1200, 1300, 1400, 1500 meters. The set of tables was taken to sea as part of the engineering information needed for the array deployment. During actual anchor lowering the amount of cable payed out at the time of anchor bottoming turned out to be very close to the amount predicted by theory.

Cable Payout Rate Analysis. After anchor bottoming the next step in the deployment was to pay out the $\mathrm{E} / \mathrm{M}$ cable over the proposed cable track.

The cable had to be payed out fast enough to cover the ground yet not so fast as to run short of cable before reaching the landing point. Therefore the amount of cable to be payed out per unit of time had to be determined as a function of ship speed and track topography. To this end the track was divided by check points into a number of segments and the corresponding bottom profile established (See Figure No. 23). The payout rate from one check point to the next could then be computed using the formula:

$$
\hat{r}=\alpha\left[\frac{(b+c-a)}{g} \bar{v}\right.
$$

where,

$$
\begin{aligned}
& \uparrow=\text { payout rate between the two end points of a given } \\
& \text { segment } \mathrm{ft} / \mathrm{sec} \\
& b=\text { distance between the two end points of the } \\
& \text { segment, as measured on the sea floot ft. } \\
& C=\text { amount of cable from the surface to the } \\
& \text { shore end of the segment ft. } \\
& \begin{aligned}
a= & \text { amount of cable from the surface to the } \\
& \text { other end of the segment }
\end{aligned} \\
& g=\begin{array}{l}
\text { distance between the two end points of the } \\
\text { segment as measured on the surface ft. }
\end{array} \\
& V=\operatorname{ship} \text { speed } \mathrm{ft} / \mathrm{sec} \\
& X=\text { coefficient }>\mid \text { given by: } \\
& \alpha=\frac{\text { total allowable length of } \mathrm{E} / \mathrm{M} \text { cable }}{\text { total length of cable track }}
\end{aligned}
$$

The different parameters are shown in Figure No. 24. The distances $a$ and $c$ were found by assuming that the cable was hanging in a straight line with the inclination it had at the time of anchor bottoming. 

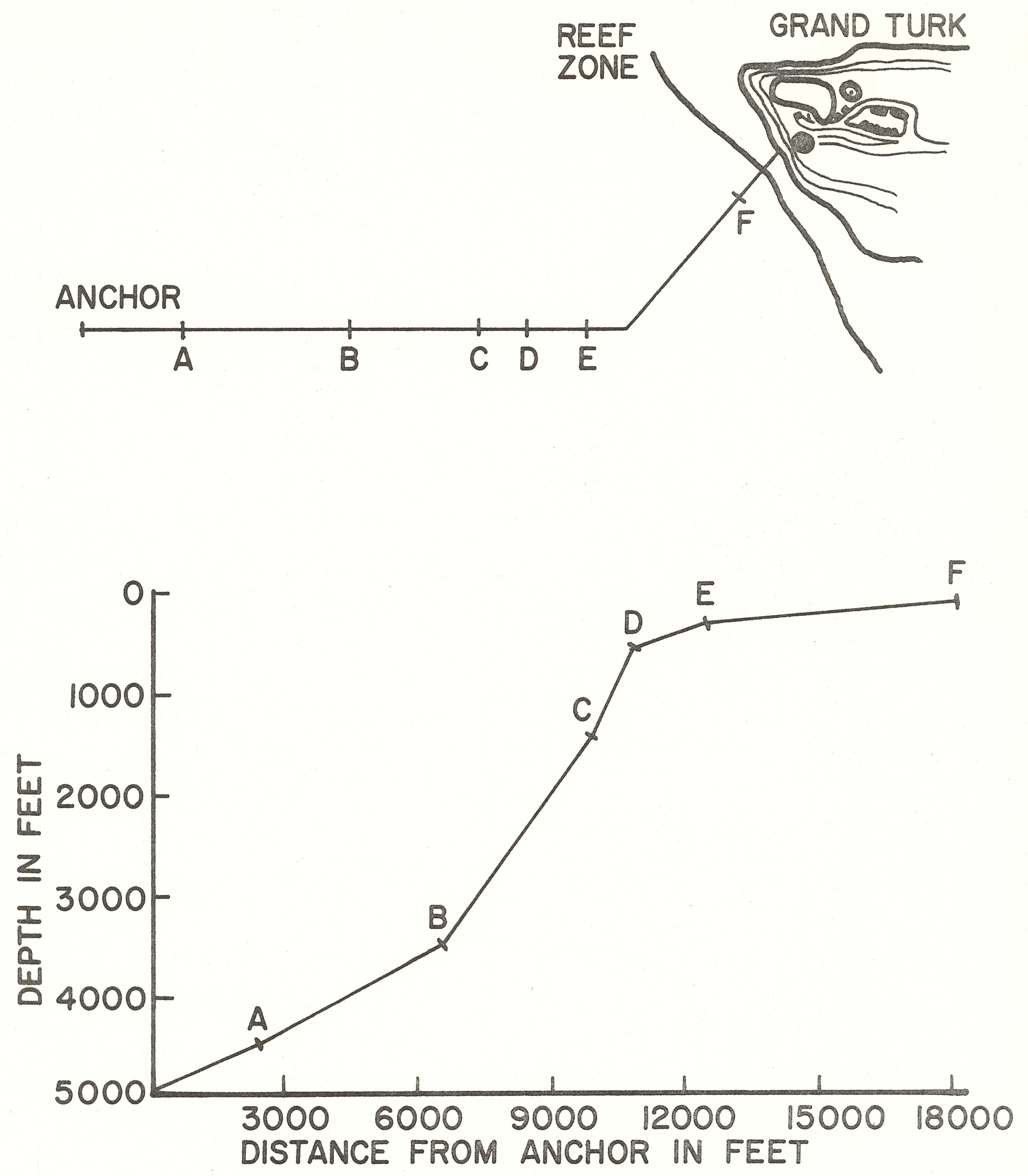

Figure 23. Bottom Profile 


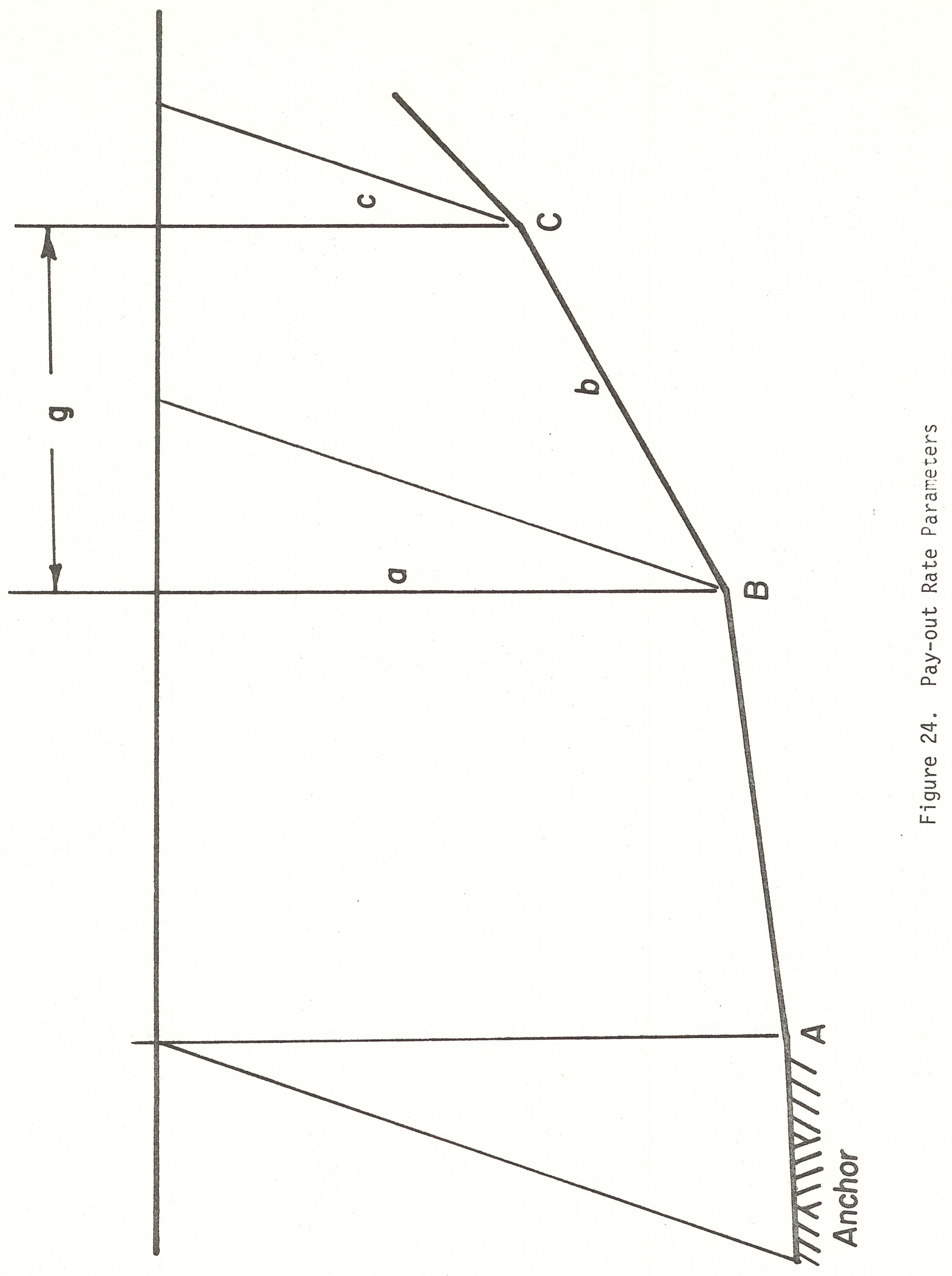


Computation results for different ship speeds and alternative tracks were tabulated and graphed as typically represented in Figure No. 25. These graphs were also taken to sea as part of the engineering information needed for the array deployment.

\subsection{Field Operations}

The field operations necessary to support the operation consisted of the following:

A) Test of the electromechanical cable, terminations and hydrophone array at Bermuda.

B) Bathymetric site survey at Grand Turk Island.

C) Installation of hydrophone assembly and cable run to reef.

D) Cable run through reef and ashore to van.

E) System test.

Each operation will be discussed in detail.

\section{A) Bermuda Test}

One hydrophone assembly, preamplifier and 4000 feet of $\mathrm{E} / \mathrm{M}$ cable were air shipped to the Bermuda Biological Station, Bermuda. The cable was reeled onto the hydrographic winch of the R/V PANULARIS and connected to the hydrophone array. The array was lowered about 300 meters in 1000 meters water depth. System electrical integrity was confirmed and ambient noise measurements made. An oscillation condition was noted when the two hydrophone pairs were paralleled. Each pair operated normally alone. This trouble was subsequently isolated and climinated. Signals from a then unidentified source on the island were heard we11. This test was terminated and the gear shipped back to Woods Hole. The test indicated that the hydrophone and preamplifiers were satisfactory. The cable and electromechanical connection were likewise acceptable.

B) Bathymetric Survey

A survey of the offshore topography at Grand Turk Island was required to determine the correct site for the hydrophone emplantment and to obtain a depth profile along the proposed cable route to the shore. A precision graphic recorder (PGR) was installed on the R/V GULF STREAM and connected to an existing UQN hull mounted transducer. Approximately 25 miles of survey track was run using radar fixes on a previously deployed navigation marker buoy and the tip of the island as the navigational control. The PGR trace was poor due to a high noise level and quenching of the hydrophone due 


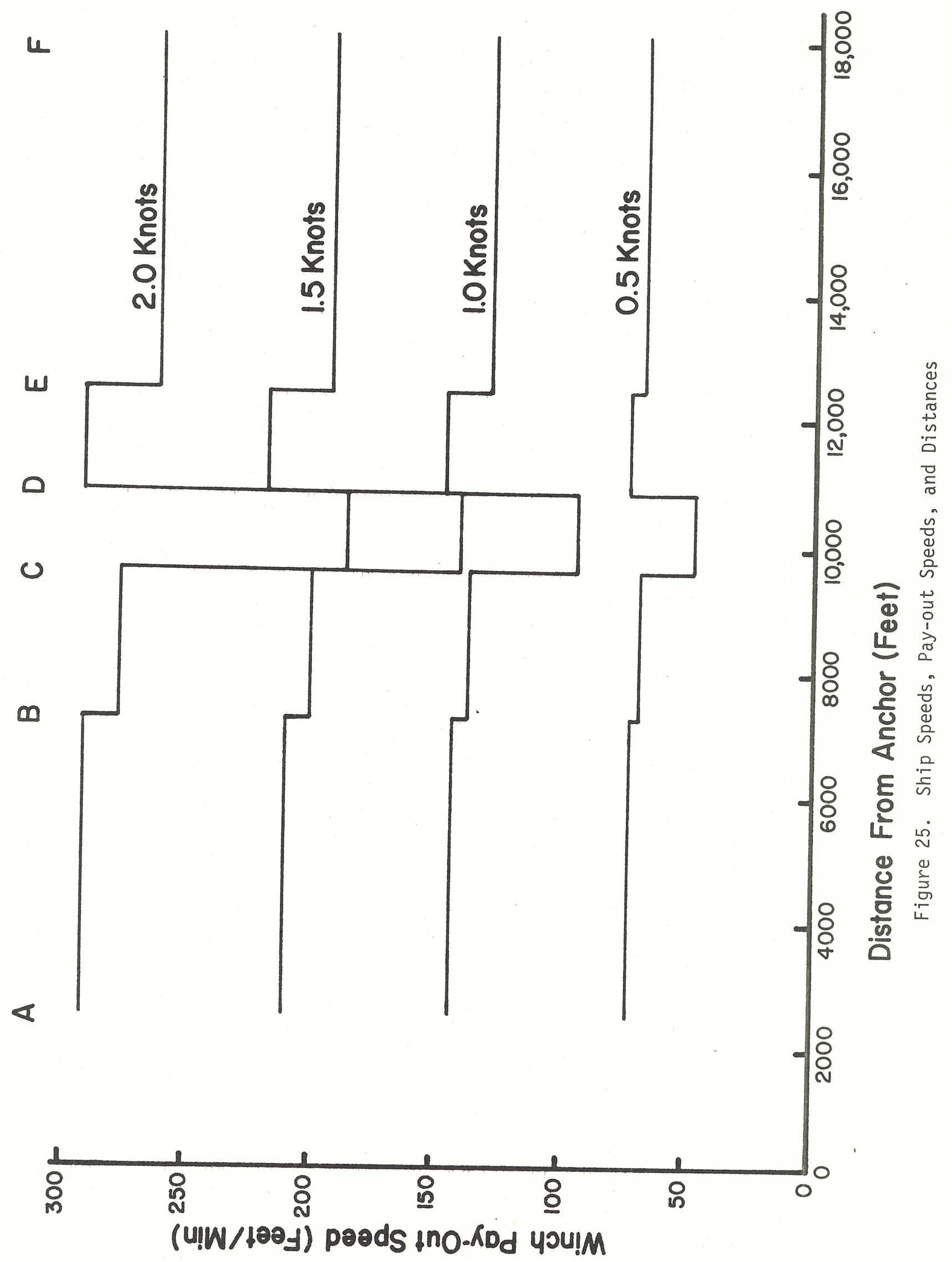


to rough seas. However depths were obtained by correlating the position of the stylus with the return signal as heard in headphones. The bathymetric data obtained proved sufficiently accurate for the operation. Figure 2 shows the proposed track route, the actual track route and depth contours. Contours obtained by this survey are shown by solid lines. Dotted lines indicate the data available prior to the survey. A marker buoy was placed at a position on the proposed track where a turn was required.

Further reconnaissance of the reef area was necessary to determine a suitable route for the cable ashore. Prior reference to aerial photographs indicated a possible break in the reef which might be suitable for the cable route.

(Figure No. 26) Reconnaissance was made by a flight over the area obtaining bearings on two possible breaks in the reef. Subsequent inspection from the lighthouse established one to be most suitable. The GULF STREAM was used to place a marker buoy just off this opening. A 5/16" wire rope tether was then attached to this buoy and led through the opening and across the reef to shore with the help of divers. The reef was confirmed to be extremely rough coral with many sea urchins and barracuda observed. The seaward boundary descended sharply to about 50 feet. Very large breaking waves, even in calm weather, were present at most times at this boundary. The cable run over the reef was determined to be just under 500 meters.

\section{C) Installation}

The actual installation took place on November 16, 1972. The wind was light easterly with little swell. The R/V GULF STREAM and GOVERNMENT BARGE proceeded to their respective positions, the navigation responsibilities provided by the GULF STREAM. Shortly after arriving on station at 0900 and while preparing to start deployment the radar on the GULF STREAM failed. It was decided to continue the operation in spite of this serious loss as 1 ) the weather was ideal, 2) we were correctly positioned prior to the breakdown, and 3) contingency marker buoys had been placed at critical points along the track. The GULF STREAM continued to navigate for both ships using visual bearings, range estimates and depth data.

The hydrophone deployment sequence is shown in five phases in Figures 27 through 31. Phase I shows the subsurface sphere attached to the 5/16" wire rope being payed out from the GOVERNMENT BARGE. The GULF STREAM meanwhile had attached to a 500 meter reel of $13 / 16 "$ polypropylene line three glass floats and an acoustic release which was made fast to the upper end of the sphere. The GULF STREAM then slowly steamed ahead paying out 300 meters of the polypropylene line and making it 


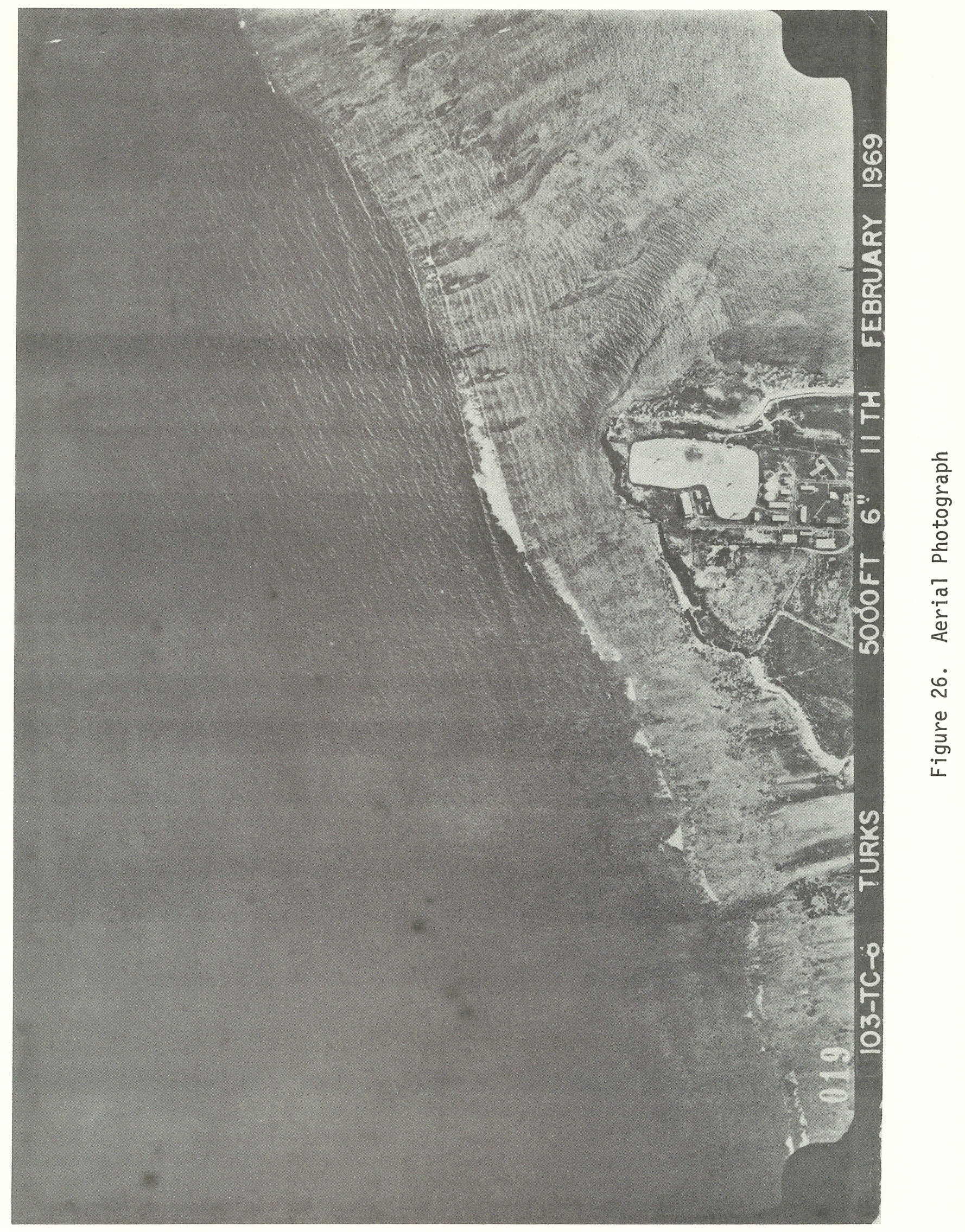



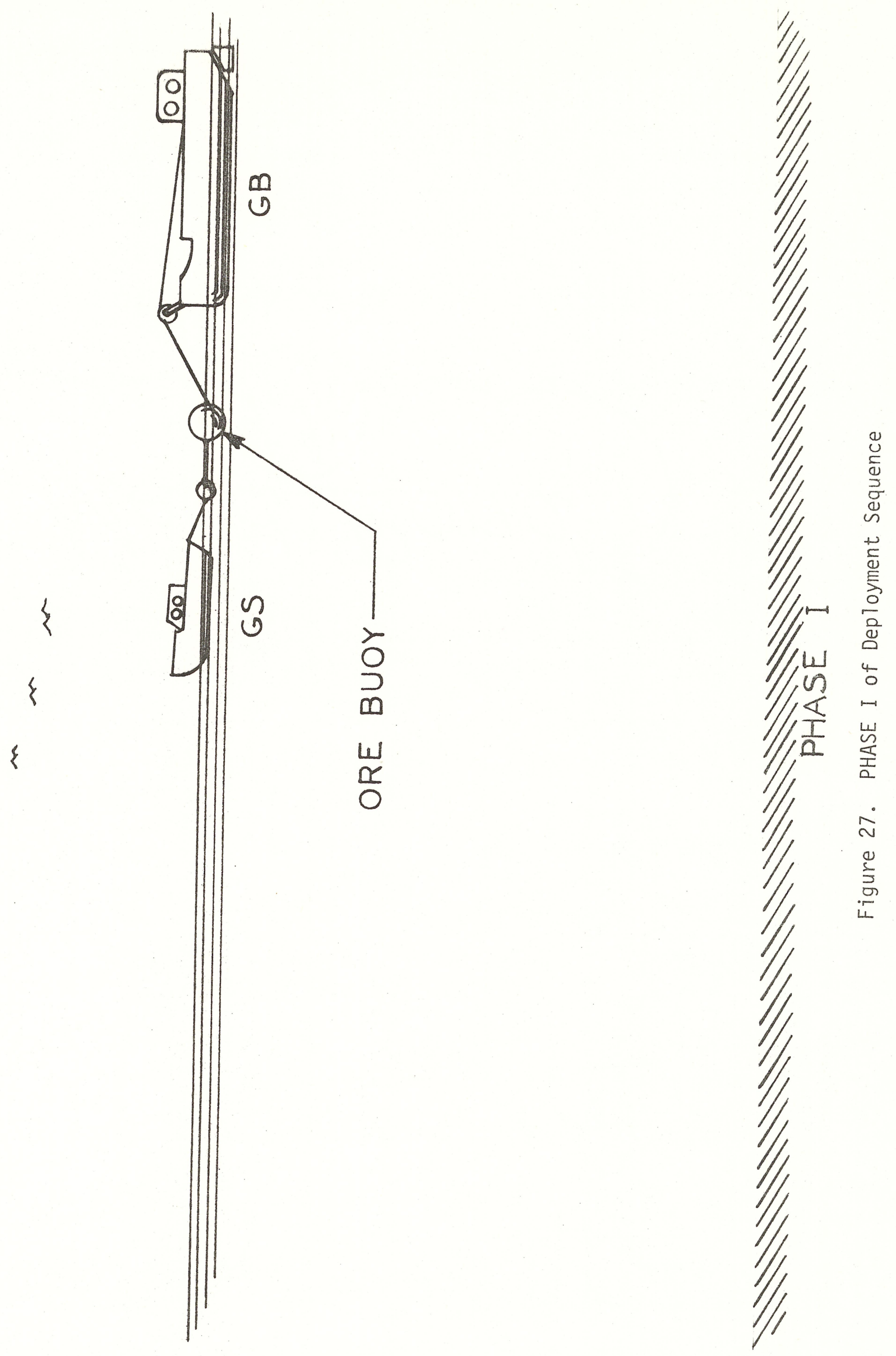

$-46-$ 

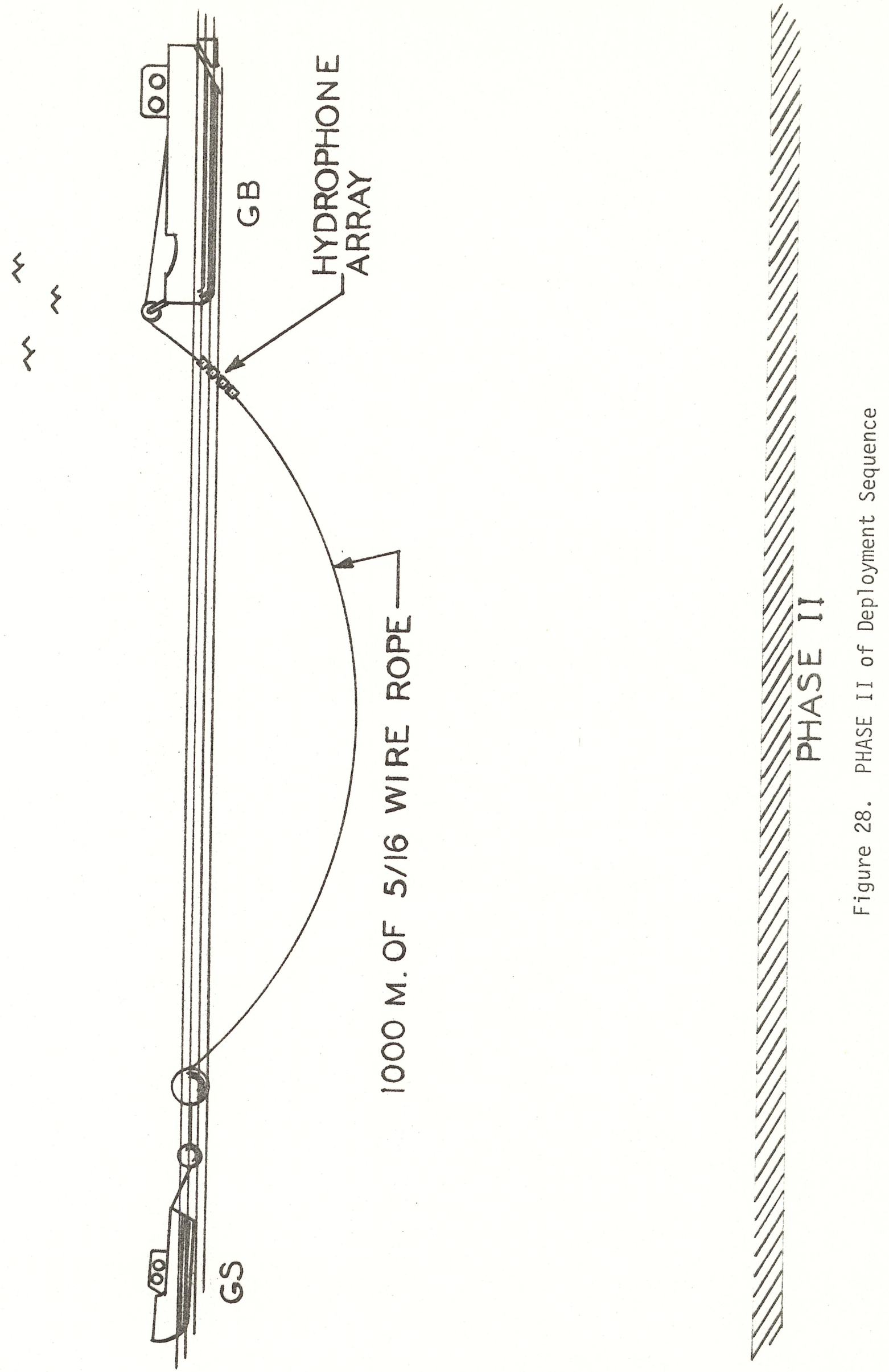

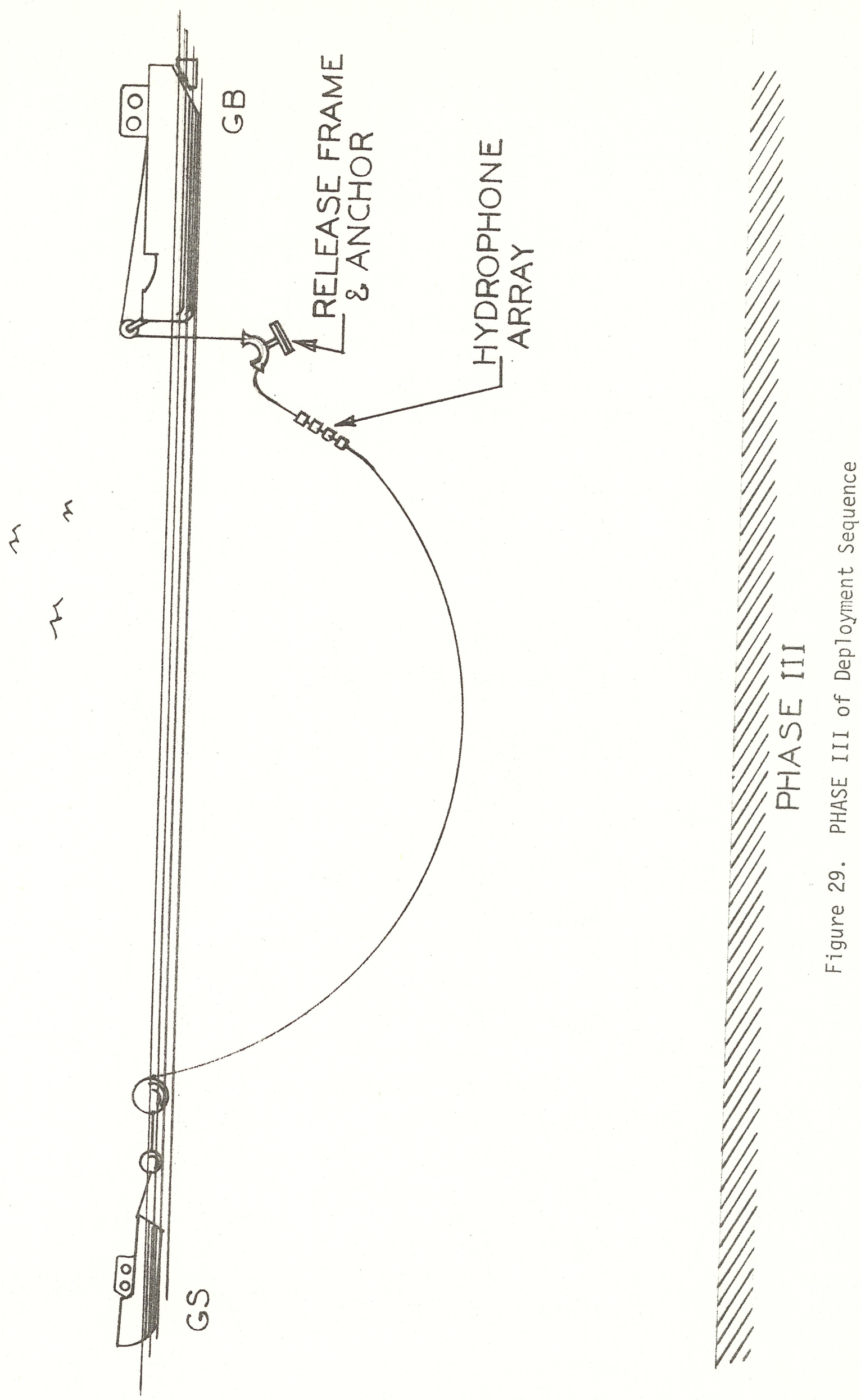


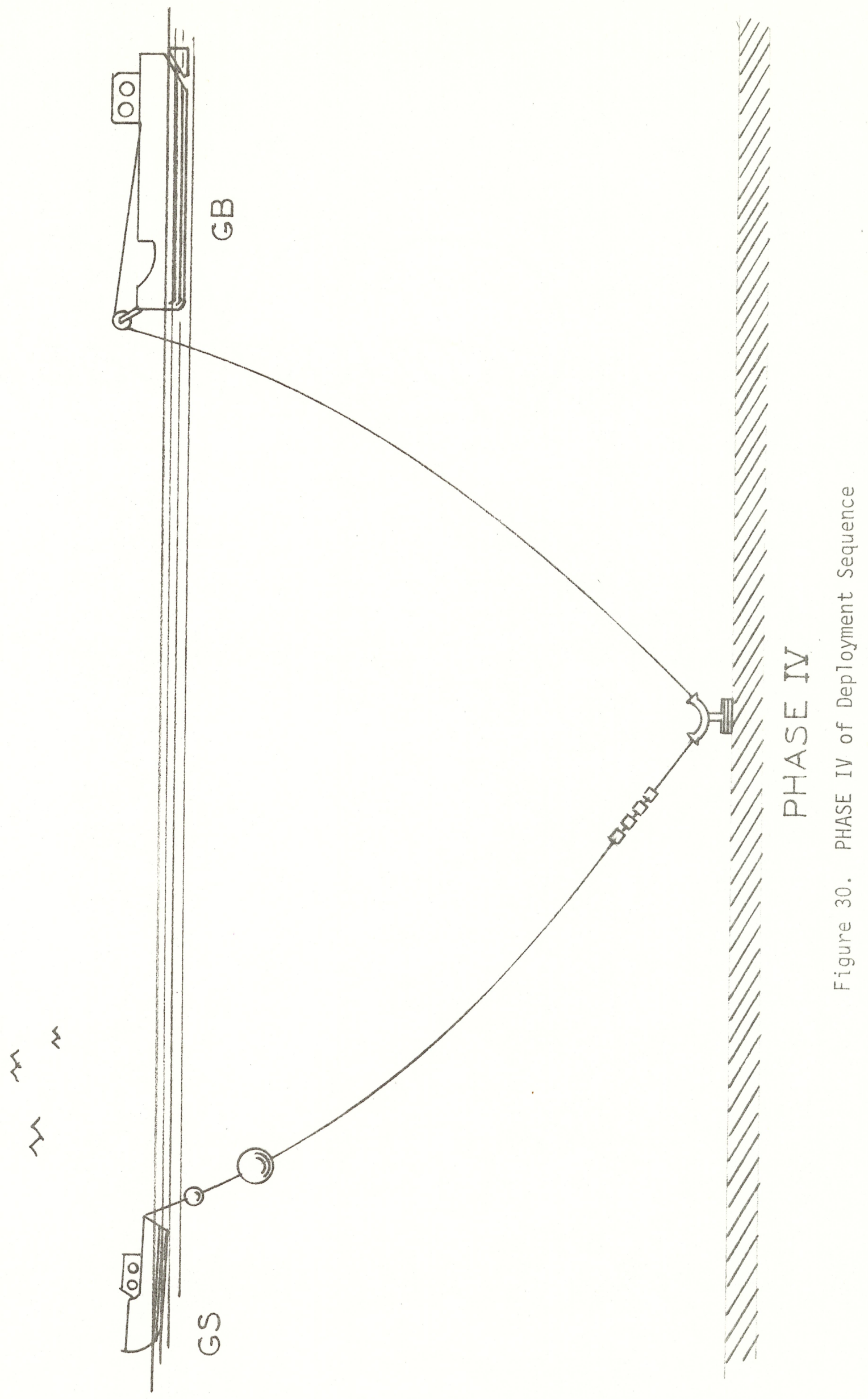




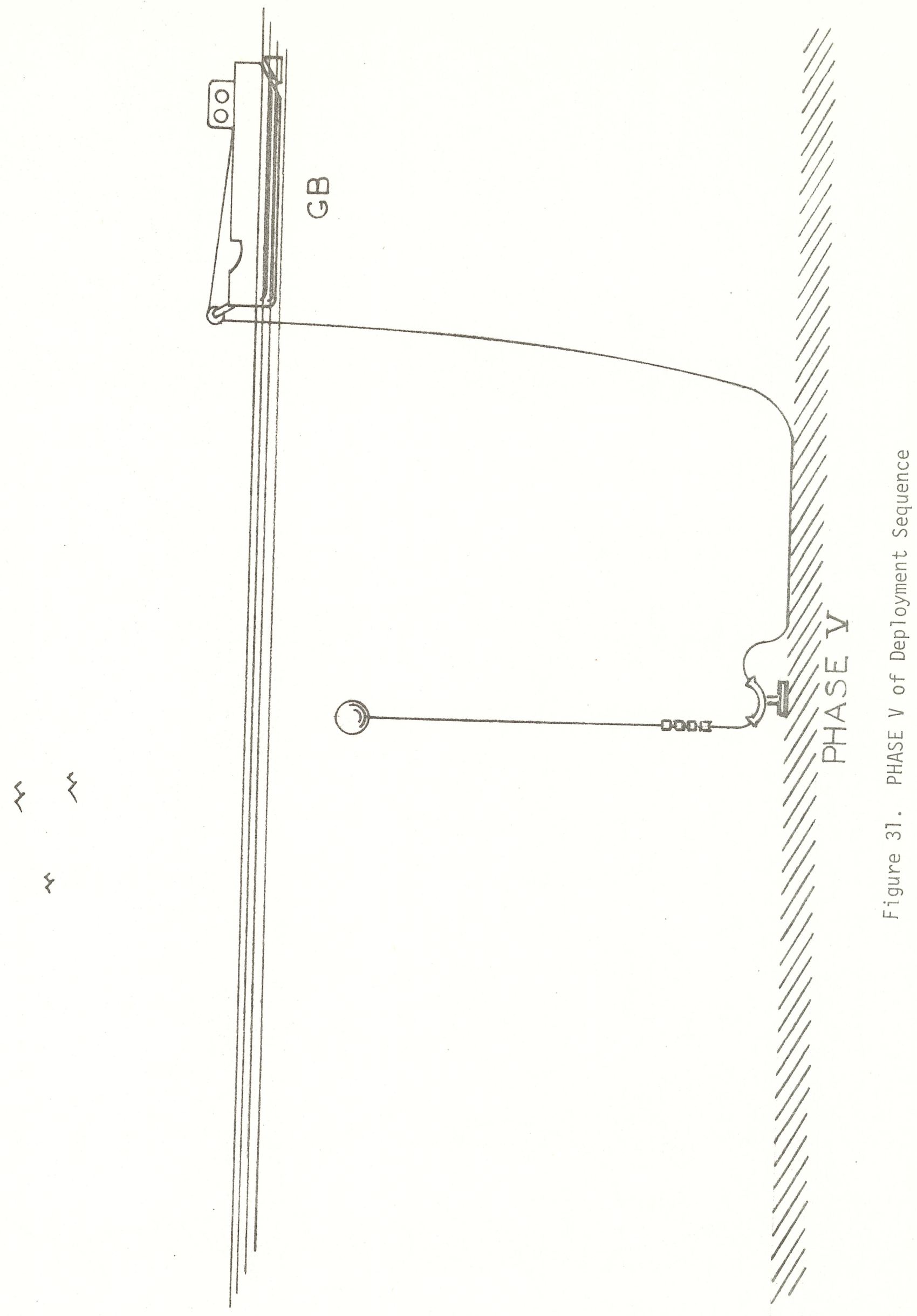


fast. The GULF STREAM continued to steam slowly ahead so that a slight strain was maintained on the line while the GOVERNMENT BARGE payed out the 1000 meters of 5/16" wire rope at $200 \mathrm{ft} / \mathrm{min}$. At this point the upper end of the hydrophone assembly was attached to the wire rope and the assembly stopped off. The electromechanical connector and cable were then led through the bow sheave and connected to the hydrophone preamplifier casing at the bottom of the hydrophone assembly. The stopper was removed and the GULF STREAM notified to again steam slow ahead while the GOVERNMENT BARGE payed out 200 meters of E/M cable. The GULF STREAM then maintained her range and position. A mid-span PLP hanger was attached to the E/M cable to stop off and the cable was passed around the U-frame and fastened. The bell mouths were attached and the acoustic release armed. The anchor was hoisted off the deck using the A-frame and chain hoist and swung over the side and slowly lowered. Phase III depicts the assembly in the water after all slip lines were released with the load on the $\mathrm{E} / \mathrm{M}$ cable over the bow sheave. A wire counter and tensiometer were attached to the $\mathrm{E} / \mathrm{M}$ cable aft of the bow sheave to monitor tension, anchor bottoming and number of feet out. At this point the anchor and $\mathrm{U}$-frame rotated $180^{\circ}$ requiring realignment by the divers. A bottom-finding pinger was installed on the anchor assembly to monitor its distance from the bottom, however its signals were never heard on the GULF STREAM.

The assembly was then lowered to the bottom at which time the indicated tension dropped. During the lowering sequence the GULF STREAM steamed as necessary to maintain the proper range on the GOVERNMENT BARGE and to ensure that the anchor bottomed at the proper location. Phase IV indicates the configuration at the time of anchor bottoming.

The GOVERNMENT BARGE immediately proceeded to back down away from the anchor location continuing to pay out cable at $200 \mathrm{ft} / \mathrm{min}$. After 10 minutes backing down the vessel proceeded forward gradually turning onto a course for the marker buoy. The ship speed was determined and maintained at 1.5 knots ( $152 \mathrm{ft} / \mathrm{min}$ ) by the chip log method using a stop watch. The radar malfunction required this emergency method. The cable was payed out at rates between 160-220 ft/min. during the run into shore.

Immediately after the anchor bottomed the GULF STREAM backed over the anchor position pulling the polypropylene rope taut so that the amount of line out could be measured and thus the depth of the subsurface buoy confirmed. The depth as measured by this method and the PGR agreed well and it was determined that the array had been placed in the proper location and at the proper depth. The polypropylene line was buoyed off with a polyform float. The GULF STREAM then 
proceeded to the corner marker buoy to mark the turning point for the GOVERNMENT BARGE as visibility was rapidly decreasing by this time. The rubber skiff and divers went ahead to the reef zone and marked the break in the reef with a light which they attached to the previously deployed polyform floats.

The lack of accurate navigation during the critical cable laying run due to the radar malfunction resulted in lower pay-out rates than planned. In fact upon arriving at the corner buoy we noted that only 15,000 ft. had been paid out. At this point the rate was increased and upon reaching the reef marker all remaining cable was payed out. This was just off the reef zone in 50 feet of water. The end of the cable was secured in a bight and buoyed off for the night. Operations were terminated at 2030.

\section{D) Cable Run To Shore}

The following morning the GULF STREAM with divers and a rubber skiff steamed to the reef buoy and attached the previously set wire rope leader to the E/M cable bight. Inspection of the cable pile-up laying on the bottom was made by the divers. The shore end of the leader wire rope was attached to a tractor at the edge of the cliff and the cable hauled ashore. The divers, using hand signals, prevented tangling of the cable as it came ashore. They also guided the quadruple armored section of the $\mathrm{E} / \mathrm{M}$ cable through the natural reef breaks previously noted. The E/M cable was eventually led up the cliff and over to the van. One hundred bags of Sacrete were then placed in burlap sacks and transported a few at a time in the rubber skiff to the cable run on the reef where the divers positioned them over the cable.

\section{E) System Test}

The cable was hooked up to the preamplifier, filter and power supply module for electrical checkout. Electrical power was temporarily obtained from a lighthouse close by for this test. The electrical characteristics of the cable appeared normal and each preamplifier drew the proper amount of current. Signals were heard on one channel only. Subsequently it was discovered that a color-coding mixup at the preamplifier input caused one hydrophone channel to be inoperative when in fact it was normal. Since the installation the array has worked normally, providing excellent reception of SOFAR floats in the MODE area.

After determining that the system was operating satisfactorily the GULF STREAM again fixed the location of the float marker of the array, fired the top acoustic release and retrieved the polypropylene tether line and release. The final configuration is depicted in Figure 31 , Phase $V$. 


\section{Conclusion}

A hydrophone listening array was designed, procured, tested and successfully implanted at Grand Turk Island, B.W.I., for use in the IDOE-MODE SOFAR float program. The system was designed to place the hydrophones in the sound axis $(1200 \mathrm{~m})$ with a float at 200 meters depth. A special anchor, acoustic release and cable attachment arrangement permitted the array to be brought back to the surface for eventual servicing.

At the time of this writing the array has been implanted and operating for more than ten months. The quality of the SOFAR float signals received from this station have proven excellent. In fact it has been reported to be the only station in a grid of four which has consistently heard all floats deployed in the MODE area.

Figure 32 shows a typical record from the listening station. Signals from three floats are clearly identified. Shown are signals as received by one channel only and by the addition of a second hydrophone pair. A signal-to-noise ratio of $26 \mathrm{db}$ was obtained in the addition mode on the strongest signal. 


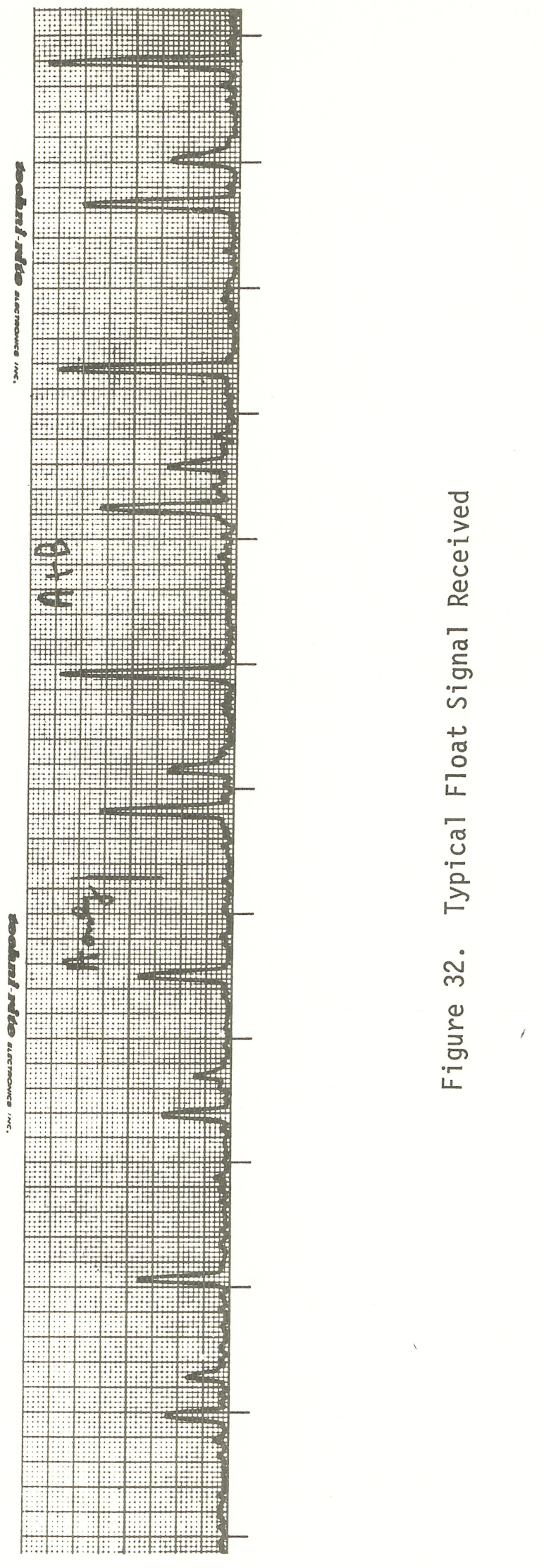

$-54-$ 


\section{REFERENCES}

1. Rossby, T. and Webb, D., "Observing Abyssal Motions by Tracking Swallow Floats in the SOFAR Channel", Deep-Sea Research, Vo1. 17, (1970), pp. 359-365.

2. Berteaux, H. O. and Chhabra, N. K., "Computer Programs for the Static Analysis of Single Point Moored Surface and Subsurface Buoy Systems", Woods Hole Oceanographic Institution, WHOI-73-72, March, 1973.

3. Kinsler, L. and Frey, A., Fundamentals of Acoustics, 2nd Ed., New York, John Wiley and Sons, Inc., 1962.

4. Skop, R. A. and O'Hara, G. J., "The Static Equilibrium Configuration of Cable Arrays by Use of Imaginary Reactions", Naval Research Laboratory, NRL Report 6819, February 28, 1969. 
APPENDICES

$-56-$ 
APPENDIX 1

DYNA-GRIP TERMINATION SPECIFICATIONS

$-57-$ 


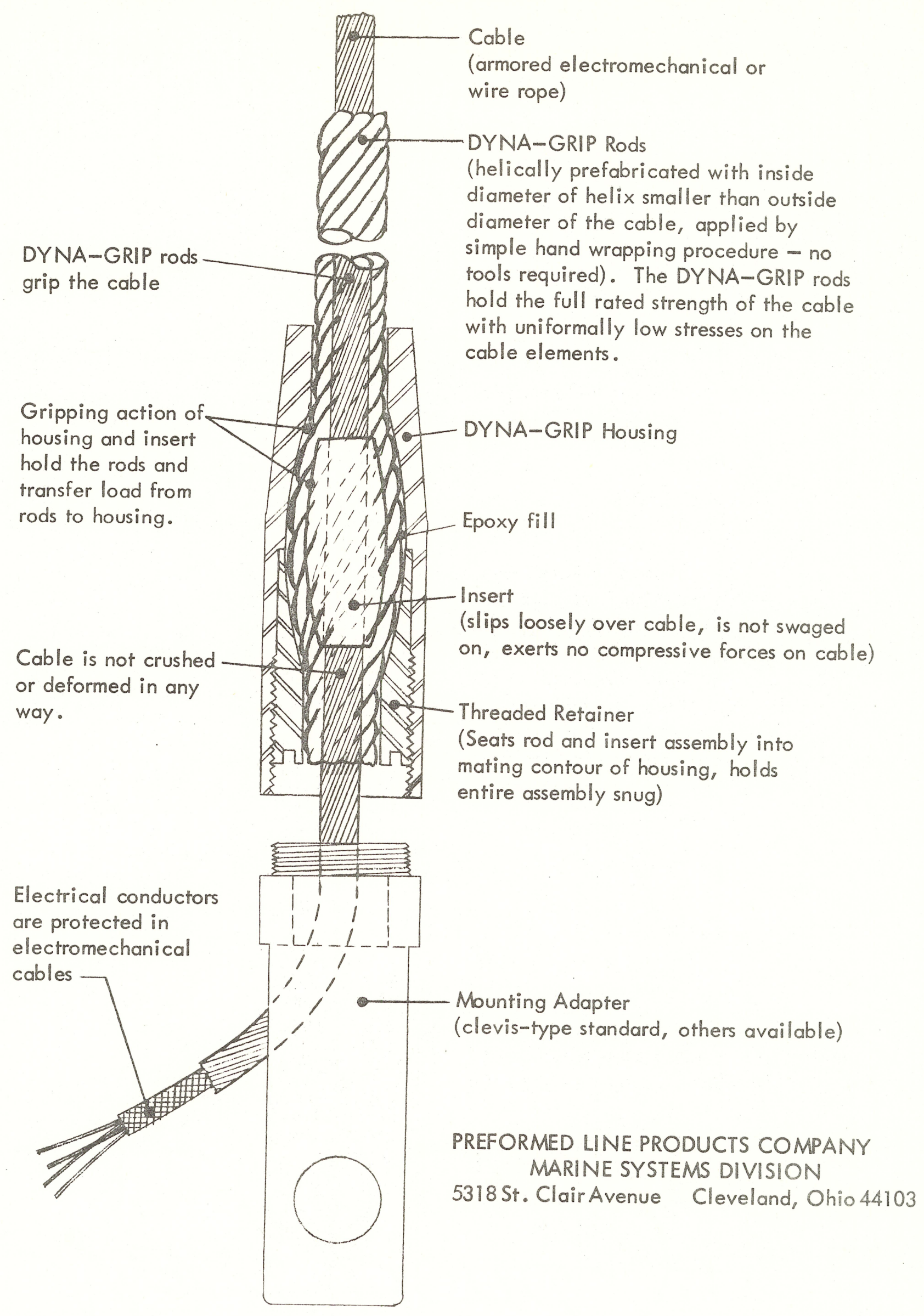




\section{APPLICATION}

The DYNA-GRIP terminations for mechanical as well as electromechanical cable are available in three basic configurations for all normal cable sizes.

The basic product line, i.e. Model 9000119-0 (for 0.250" OD cable), is shown in the following application procedure and requires the use of an epoxy filler. This epoxy does not" however, bond the customer's cable and its included ellectrical core to the fitting. The customer"s cable must be "flloating" within the fitting body, free from radial pressure so that mechanical conductor breakage does not occur. More briefly, the PREFORMED DYNA-GRIP termination elliminates mechanical stress on electrical conductors. Many applications, of a more static load nature, do not require the use of epoxy and are ready for use immediately after application.

The split-clamp DYNA-GRIP termination, i.e.Model 9000119-1 (for 0.250 " OD cable) is used when the cable end is not available and must be applied in the mid-span of a cable. This unit is also constrained to the use of an internal epoxy as above.

The latest configuration of the DYNA-GRIP termination eliminates the need for epoxy casting at installation and provides a mechanical (and electrical) fitting for dynamic and high impact load usage immediately after installation. This pre-potted DYNA-GRIP termination, i.e. Model 9000119-2 (for 0.250" OD cable), is the most convenient to apply when speed and installation at sea are paramount. The only sacrifice is slightly additional cost for the pre-assembly labor. 
APPENDIX 2

NOTES FOR A COMPUTER PROGRAM

TO COMPUTE THE EQUILIBRIUM

TRAJECTORY OF A CABLE

SUPPORTING A POINT LOAD

by

H. O. Berteaux 


\section{Problem Statement}

Given a cable of discretely variable characteristics(cross section " $A$ ", modulus of elasticity "E", line weight density "W") with both ends fixed in space and supporting a point load at a known distance from either end, find the equilibrium trajectory and the tension distribution in the cable. (Figure 1)

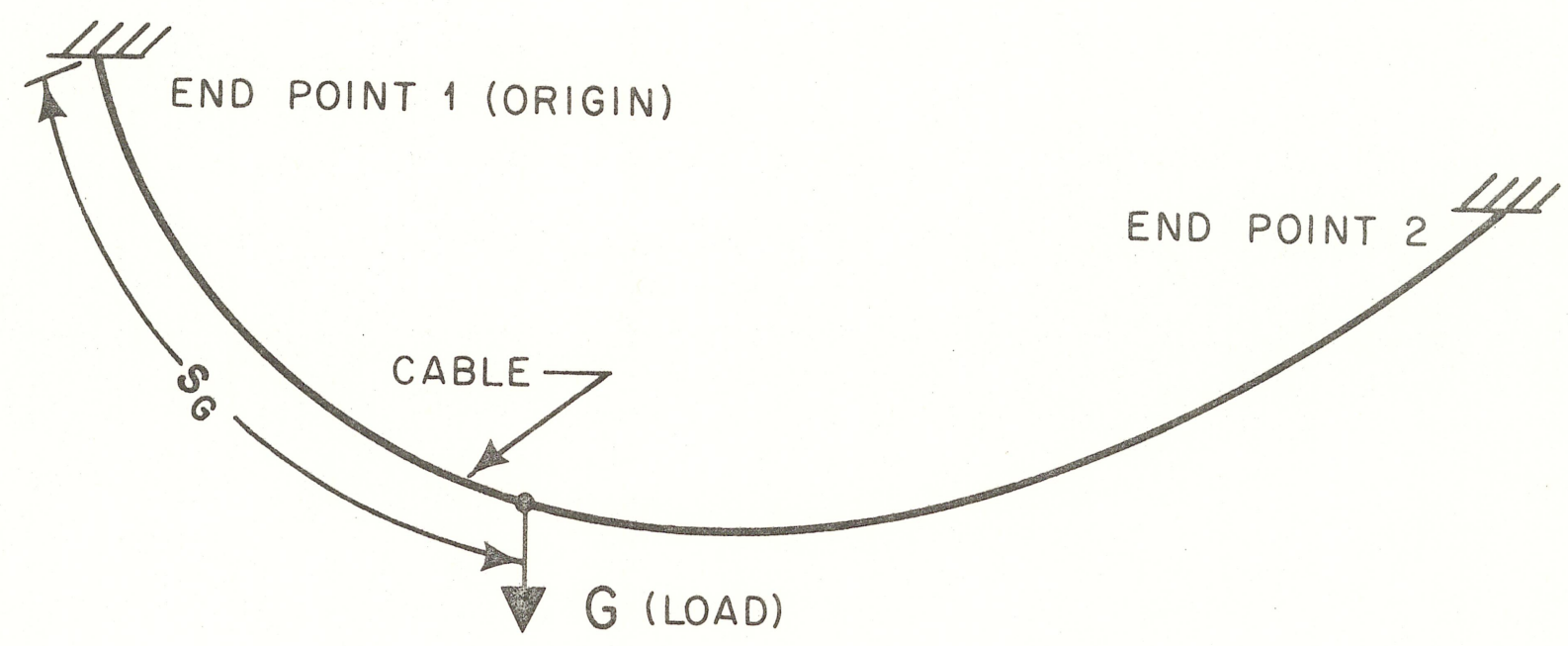

Figure 1

2. Relevant equations

2.1 Cable equations. It can be seen from a free body diagram (Figure 2) that the cable equilibrium equations are: 


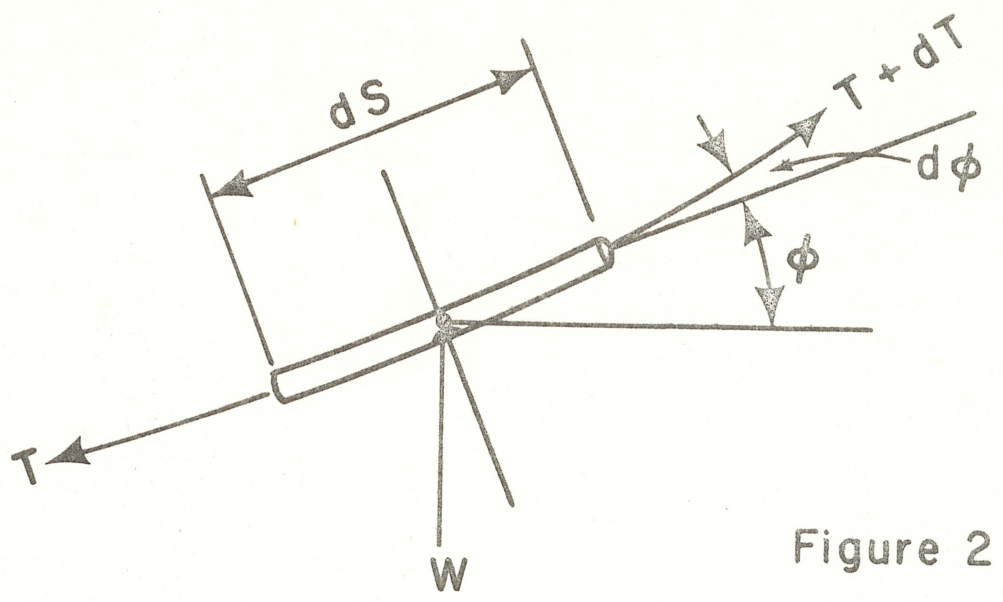

$$
\begin{aligned}
\mathrm{dT} & =\mathrm{W} \sin \phi \mathrm{ds} \\
\mathrm{Td} \phi & =\mathrm{W} \cos \phi \mathrm{ds}
\end{aligned}
$$

$$
\text { where } \begin{aligned}
W & =\text { weight per unit of length } \\
\phi & =\text { angle with horizontal } \\
\mathrm{d} \phi & =\text { change of angle over length ds } \\
\mathrm{T} & =\text { tension } \\
\mathrm{dT} & =\text { change of tension over length ds } \\
\mathrm{ds} & =\text { length of cable element }
\end{aligned}
$$

\subsection{Point load equation}

The point load constitutes a discontinuity preventing the integrations of (2.1) and (2.2) at the point of attachment $\left(S_{G}\right)$. The equilibrium equations to be satisfied at $S=S_{G}$ are: (See Figure 3).

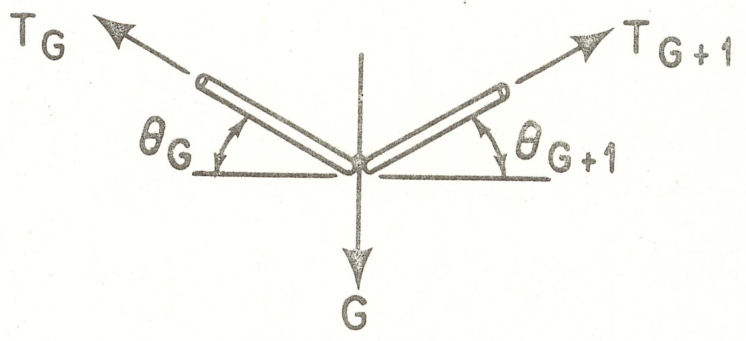

Figure 3 


$$
\begin{aligned}
& T_{G} \cos \theta_{G}=T_{(G+1)} \cos \theta_{(G+1)} \\
& T_{G} \sin \theta_{G}+T_{G+1} \sin \theta_{G+1}=G
\end{aligned}
$$

$\begin{array}{lll}\text { where } \mathrm{T}_{\mathrm{G}} & = & \text { tension to the left of } \mathrm{G} \\ { }_{\mathrm{T}+1} & = & \text { tension to the right of } \mathrm{G} \\ { }^{\Theta_{\mathrm{G}}} & = & \text { angle to the left of } \mathrm{G} \text { (as shown) } \\ { }_{\mathrm{G}+1} & = & \text { angle to the right of G (as shown) } \\ \mathrm{G} & = & \text { point load (1bs.) }\end{array}$

\section{Computation Process}

3.1 Cable segmentation. The computer program divides the entire cable length (unstretched) into $N$ segments of equal length.

$\mathrm{N}$ is an input to the program. The computer program locates

the closest segment to point load G.

3.2 Integration Process is carried from the origin, by finite elements of length $L=\frac{S}{N}$ where $S=\sum_{i} S_{i}$

$$
\begin{aligned}
S= & \text { total cable length } \\
S_{i}= & \text { length of cable with homogeneous } \\
& \text { characteristics (same } E, W, \& A \text { ) }
\end{aligned}
$$

\subsubsection{Assumed tension at origin}

Tension at origin has two Cartesian components $\mathrm{T}_{1 \mathrm{x}}$ and $\mathrm{T}_{1 \mathrm{y}}$ and is given by:

$$
\mathrm{T}_{1}=\sqrt{\mathrm{T}_{1 \mathrm{x}}^{2}+\mathrm{T}_{1 \mathrm{y}}^{2}}
$$


Assumed values of the tension components are:

$$
T_{1 x}=\left(\sum_{i} w_{i} s_{i}+G\right)\left(\underline{S-S_{G}}\right)
$$

$$
T_{1 y}=\left(\sum_{i} w_{i} S_{i}+G\right) \quad \underline{\left(S-S_{G}\right)}=T_{1 x}
$$

\subsubsection{Integration over 1st segment}

Computations should be performed in the following order:

a. Cable inclination $\phi_{1}$

$$
\phi_{1}=\frac{\pi}{2}+\tan ^{-1} \frac{\mathrm{T}_{1 y}}{\mathrm{~T}_{1 x}}
$$

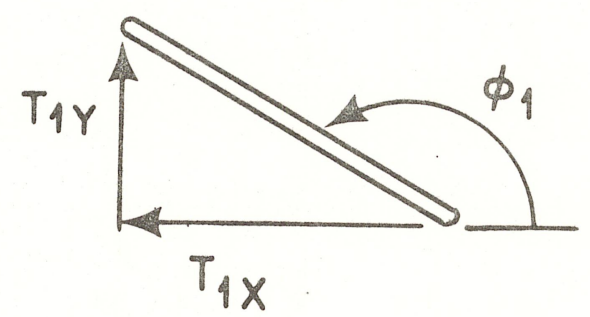

b. Change of tension over first segment length

From (2.1)

$$
\Delta \mathrm{T}=\mathrm{W}_{1} \mathrm{~L} \sin \phi_{1}
$$

where $w_{1}$ is the weight/foot in 1bs. of the cable of the 1st segment and $L=\frac{S}{N}(f t$.

$\phi_{1}$ is given by (3.5). 
๔. Change of inclination over first segment length

Irrom (2.2)

$$
\Delta \phi_{1}=\frac{\mathrm{W}_{1} \mathrm{~L} \cos \phi_{1}}{\mathrm{~T}_{1}}
$$

d. Coordinates $X_{1} \& Y_{1}$ of end points

Under the tension $\mathrm{T}_{1}$ the cable segment length stretches an amount $\Delta \mathrm{L}_{1}$ given by Hookes law

$$
\Delta \mathrm{L}_{1}=\frac{\mathrm{T}_{1} \mathrm{~L}}{\mathrm{~A}_{1} \mathrm{E}_{1}}
$$

where $A_{1}=$ cross section of 1 st segment

$$
E_{1}=\text { Modulus of Elasticity }
$$

The stretched length of the first segment is therefore:

Stretched Length $=L_{1}+\Delta L_{1}=L_{1}^{\prime}$

The coordinates of the segment's end points are:

$x_{1}=\left(L_{1}^{\prime}\right) \cos \phi_{1}$

$Y_{1}=\left(L_{1}^{\prime}\right) \sin \phi_{1}$

\subsubsection{Integration over 2nd segment}

Computations are:

a. Tension $\mathrm{T}_{2}=\mathrm{T}_{1}+\Delta \mathrm{T}_{1}$

b. Inclination $\phi_{2}=\phi_{1}+\Delta \phi_{1}$

c. Change of tension over 2nd segment

$$
\Delta \mathrm{T}_{2}=\mathrm{W}_{2} \mathrm{~L} \sin \phi_{2}
$$

d. Change of inclination over 2 nd segment

$$
\Delta \phi_{2}=W_{2} \mathrm{~L} \cos \phi_{2}
$$


e. Coordinates of 2 nd segment

$$
\begin{aligned}
& \Delta \mathrm{L}_{2}=\frac{\mathrm{T}_{2} \mathrm{~L}}{\mathrm{~A}_{2} \mathrm{E}_{2}} \\
& \mathrm{~L}_{2}^{\prime}=\mathrm{L}+\Delta \mathrm{L}_{2} \\
& \mathrm{X}_{2}=\left(\mathrm{L}_{2}^{\prime}\right) \cos \phi_{2} \\
& Y_{2}=\left(\mathrm{L}_{2}^{\prime}\right) \sin \phi_{2}
\end{aligned}
$$

\subsubsection{Continued Integration}

The integration process repeats itself until

$S=S_{G} \cdot$ The tension in the segment to the right of $G$ is then found from the equilibrium equations (2.3) and (2.4). The integration process if then resumed until all segments are exhausted.

\subsubsection{Error (Definitions)}

The (computed) end point of the cable will not coincide with the true end point of coordinates $(a, b)$. (See Figure 4).

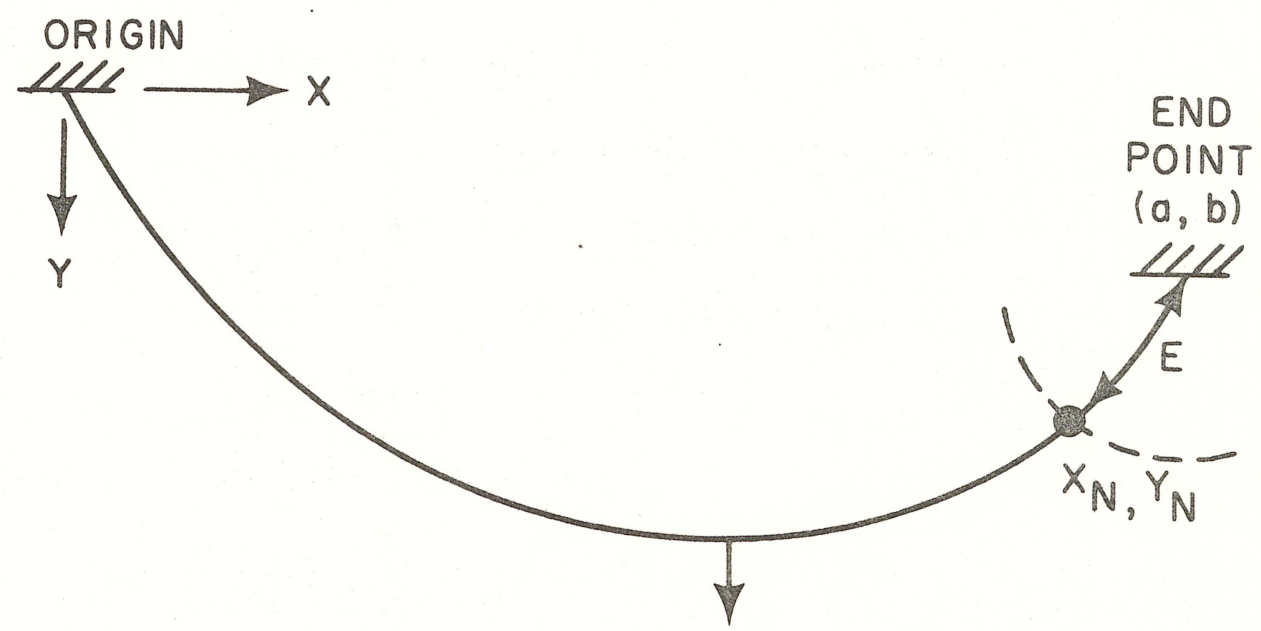

Figure 4 
The error "E" is then defined by:

$$
E=\sqrt{\left(a-X_{N}\right)^{2}+\left(b-Y_{N}\right)^{2}}
$$

\section{2 .6 Iteration}

In order to bring the computed end point closer to the end point $(a, b)$ a correction must be made on $T_{1 x}$ and $T_{1 y}$ the cartesian components of the assumed tension $T_{1}$.

Following Skop's method, (Reference No.4) the components wil1 be changed by an amount $\Delta \mathrm{T}_{1 \mathrm{x}}$ and $\Delta \mathrm{T}_{1 \mathrm{y}}$ given by:

$$
\begin{aligned}
& \Delta \mathrm{T}_{1 \mathrm{x}}=\mathrm{T}_{1} \quad\left(\frac{\mathrm{a}-\mathrm{x}}{\mathrm{E}}\right) \quad \frac{1}{2^{\mathrm{K}}} \\
& \Delta \mathrm{T}_{1 y}=\mathrm{T}_{1} \quad \frac{\mathrm{b}-y_{\mathrm{N}}}{(\mathrm{E})} \quad \frac{1}{2^{\mathrm{K}}}
\end{aligned}
$$

Where $K$ is an integer $K=1,2,3 \ldots$ and $\frac{1}{2} K$ is the converging factor of iteration.

That is, at the end of the 2nd computation a new error $E^{\text {? }}$ is found. If $E^{?} \times E$ then a positive step has been made. If $E^{\prime}>E$ this means that the correction was too large and therefore $K$ must be increased by one unit. This check is performed at the end of each iteration computation. The iteration stops when the error falls within a prescribed limit. 
3.2.7 Error limit could be defined as $E_{\text {limit }}=\frac{S}{Q}$ Where $Q$ is left as an input $(Q=1000$ for example).

4. Computer Inputs

The user should input:

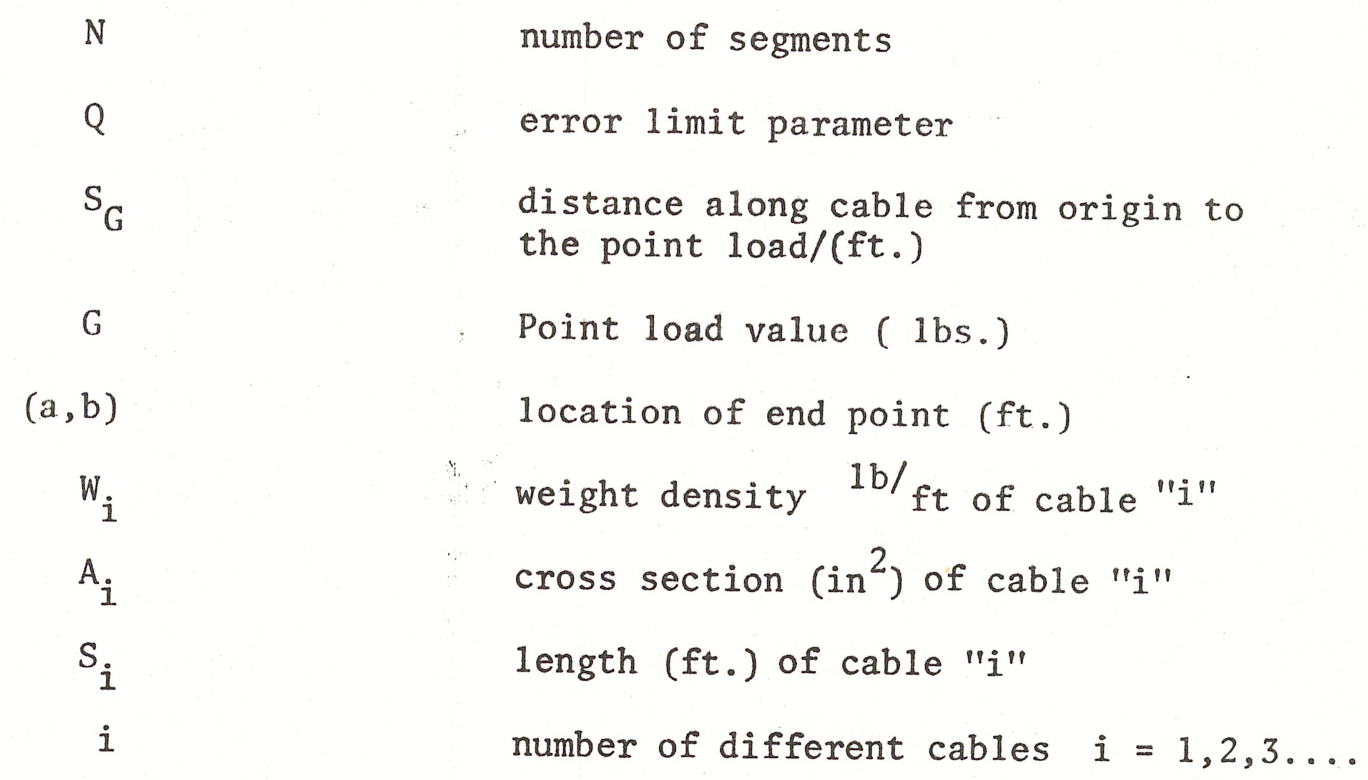

5. Computer Outputs

5.1 Printout Typical outputs should display for each segment the horizontal and vertical coordinates of both the segment and the point load as well as the tension and type of cable.

5.2 Plot A plot subroutine should plot the cable trajectory (to scale) at the end of the computations. 
APPENDIX 3

PROGRAM LISTING FOR COMPUTER PROGRAM

WHICH COMPUTES THE EQUILIBRIUM

TRAJECTORY OF A CABLE SUPPORTING A

POINT LOAD 


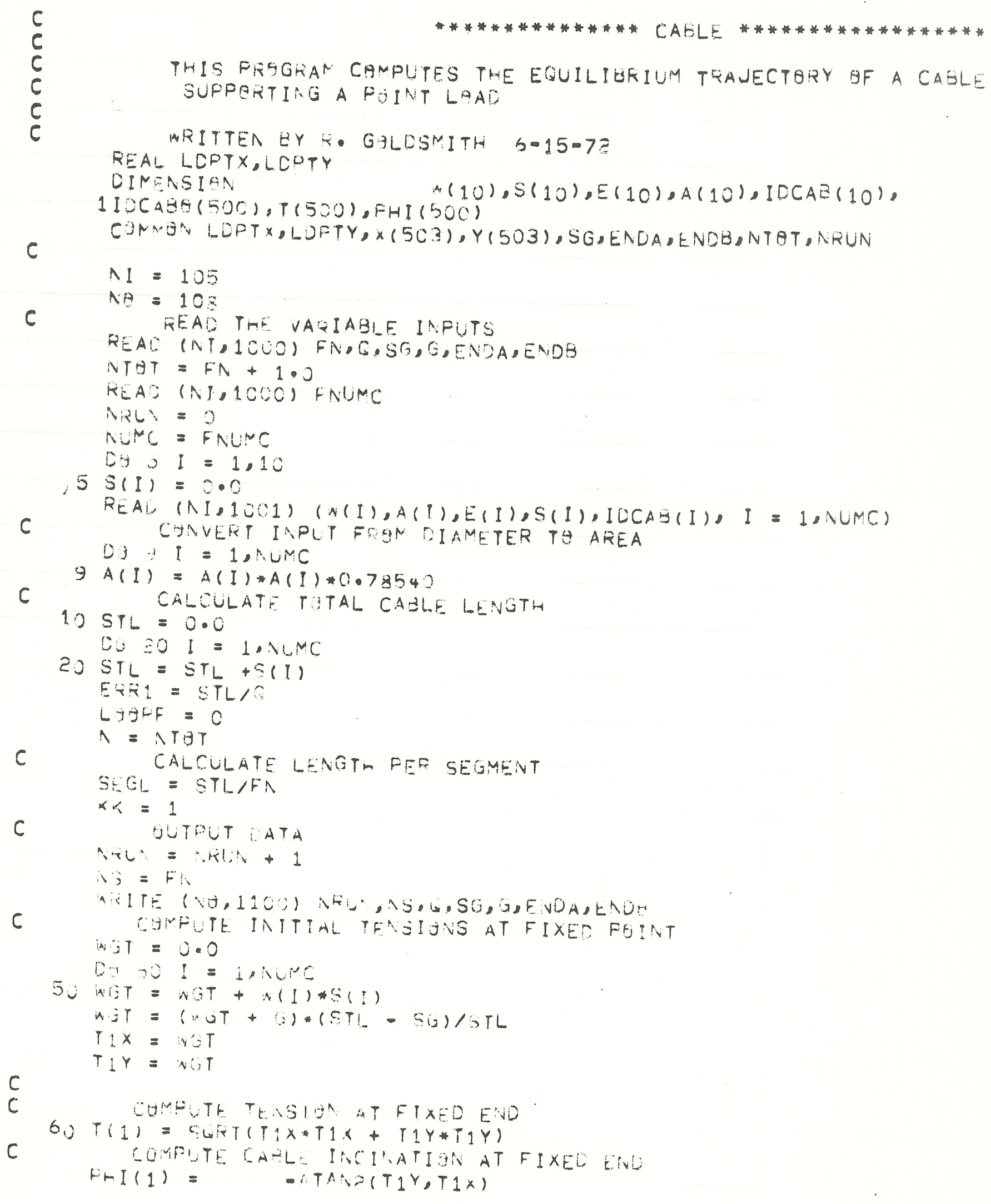




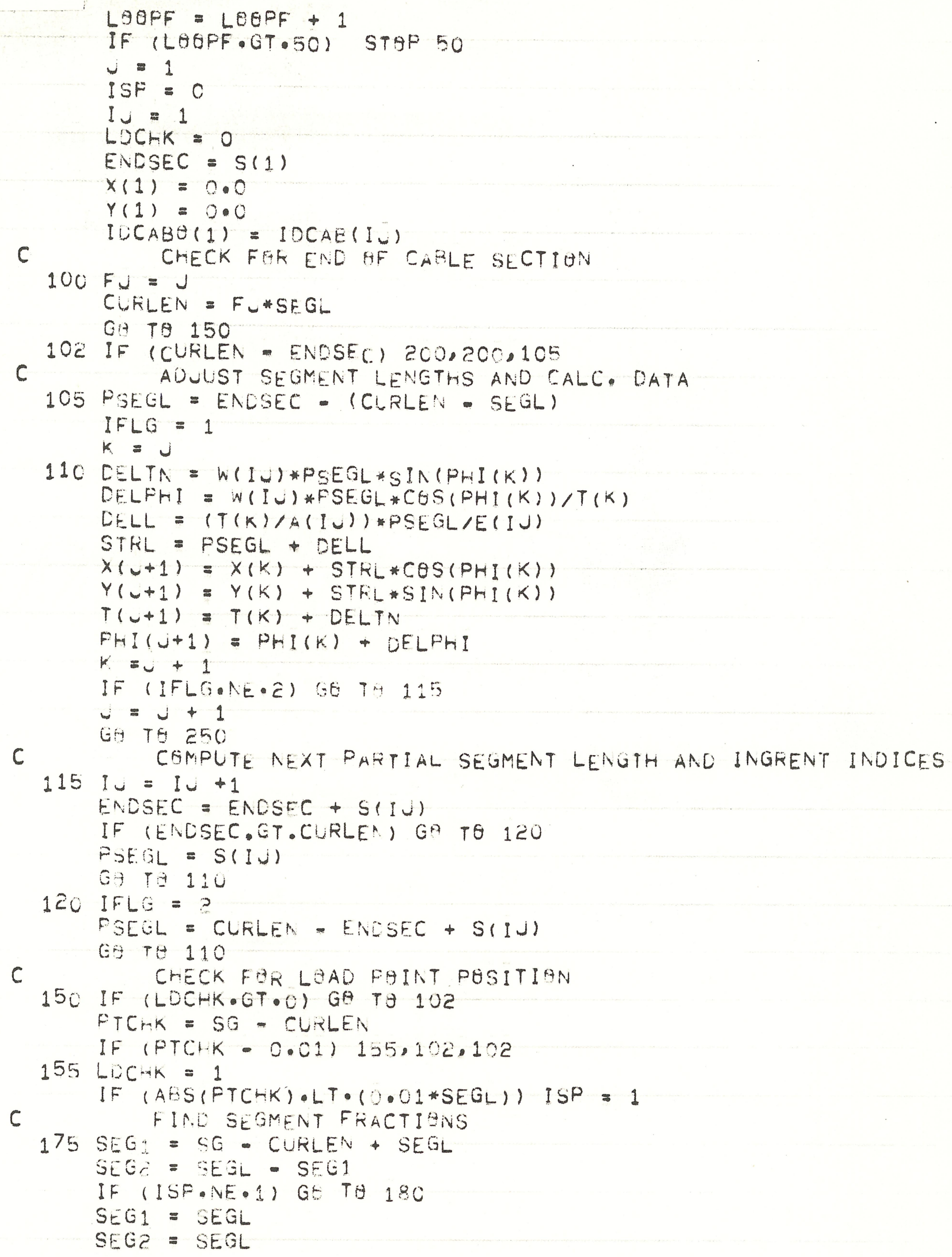




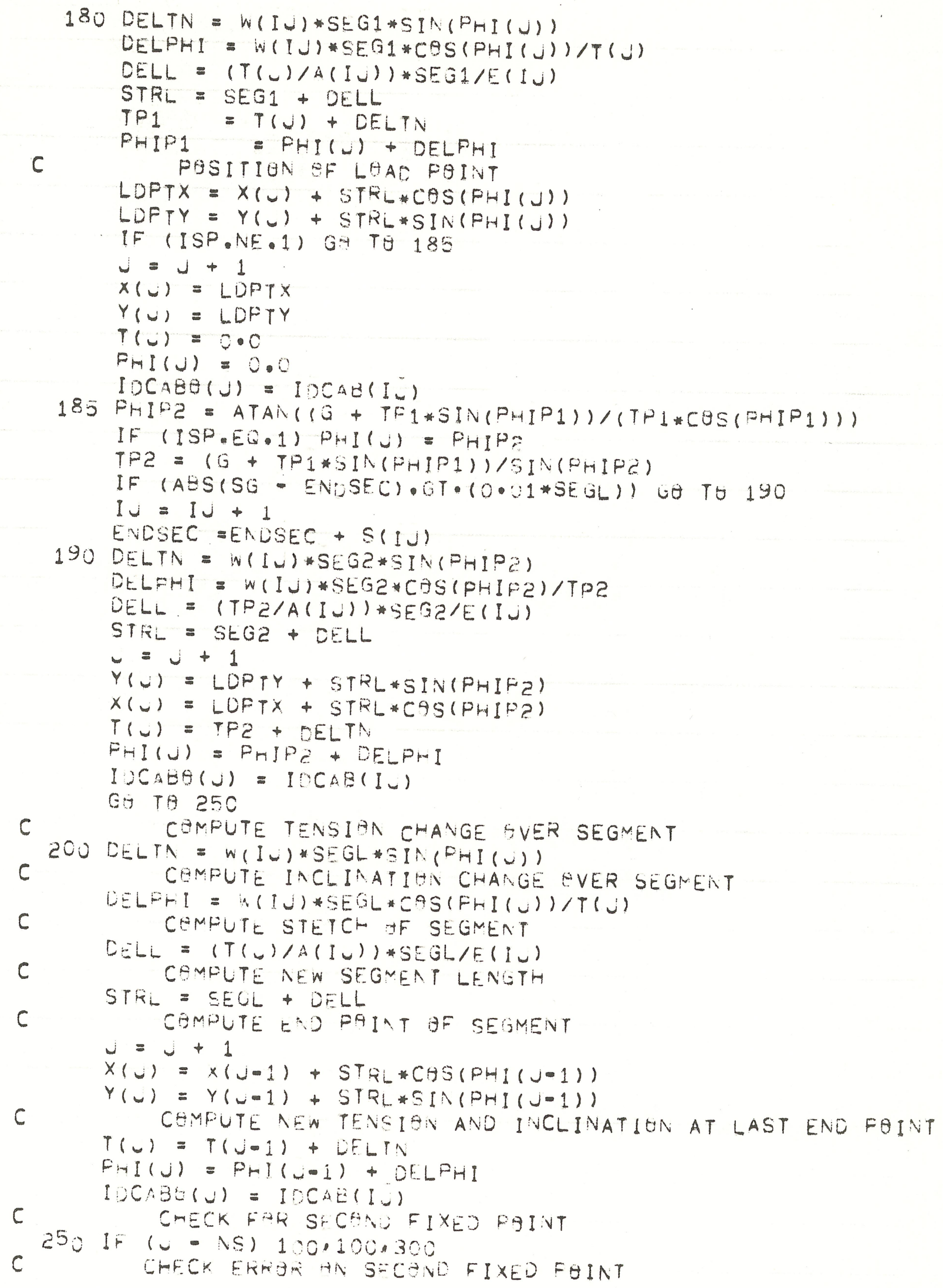




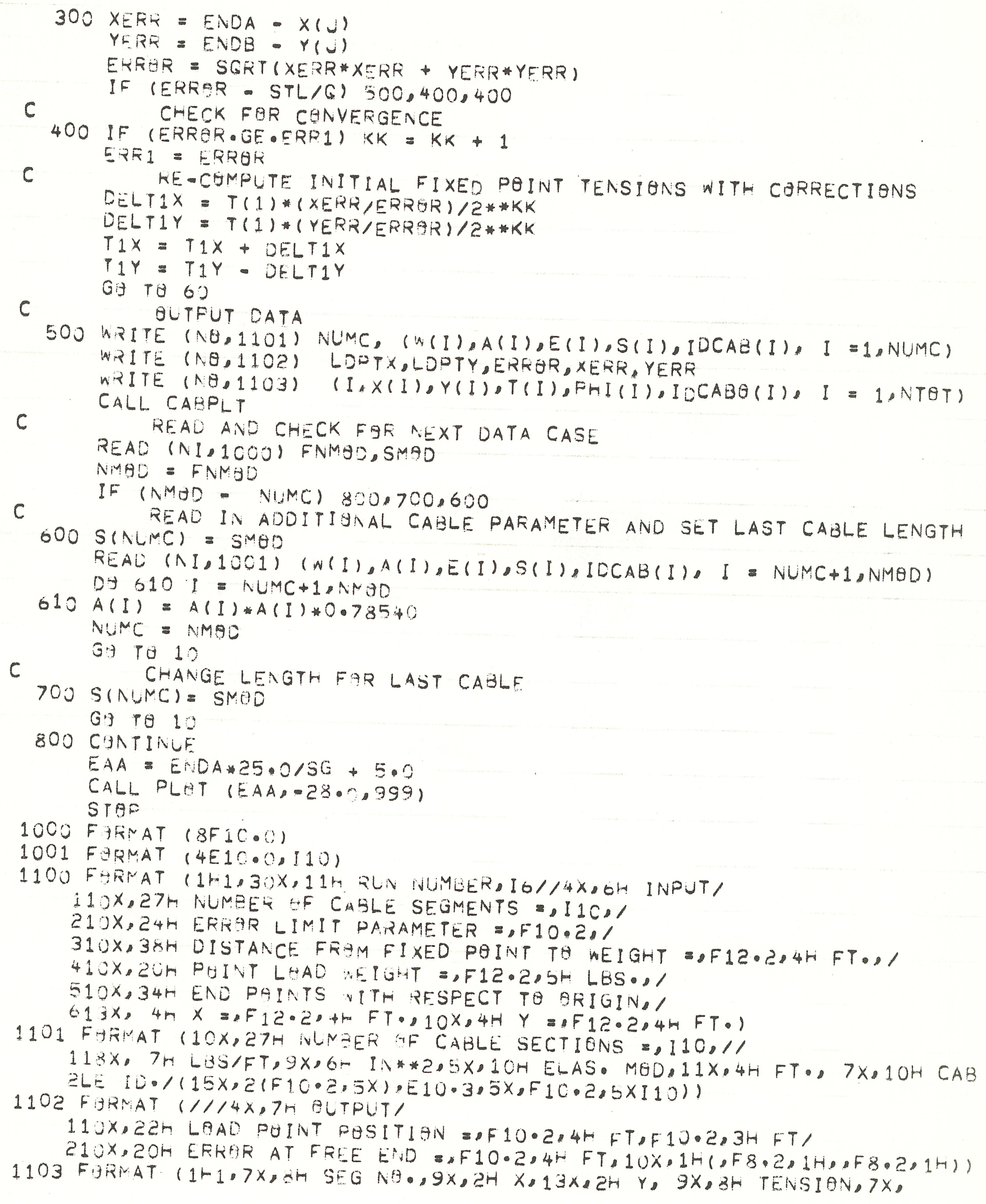




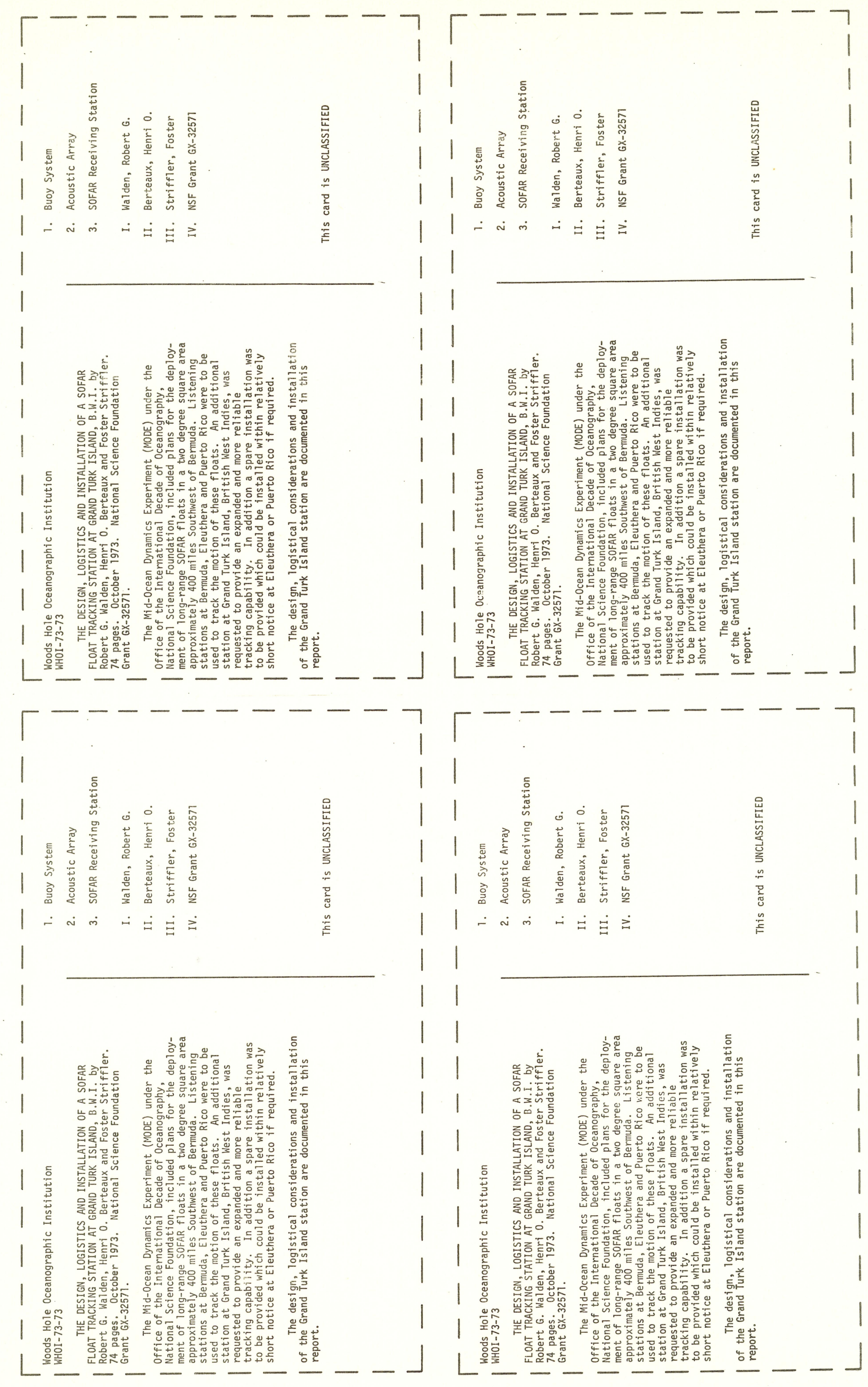




\begin{tabular}{|c|c|c|}
\hline $\begin{array}{l}\text { BIBLIOGRAPHIC DATA } \\
\text { SHEET }\end{array}$ & \begin{tabular}{|l|l|} 
1. Report No. & 2. \\
\end{tabular} & 3. Recipient's Accession No. \\
\hline \multirow{2}{*}{\multicolumn{2}{|c|}{$\begin{array}{l}\text { 4. Title and Subtitle } \\
\text { THE DESIGN, LOGISTICS AND INSTALLATION OF A SOFAR FLOAT } \\
\text { TRACKING STATION AT GRAND TURK ISLAND, B.W.I. }\end{array}$}} & $\begin{array}{l}\text { 5. Report Date } \\
\text { October } 1973 \\
\end{array}$ \\
\hline & & 6. \\
\hline \multirow{3}{*}{\multicolumn{2}{|c|}{$\begin{array}{l}\text { 7. Author(s) } \\
\text { Robert G. Walden, Henri 0. Berteaux and Foster Striffler } \\
\text { 9. Performing Organization Name and Address } \\
\text { Woods Hole Oceanographic Institution } \\
\text { Woods Hole, Massachusetts } 02543\end{array}$}} & $\begin{array}{l}\text { 8. Performing Organization Rept. } \\
\text { No. WHOI }-73-73\end{array}$ \\
\hline & & 10. Project/Task/Work Unit No. \\
\hline & & $\begin{array}{l}\text { 11. Contract/Grant No. } \\
\text { NSF GX-32571 }\end{array}$ \\
\hline \multirow{2}{*}{\multicolumn{2}{|c|}{$\begin{array}{l}\text { 12. Sponsoring Organization Name and Address } \\
\text { National Science Foundation } \\
\text { GX-32571 }\end{array}$}} & $\begin{array}{l}\text { 13. Type of Report \& Period } \\
\text { Covered } \\
\text { Technical } \\
\end{array}$ \\
\hline & & \\
\hline \multicolumn{3}{|c|}{ 16. Abstracts } \\
\hline \multicolumn{3}{|c|}{$\begin{array}{l}\text { 16. Abstracts } \\
\text { The Mid-0cean Dynamics Experiment (MODE) under the Office of the International } \\
\text { Decade of Oceanography, National Science Foundation, included plans for the deploy- } \\
\text { ment of long-range SOFAR floats in a two degree square area approximately } 400 \text { miles } \\
\text { Southwest of Bermuda. Listening stations at Bermuda, Eleuthera and Puerto Rico were } \\
\text { to be used to track the motion of these floats. An additional station at Grand Turk } \\
\text { Island, British West Indies, was requested to provide an expanded and more reliable } \\
\text { tracking capability. In addition a spare installation was to be provided which } \\
\text { could be installed within relatively short notice at Eleuthera or Puerto Rico if } \\
\text { required. }\end{array}$} \\
\hline \multicolumn{3}{|c|}{$\begin{array}{l}\text { The design, logistical considerations and installation of the Grand Turk Island } \\
\text { station are documented in this report. }\end{array}$} \\
\hline \multicolumn{3}{|c|}{ 7. Key Words and Document Analysis. 17a. Descriptors } \\
\hline
\end{tabular}

17b. Identifiers/Open-Ended Terms

17c. COSATI Field/Group

18. Availability Statement 